\title{
The Design of Robust Helium Aerostats
}

\author{
Jonathan I. Miller \\ Department of Mechanical Engineering \\ McGill University, Montreal \\ August, 2005
}

\begin{abstract}
A thesis submitted to McGill University in partial fulfillment of the requirements for the degree of Master of Engineering
\end{abstract}

(C) Jonathan I. Miller 2005

All rights reserved. This thesis may not be reproduced in whole or in part, by photocopy or other means, without the permission of the author. 


$\begin{array}{ll}\begin{array}{l}\text { Library and } \\ \text { Archives Canada }\end{array} & \begin{array}{l}\text { Bibliothèque et } \\ \text { Archives Canada }\end{array} \\ \begin{array}{l}\text { Published Heritage } \\ \text { Branch }\end{array} & \begin{array}{l}\text { Direction du } \\ \text { Patrimoine de l'édition }\end{array} \\ \begin{array}{l}\text { 395 Wellington Street } \\ \text { Ottawa ON K1A 0N4 }\end{array} & \begin{array}{l}\text { 395, rue Wellington } \\ \text { Ottawa ON K1A ON4 } \\ \text { Canada }\end{array} \\ \end{array}$

Your file Votre référence ISBN: 978-0-494-24998-7 Ourfile Notre référence ISBN: 978-0-494-24998-7

NOTICE:

The author has granted a nonexclusive license allowing Library and Archives Canada to reproduce, publish, archive, preserve, conserve, communicate to the public by telecommunication or on the Internet, loan, distribute and sell theses worldwide, for commercial or noncommercial purposes, in microform, paper, electronic and/or any other formats.

The author retains copyright ownership and moral rights in this thesis. Neither the thesis nor substantial extracts from it may be printed or otherwise reproduced without the author's permission.
AVIS:

L'auteur a accordé une licence non exclusive permettant à la Bibliothèque et Archives Canada de reproduire, publier, archiver, sauvegarder, conserver, transmettre au public par télécommunication ou par l'Internet, prêter, distribuer et vendre des thèses partout dans le monde, à des fins commerciales ou autres, sur support microforme, papier, électronique et/ou autres formats.

L'auteur conserve la propriété du droit d'auteur et des droits moraux qui protège cette thèse. $\mathrm{Ni}$ la thèse ni des extraits substantiels de celle-ci ne doivent être imprimés ou autrement reproduits sans son autorisation.
In compliance with the Canadian

Privacy Act some supporting forms may have been removed from this thesis.

While these forms may be included in the document page count, their removal does not represent any loss of content from the thesis.
Conformément à la loi canadienne sur la protection de la vie privée, quelques formulaires secondaires ont été enlevés de cette thèse.

Bien que ces formulaires aient inclus dans la pagination, il n'y aura aucun contenu manquant. 


\section{Abstract}

Tethered helium aerostats are receiving renewed attention in the scientific and surveillance communities. However, conventional aerostats cannot consistently survive high winds. The goal of this research was to design an aerostat that could be deployed for very long periods, thus reducing operating costs and interruptions in data acquisition. Existing designs and fabrication techniques were first reviewed and replicated in the construction of a $2.5 \mathrm{~m}$ diameter spherical aerostat. The constructed balloon was then flown outdoors to observe its operational qualities. A low-cost data acquisition system was assembled to characterize the balloon's dynamics. The results were used to inform a Finite Element Analysis model evaluating the critical stresses in a $10.15 \mathrm{~m}$ diameter balloon's envelope and its tendency to "dimple" when subjected to high wind speeds. A second model was created to appraise the performance of an aerostat with a partially hard shell, made of carbon fiber, in highly loaded areas. 


\section{Résumé}

Les aérostats captifs au hélium recoivent de plus en plus d'attention de la communauté scientifique ainsi que de ceux qui s'interessent à la surveillance. Par contre, les aérostats conventionnels ne peuvent supporter les vents forts. Le but de cette recherche était de concevoir un aérostat pouvant être déployé pour de longues périodes, afin de réduire les coûts d'opération ainsi que les interruptions d'acquisition de données. Les techniques de fabrication ont d'abord été revues et reproduites dans la construction d'un aérostat sphérique de 2,5 $\mathrm{m}$ de diamètre. Le ballon construit a ensuite été déployé à l'extérieur pour observer ses caractéristiques d'opération. Un système d'acquisition de données à faible coût a été assemblé pour étudier la dynamique du ballon. Ces résultats ont été utilisés pour informer une modèle d'analyse par éléments finis, permettant d'évaluer les régions de stress critiques pour une enveloppe de ballon de $10,15 \mathrm{~m}$ de diamètre et sa tendance à former des «fossettes » lorsque soumis à des vents de haute vitesse. Un deuxième modèle a été créé pour estimer la performance d'un aérostat à coquille partiellement rigide, faite de fibre de carbone, aux endroits très chargés. 


\section{Acknowledgements}

I would like to express my sincerest appreciation to the many people who helped and supported me throughout my education. First and foremost, I would like to thank Professor Meyer Nahon for his immense guidance, encouragement, and infinite patience. It never ceases to amaze me how devoted he is to his students' success, being ever available in even the busiest of times. I would also like to acknowledge Professors Inna Sharf and James Nemes for their support with the Finite Element Analysis software, and Professor Larry Lessard for introducing me to carbon fiber.

I am very grateful to my fellow graduate student Philippe Coulombe Pontbriand, who brought a constant array of fresh and innovative ideas to the project as well as an unshakable positive attitude. I would also like to thank Ricky Anderson from Lamcotec, and Tim Cole, Brian Critelli, and other members of the Balloon Federation of America Gas Division for their guidance and direction in building the prototype $2.5 \mathrm{~m}$ aerostat. My gratitude further goes to summer student Domenico Mazzoca, without whom the balloon would not have gotten off the ground. I would also like to acknowledge James Straughton from the Department of Plant Sciences for his assistance with the experimental facilities. Finally, I would like to express a deep appreciation towards my family and friends, for supporting me through the most difficult of times. Without them, I would not be half the person I am today.

The funding for this project as well as my personal funding were both provided by the Natural Sciences and Engineering Research Council of Canada (NSERC). 
To my sisters, Jessica and Abby, the bookends who stand on either side of me 


\section{Table of Contents}

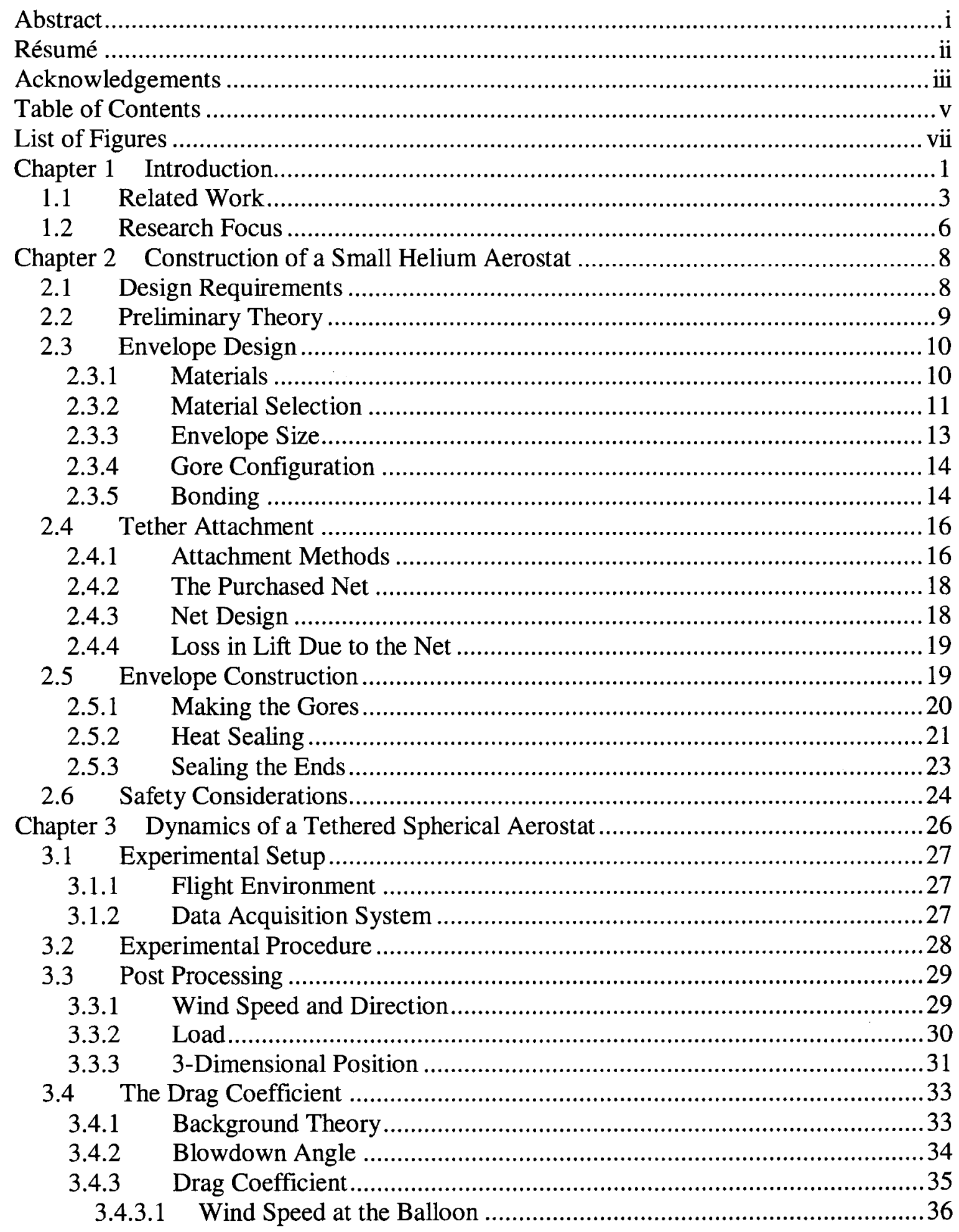


3.4.3.2 Drag Coefficient Results..................................................................

3.5 The Aerostat Oscillations .......................................................................... 38

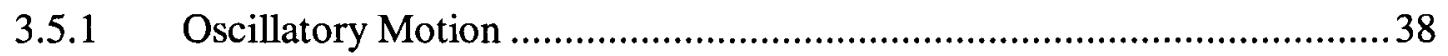

3.5.2 Oscillation Frequencies ................................................................. 41

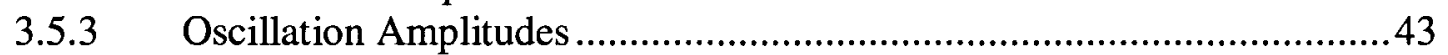

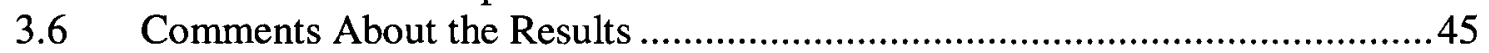

Chapter 4 Finite Element Analysis of a Fabric Aerostat.................................................46

4.1 Finite Element Model...............................................................................4

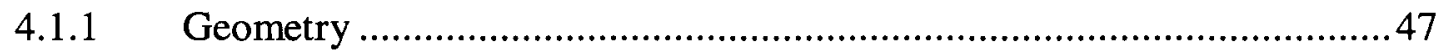

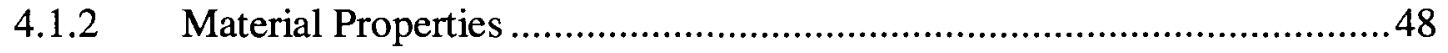

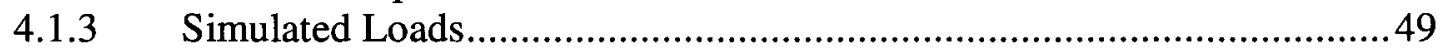

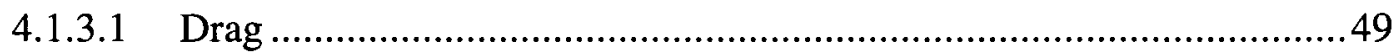

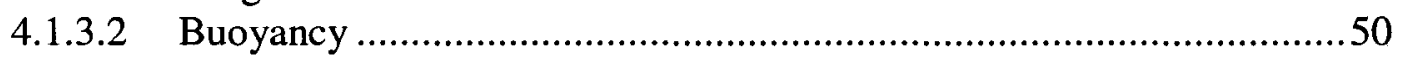

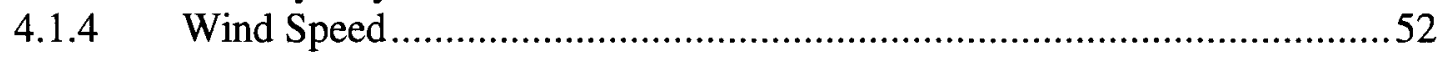

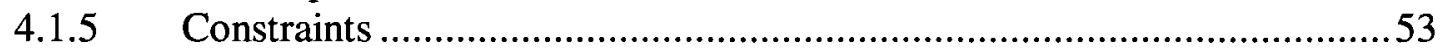

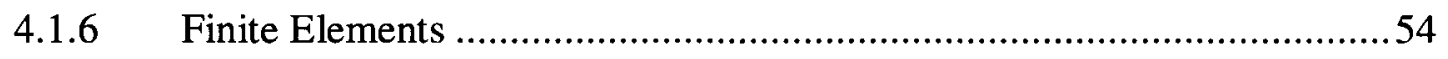

4.2 The Finite Element Analysis ……………………...................................5

4.2.1 Expected Results ...........................................................................5

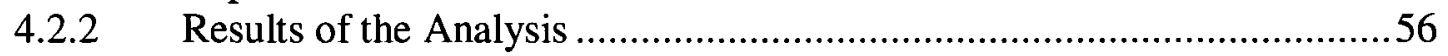

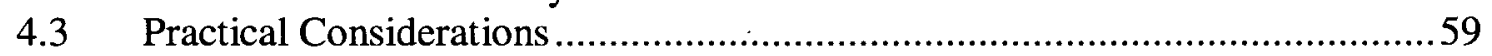

Chapter 5 Partial-Hard Aerostat Design.................................................................. 62

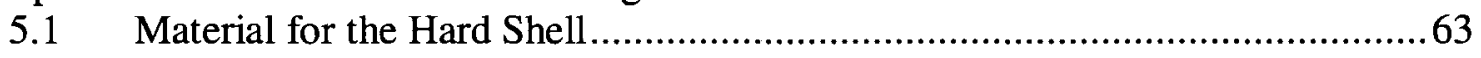

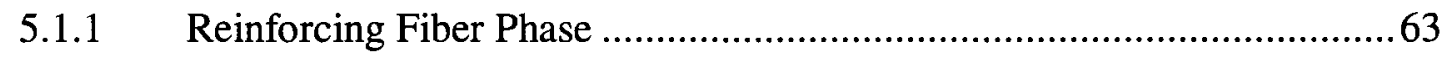

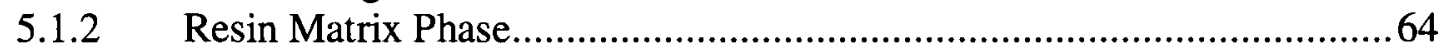

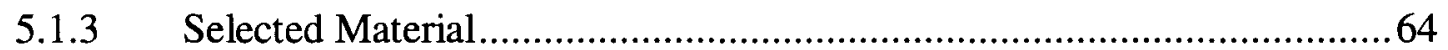

5.2 Designing the Partial-Hard Balloon ............................................................65

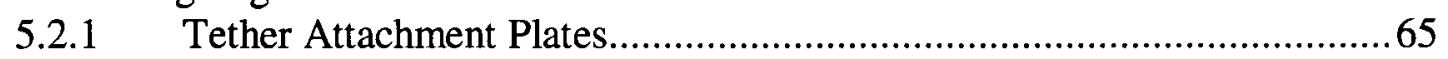

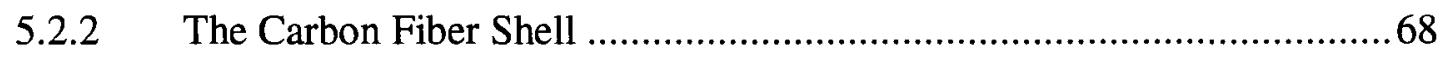

5.2.3 The Fabric Envelope-Carbon Fiber Shell Interface ……......................... 70

5.3 Finite Element Model...........................................................................

5.3.1 The Carbon Fiber Shell ................................................................

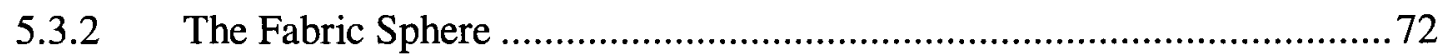

5.3.3 Loads, Constraints, and Other Approximations......................................73

5.4 Initial Results of the Finite Element Analysis ................................................73

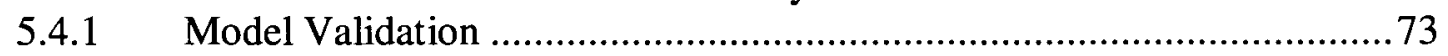

5.4.2 Stresses and Displacement in the Fabric Sphere.....................................74

5.4.3 Stresses in the Carbon Fiber Shell ......................................................

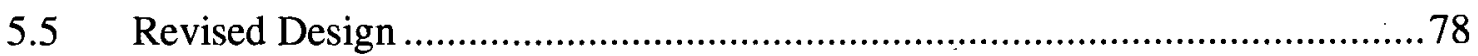

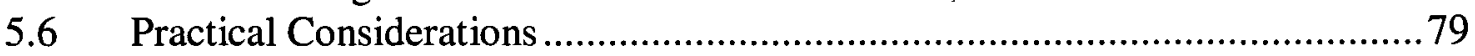

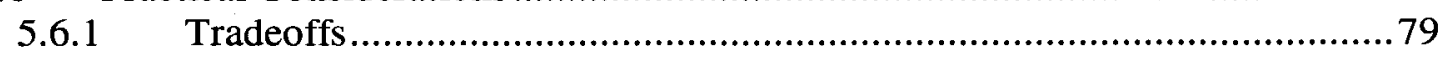

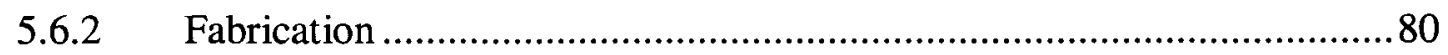

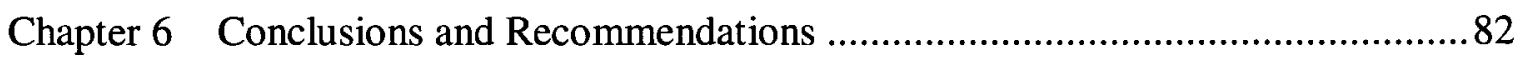

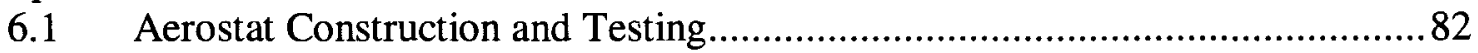

6.2 Structural Analysis and Partial-Hard Balloon Design ......................................8 83

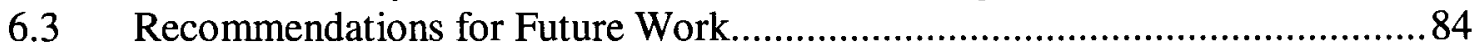

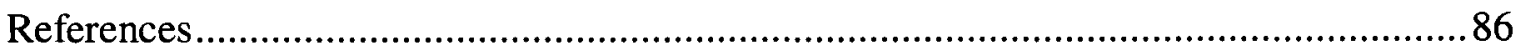




\section{List of Figures}

Figure 1.1 - Tethered Aerostat System [2] …........................................................... 1

Figure 1.2 - The TARS (left) and REAP (right) Aerostat Systems [7], [8]......................2

Figure 1.3 - NRC's Proposed Large Adaptive Reflector [9] .........................................2

Figure 2.1 - Free Body Diagram of a Spherical Aerostat in a Wind Flow .......................9

Figure 2.2 - Balloon Gores (Cylindrical Gore System) [29] ...................................... 10

Figure 2.3 - TCOM's Envelope Laminate [1], [2]................................................. 11

Figure 2.4 - Gore Types [29] ........................................................................... 14

Figure 2.5 - Balloon Bonded Coating-to-Coating ...................................................... 15

Figure 2.6 - Tether Attachment Using Load Patches [2] .......................................... 16

Figure 2.7 - Tether Attachment Using Straps ....................................................... 17

Figure 2.8 - A Modern, and Jacques Charles' Netted Balloon [23], [33] ....................... 17

Figure 2.9 - Sample Smalley Chart ........................................................................20

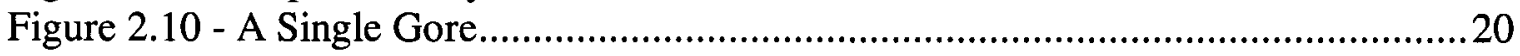

Figure 2.11 - Creating a Full Seam from Two Half-Seams......................................21

Figure 2.12 - The Ironing Template ...................................................................22

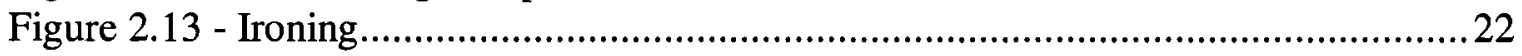

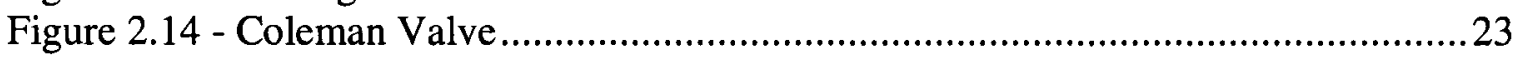

Figure 2.15 - Balloon, Net, and Rip Panel...............................................................225

Figure 3.1 - Experimental Setup .........................................................................27

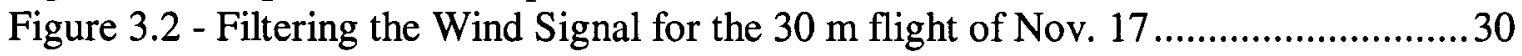

Figure 3.3 - Measured Wind Direction Signal for the $15 \mathrm{~m}$ Flight of Nov. 15 ...............31

Figure 3.4 - Decomposing the Aerostat's Position .....................................................32

Figure 3.5 - Illustrating the Imprecision in the GPS Position Measurements for the $30 \mathrm{~m}$

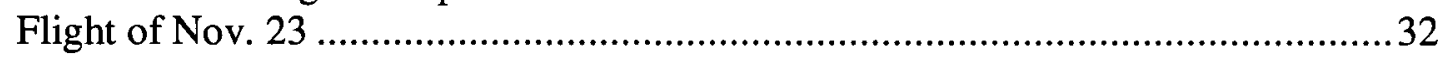

Figure 3.6 - Quasi-Static Free Body Diagram of the Balloon in Flight ...........................34

Figure 3.7 - The Wind Speed at the $10 \mathrm{~m}$ Sensor and the Altitude of the Balloon for the

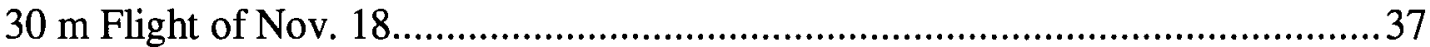

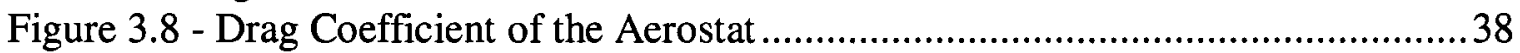

Figure 3.9 - Bird's-Eye View of the Aerostat's Oscillatory Motion...............................39

Figure 3.10 - The Transverse Motion During a Section of Constant Mean Wind Direction

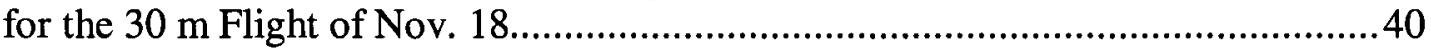

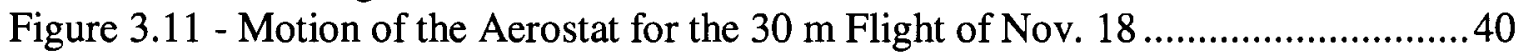

Figure 3.12 - Power Spectral Density of the Transverse Motions for the $30 \mathrm{~m}$ Flight of Nov. 18

Figure 3.13 - Transverse Oscillations for the $30 \mathrm{~m}$ Flight of Nov. 18 ..........................42

Figure 3.14 - Normalized Transverse Oscillation Frequencies ...................................43

Figure 3.15 - Transverse Oscillation Amplitudes for the $30 \mathrm{~m}$ Flight of Nov. 18..........44

Figure 3.16 - Normalized Transverse Oscillation Amplitudes .....................................44

Figure 4.1 - Side and Bottom Views of the $10.15 \mathrm{~m}$ Diameter Aerostat Model..............47

Figure 4.2 - A Real and Simulated Load Patch........................................................48

Figure 4.3 - Static Pressure Distribution Over a Smooth, Fixed Sphere [52]..................50

Figure 4.4 - The Mechanism of Buoyant Lift [1], [25] .............................................5 51

Figure 4.5 - An Aerostat Before and After Dimpling ............................................53 
Figure 4.6 - Change in Maximum Envelope Stress with Mesh Size.............................55

Figure 4.7 - Constraint Force on the Subtethers ................................................56

Figure 4.8 - Constraint Force in Each Tether (Bottom View of the Aerostat) .................57

Figure 4.9 - Stress Profile Over the Envelope in a $20 \mathrm{~m} / \mathrm{s}$ Wind (Range Narrowed to 1.02

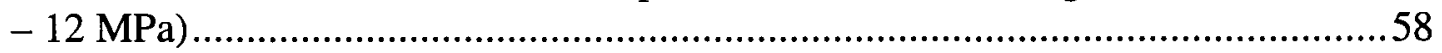

Figure 4.10 - Displacement Profile Over the Envelope in a $20 \mathrm{~m} / \mathrm{s}$ Wind (Range

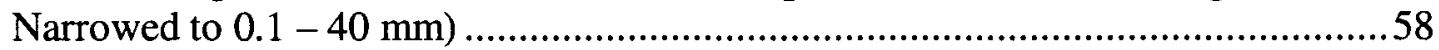

Figure 4.11 - Rise in Maximum Envelope Stress with Drag Force .............................60

Figure 5.1 - Carbon Fiber Fabric Types [55], [56]...............................................6 63

Figure 5.2 - Attaching the Tethers to the Aerostat ..................................................65

Figure 5.3 - Stresses in the Tether Attachment Plates...............................................67

Figure 5.4 - Dimensions of the Tether Attachment Plates..........................................68

Figure 5.5 - Partial-Hard Balloon at the Dimpling Speed of $20 \mathrm{~m} / \mathrm{s}$............................69

Figure 5.6 - Attaching the Fabric Balloon with Straps.......................................... 70

Figure 5.7 - The Simulated Carbon Fiber Shell and Tether Attachment Plates .............. 72

Figure 5.8 - The Simulated Straps..................................................................... 73

Figure 5.9 - Stresses and Displacements in the Fabric Section .................................... 74

Figure 5.10 - Stress in the Carbon Fiber Shell (Undeformed Shape) ............................77

Figure 5.11 - Redesigned Carbon Fiber Shell..........................................................78

Figure 5.12 - Stresses in the Revised Carbon Fiber Shell ...........................................79

Figure 5.13 - Fitting the Shell Into a Standard Semi-Truck Trailer .............................. 81 


\section{Chapter 1 Introduction}

The tethered helium aerostat is an old concept that is being revitalized due to the advent of new materials and applications. A typical tethered aerostat system, Figure 1.1 below, consists of a fabric envelope to contain the lifting gas, one or more tethers to moor the balloon to the ground, a flying harness to distribute the tether load over the aerostat, load patches through which the flying harness is attached to the envelope, and occasionally an electronically controlled pressure regulation system [1].

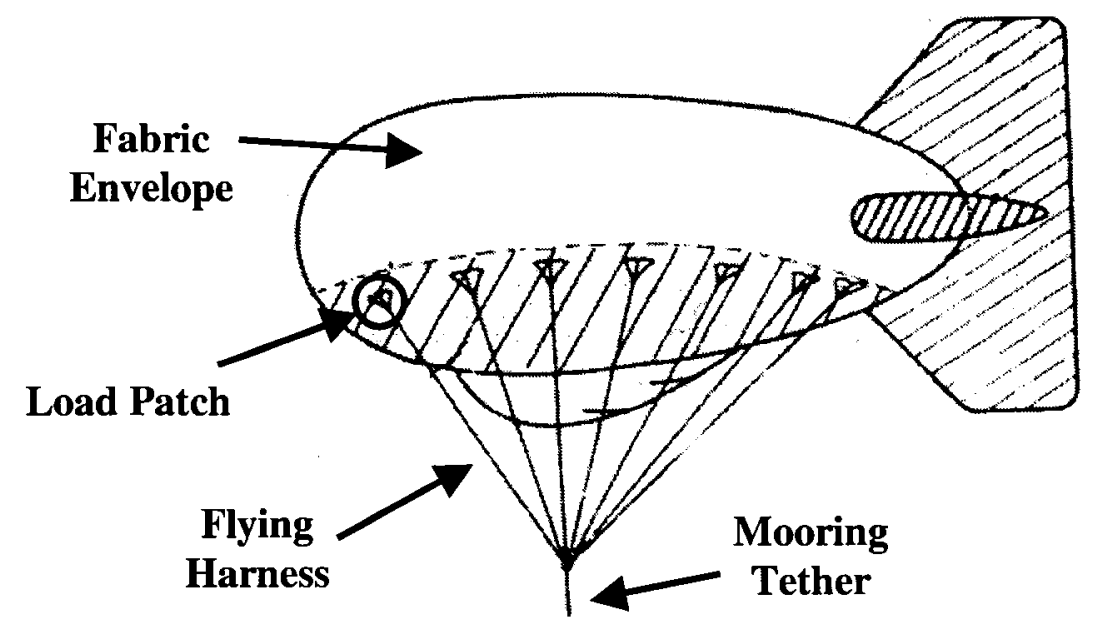

Figure 1.1 - Tethered Aerostat System [2]

Silent and non-intrusive, aerostats are particularly well suited for a variety of experiments of an environmental nature, such as supporting aerial imaging cameras for the observation of the behavior patterns of marine mammals [3]. Surveillance is another important area of application for modern aerostats. In this era of heightened concern 
about security, the United States Army and Border Patrol regularly uses tethered aerostats because they have long-duration surveillance capabilities and provide better coverage than surface-based radars [4]. TARS (Tethered Aerostat Radar System, Figure 1.2), a large aerostat-based border surveillance system, is currently being used for drug interdiction efforts in the southern United States [4]. The RAID (Rapid Aerostat Initial Deployment) prototype has helped alert the US Army of potentially fatal attacks in Afghanistan, and the REAP (Rapid Elevated Aerostat Platform, Figure 1.2), was built by Bosch Aerospace for the same purpose in Iraq [4], [5]. Another unusual application for a tethered aerostat is NRC's proposed Large Adaptive Reflector radio telescope, shown in Figure 1.3, which uses an aerostat to support its receiver at the reflector focus [6].
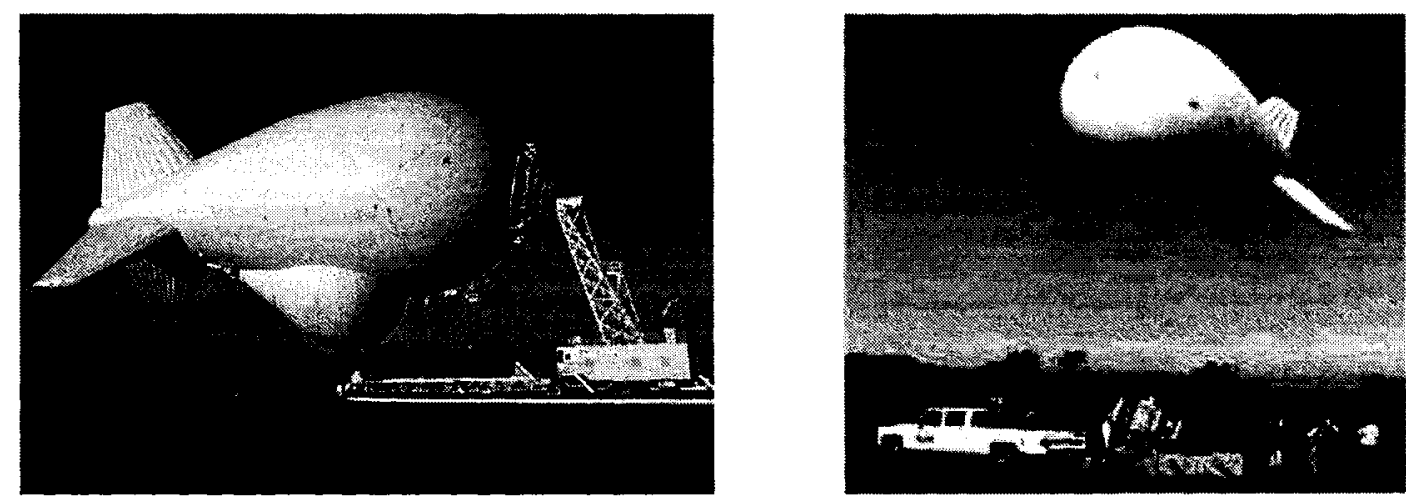

Figure 1.2 - The TARS (left) and REAP (right) Aerostat Systems [7], [8]

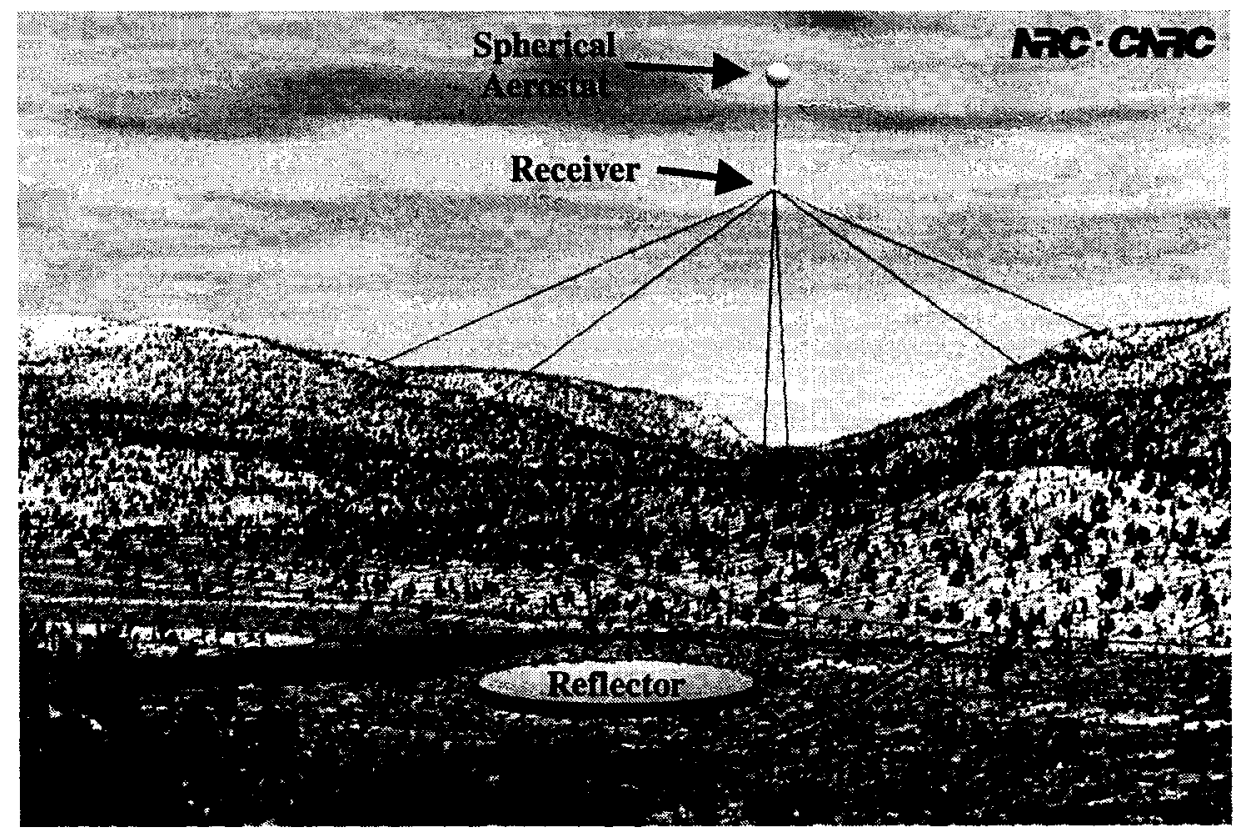

Figure 1.3 - NRC's Proposed Large Adaptive Reflector [9] 
In many of the aforementioned applications, it is critical, with respect to minimizing the operating costs as well as maintaining a constant stream of data acquisition, that the aerostat remain aloft for long durations of time without having to be retrieved and redeployed. Yet the airborne time of today's typical tethered aerostat system is generally limited by weather [4]. Balloons are not reliably able to survive high winds due to "dimpling", or a loss in envelope shape caused by the inflated fabric being unable to resist high surface pressures, and due to the point loads produced where the mooring lines meet the envelope. The use of synthetic materials and laminates with high strength-to-weight ratios, such as nylon and polyester, coupled with weather-resistant, heat-sealable and impermeable coatings, such as polyurethane, has improved the survivability and reliability of modern aerostats [1]. To create a near-perpetually deployed aerostat, however, other changes, such as the use of an ultra-robust envelope partially made from a hard material, must be investigated.

Designing a better aerostat requires knowledge of the conventional materials and construction techniques used to build tethered balloons, the dynamics of buoyant bodies, and how the stresses from the tether loads are distributed over the envelope. The research discussed in this thesis could have been performed on either spherically shaped aerostats or blimp-shaped, streamlined balloons. Although they have a higher drag coefficient, spherical aerostats were chosen for the analysis as they have a more optimum lift-toweight ratio, cost less and are simpler to manufacture and operate, see lower hoop stresses, and do not require a special ground-mooring apparatus to allow weathervaning [1].

\subsection{Related Work}

Tethered aerostat systems have received limited attention in the literature and the work has predominantly focused on the dynamics of streamlined aerostats, rather than construction methods for or structural analyses of spherical aerostats. In 1977 Arnold, who was working for aerostat development giant TCOM, discussed the requirements of materials used for tethered aerostats as well as the conventional fabrication methods for their hulls and the appropriate moorings systems [2]. Arnold's paper remains one of the 
few sources of such information that specifically focused on modern aerostat construction. However, concepts from the construction of other dirigibles, such as manned gas balloons and airships, can be drawn on and extended to the domain of aerostats.

The techniques used for fabricating gas balloons have changed little over the last century, and the 1926 work by Upson remains a key reference for the design and construction of gas envelopes and mooring structures [10]. In 1997 and 1998, Recks provided very thorough and more modern guides to building personal Helium blimps [11], [12]. These guides contain a wealth of information about envelope material, plotting 2-dimensional gores, and assembly procedures. More recently, in 1999, Khoury and Gillett [1] wrote a comprehensive review of numerous aspects of airship design. This included higher-level information on the materials and bonding procedures that are used in classical and modern airship envelopes and are also applicable to aerostat construction.

Despite the simplicity of the system, there have been few studies on the dynamics of tethered, buoyant spheres in a forcing fluid flow. The most relevant work was performed by Williamson and Govardhan who, in 1997, found that tethered, buoyant spheres in a steady flow will not maintain a constant angle but will tend to oscillate in a characteristic figure-of-8 motion [13]. They reported that the oscillation amplitudes were dependent on the flow speed and that the drag coefficients of the spheres were up to $100 \%$ higher than those for smooth, fixed spheres. Williamson and Govardhan also went on to investigate the influence of vortex shedding in exciting tethered spheres of differing sizes and tether lengths [14]. They found that there was a resonance when the stationary shedding frequency coincided with the natural pendulum frequency of the tethered systems, known as the 'lock in' phenomenon. Low mass spheres, however, oscillated at frequencies corresponding neither to the natural frequency nor to the vortex shedding frequency. Williamson and Govardhan et al. extended this analysis in 2001 [15], reporting high-speed modes of buoyant and heavy tethered sphere vibrations occurring at stream speeds higher than can be explained by classical lock-in. They only offered an explanation for this phenomenon in 2005, during a more thorough review of vortexinduced sphere vibrations [16], by speculating that a motion-induced force must have been exciting the tethered sphere's oscillation frequency. 
The only study found of the hull stresses on a tethered aerostat in flight was performed in 1982 by Hunt for TCOM [17]. Hunt used NASTRAN to study the stress contours over TCOM's larger aerostats. The balloons in the model were subjected to different internal pressures, gravitational forces, and experimentally determined aerodynamic pressures for a range of wind speeds from $0-90$ knots. Hunt evaluated the stresses in the tethers, whether buckling would occur, and the safety factors of the aerostat, finding the highest stresses were at the maximum diameter of the balloon and the load patches. The analysis was limited, though, as it considered only small deflections and used a coarse mesh, constrained by the computational power available, that did not allow for detailed stress concentration results. Hunt performed a second finite element stress analysis in 1993 to determine the survivability of a light weight nose structure for mooring an aerostat in high winds [18]. This analysis was complemented by a nonlinear dynamic simulation of the moored aerostat and demonstrated that the structure could withstand 90-knot winds with the appropriate safety factor, but it provided little information about the stresses in the hull. Other finite element analyses of lighter-than-air vehicles or structures, such as those by Amiryants et al. in 2002 [19] and Kraska in 2002 [20], give good insight into how to model a thin-walled, buoyant pressure vessel. However, these works looked at airship dynamics and envelope bending, rather than at detailed stress contours. Similarly, the finite element analyses of related tethered, fabric systems, such as sails or parachutes, focused on inflation characteristics rather than on stresses in the tether-attachment region, and are not appropriate to the task of evaluating aerostat failure.

In 1980, Durney outlined the causes of local failure in large aerostat envelopes [21]. He devised a means of preventing the propagation of local failures into catastrophic failures by installing a network of high-strength rip-stop material, thereby reducing damages and repair costs, but did not look into preventing local failures in the first place. Other studies directed at improving the robustness of free balloons, such as research on superpressure "pumpkin" shapes that allow long duration stratospheric flight [22], have not yet produced findings that lend themselves to mitigating failures due to concentrated loads in tethered aerostats. 


\subsection{Research Focus}

The research described here was directed at investigating new concepts for the design of a robust tethered, spherical balloon capable of withstanding high winds for long periods of time. As a first step, existing construction techniques were reviewed, replicated, and tested. The techniques were then improved upon with the aid of modern methods of analysis, design, and construction.

Conventional aerostat construction and design techniques were investigated from literature and by building a $2.5 \mathrm{~m}$ diameter spherical balloon designed for a maximum wind speed of $10 \mathrm{~m} / \mathrm{s}$, as discussed in Chapter 2. An appropriate envelope material was first selected and the size of the aerostat determined based on the lift requirements. Tether attachment and bonding methods were then chosen with the intent of finding a compromise between ease of implementation and robustness. The balloon was constructed by first transforming the $3 \mathrm{D}$ shape to $2 \mathrm{D}$ gores using standard $\mathrm{CAD}$ calculations and then heat-sealing the gores together to make the final envelope. When the envelope was completed, a safety device for inducing a controlled descent was installed.

The constructed balloon was flown to study its dynamics in various natural wind conditions and the details of the experiment are outlined in Chapter 3. The flights were performed in an open field at altitudes of 15,30 , and 45 meters with the aerostat tethered to the ground using a single lightweight synthetic rope. During the experiments the wind speed and direction, and the load in the main tether were all recorded. The aerostat's 3dimensional position was logged using an inexpensive differential GPS system. From the collected data, the drag coefficient and frequencies of motion of the tethered-aerostat system were studied as a function of wind condition. The merits of using an inexpensive differential GPS system to study tethered aerostat dynamics were also evaluated.

The results of the assessment of the operational qualities of the spherical aerostat were used to inform a structural analysis of the balloon's envelope, as described in Chapter 4. A CAD model of the tethered fabric inflatable was developed using Finite Element Analysis. Internal pressure and approximate aerodynamic surface pressures were applied to the model, and the wind speed at which the aerostat would first dimple was 
ascertained. The critical stresses in the envelope were then determined for this wind speed. To verify the accuracy and applicability of the model, the results were crossreferenced with analytic approximations and the experimental observations.

In Chapter 5, the results from the finite element analysis were used to design an ultra-robust aerostat with a partially hard shell, made of carbon fiber, in critical areas. The shell served the dual purpose of increasing the balloon's resistance to point loads from the tethers on the envelope and to prevent dimpling due to peak pressures at the stagnation point. A second FEA model was assembled to evaluate the structural performance of this partial-hard model against the fully fabric model. Comments were made on the usefulness of a partial-hard shell as compared to a fully fabric envelope, while considering the tradeoffs between an increased structural integrity and the envelope weight gain and more complicated build process.

The conclusions of the research as well as recommendations for improvements and future work are discussed in Chapter 6. 


\section{Chapter 2 Construction of a Small Helium Aerostat}

In order to better understand the issues involved in robust aerostat design, a singletethered aerostat was built using conventional construction methods. A spherical aerostat shape was chosen in order to allow the prototypes to be easily and repeatedly constructed. Following a review of construction methods and materials commonly used on modern aerostat envelopes, a suitable envelope size, configuration, and tether attachment method were selected, and the appropriate safety precautions applied.

\subsection{Design Requirements}

To achieve a good compromise between cost, ease of storage and handling, and a usable product, it was decided to construct the smallest balloon possible that would stay aloft in a $10 \mathrm{~m} / \mathrm{s}$ wind. This is the maximum operational wind speed typically used by Aerophile and Aerostar for their Helium inflatables [23], [24]. In consultation with Tim Cole, one of the world's foremost balloonists, it was determined that the aerostat should have at least $44.1 \mathrm{~N}(4.5 \mathrm{~kg})$ of net static lift when considering only the weight of the Helium and envelope in the lift calculation. It was decided that the balloon would need to drop $100 \mathrm{~m}$ within a minute in a $10 \mathrm{~m} / \mathrm{s}$ wind in case of an emergency where a rapid, controlled descent must be induced so the aerostat does not escape captivity. A final constraint was that the material employed in the envelope had to be workable and not require the use of special equipment for construction of the balloon. 


\subsection{Preliminary Theory}

Consider a tethered aerostat in a constant wind flow. It is commonly approximated for design purposes that the tether and aerostat will be "blown down" to a certain angle with respect to the vertical, as depicted in Figure 2.1, and eventually remain at that angle once a steady-state has been reached. If this is so, accelerations may be neglected, and the forces acting on the aerostat are those due to the tether, drag, and buoyancy. These forces are depicted in the free body diagram of Figure 2.1 .
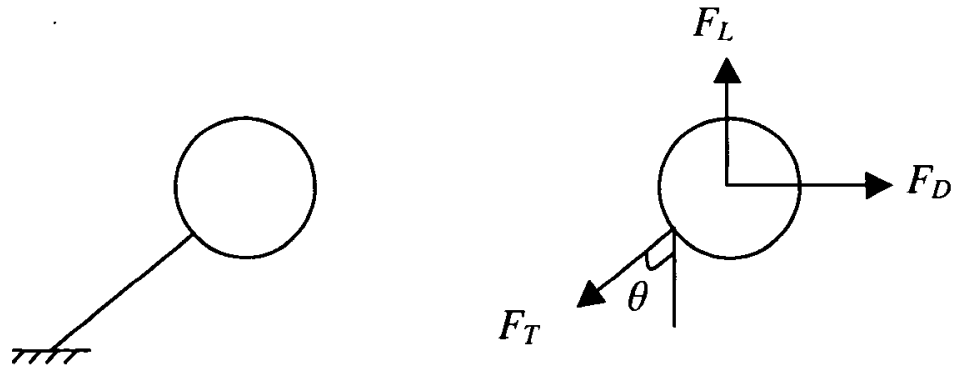

\section{Figure 2.1 - Free Body Diagram of a Spherical Aerostat in a Wind Flow}

When considering a sphere, Archimede's principle of buoyant force equaling the weight of the displaced fluid takes the form

$$
F_{b}=\frac{4}{3} \pi r^{3} \rho_{a i r} g
$$

where $F_{b}$ is the buoyant force, $g$ is the gravitational acceleration of $9.81 \mathrm{~m} / \mathrm{s}^{2}, r$ is the balloon radius, and $\rho_{a i r}$ is the density of the surrounding air. The net static lift of the aerostat, $F_{L}$, is the buoyancy less the weight of the envelope and enclosed Helium, and can be written as

$$
F_{L}=F_{b}-\frac{4}{3} \pi r^{3} \rho_{H e} g-(1.15)\left(4 \pi r^{2} \gamma g\right)
$$

where $\rho_{H e}$ is the density of Helium, and $\gamma$ the weight per unit area of the envelope material. The factor of 1.15 is included in the envelope weight to account for the extra weight of seams, valves, patches, and any other extra components, as recommended by Upson [10].

The drag force, $F_{D}$, on a stationary, fixed sphere subjected to a fluid flow is [25] 


$$
F_{D}=\frac{1}{2} C_{D} \rho_{\text {air }} u^{2} \pi r^{2}
$$

In equation ( 2.3 ), $u$ is the wind speed and $C_{D}$ the drag coefficient of the system. Assuming the tethered balloon is stationary at an equilibrium "blowdown" angle in the wind flow, the force in the tether, $F_{T}$, may be calculated as

$$
F_{T}=\sqrt{F_{L}^{2}+F_{D}^{2}}
$$

Since the mooring tether was expected to be small, on the order of $1.5 \mathrm{~mm}$ in diameter and $1 \mathrm{~N} / 100 \mathrm{~m}$ in weight, the effect of its weight and drag on the aerostat was neglected for calculations of the forces seen by the inflatable.

\subsection{Envelope Design}

In conventional spherical aerostat construction, the envelope is most commonly made from 2-dimensional slices of material, or gores, that are assembled to make the 3dimensional shape (Figure 2.2). Constructing Helium inflatable envelopes therefore required consideration of materials, gore bonding methods, and envelope size.
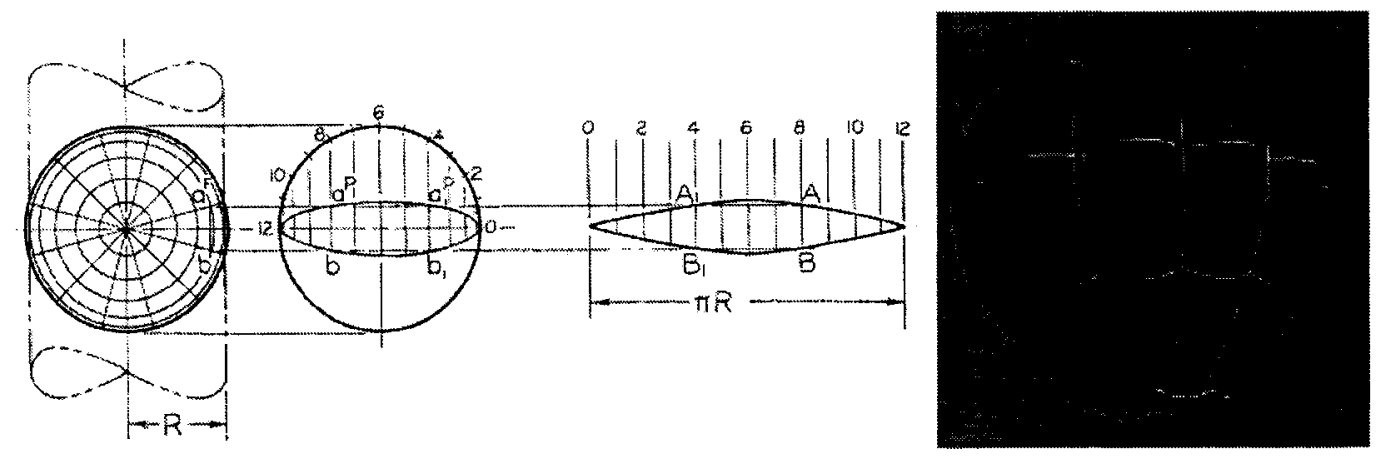

Figure 2.2 - Balloon Gores (Cylindrical Gore System) [29]

\subsubsection{Materials}

In 1977, Arnold listed a set of criteria for the tensile, shear, and tear strength, ply adhesion, and flexlife of a material used for large aerostats, such as TCOM's $250000 \mathrm{ft}^{3}$ $\left(7000 \mathrm{~m}^{3}\right)$ Mark VII [2]. These criteria dictate that fabrics must have a high strength-toweight ratio, low Helium permeability, good flexure and abrasion resistance, and strong and reliable joining techniques. The material must also feature low creep to ensure the 
shape is maintained, high tear resistance, and a high resistance to environmental degradation [1]. One of the most significant advances in aerostat design over the past few decades is the use of synthetic materials and laminates with high strength-to-weight ratios, rather than traditional natural fibers, in order to meet these criteria [1].

Large aerostats employ laminates consisting of a layer to protect against the environment, a gas retention layer, and a woven load-bearing layer, as illustrated in Figure 2.3 [1], [2]. For example, TCOM has been successfully using an $8 \mathrm{oz} / \mathrm{yd}^{2}$ $\left(271 \mathrm{~g} / \mathrm{m}^{2}\right)$ Dupont polyvinylflouride/polyester/polyester laminate, Tedlar/Mylar/Dacron, bonded with the Dupont polyester elastomer Hytrel for over 25 years [2].

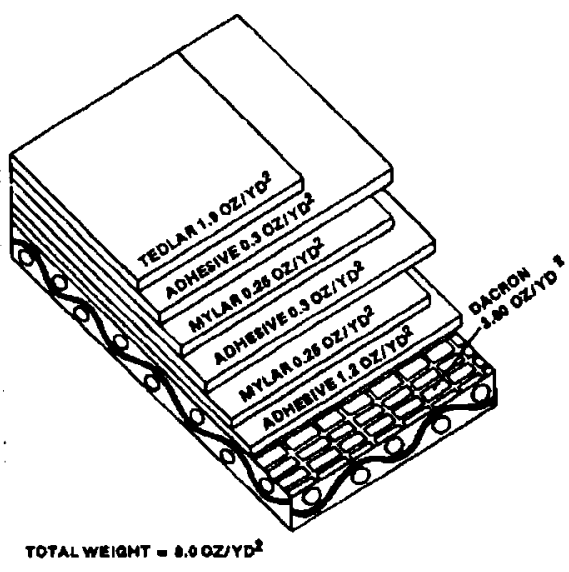

Figure 2.3 - TCOM's Envelope Laminate [1], [2]

Smaller aerostats, such as those considered here, tend to employ ultra-light materials that consist of only a load-bearing base with a linen binding and rip-stop thread, and an applied coating or film as the gas barrier. Polyesters such as Dacron, polyamides such as nylon, and polyurethane are the most suitable base fabrics because of their high strength-to-weight ratios, and ease of manipulation, bonding, and construction [1], [11]. Common gas barrier components include neoprene, polyurethane, and polyvinylfluoride.

\subsubsection{Material Selection}

There are few small-scale distributors of laminated synthetic Helium inflatable material. Rather, the market consists predominantly of companies that sell finished aerostats or coated fabric to airship manufacturers. Selection of material was therefore constrained by issues of availability. 
Recks supplied a list of distributors who specialize in fabrics for smaller Helium inflatables [11], from which only Perftex, Uretek, and Lamcotec still cater to balloon builders and manufacturers. Following a process of consultation with members of the Balloon Federation of America Gas Division (BFA) [26] and with the companies themselves, Lamcotec [27] was chosen as the as the optimum supplier, both because of their experience dealing with amateur and professional balloonists and because they could provide the material on a timely basis.

Lamcotec and the members of BFA recommended urethane-coated nylon for small aerostats since it can be heat-sealed in-house using a common iron, and has successfully been applied to small manned Helium balloons. Samples of available materials were provided for evaluation by Lamcotec. Based on this, the $4.2 \mathrm{oz} / \mathrm{yd}^{2}$ $\left(142 \mathrm{~g} / \mathrm{m}^{2}\right)$ single-coated heat-sealable \#109 70 denier urethane-coated nylon taffeta was selected, as it was the lightest material available that could be easily manipulated while also meeting the design requirements with respect to break strength, as discussed in section 2.3.3. The properties of the selected material are shown in Table 2.1.

Table 2.1 - Properties of Lamcotec's \#109 Heat-Sealable 70 Denier Urethane-Coated Nylon Taffeta [27]

\begin{tabular}{|c|c|c|c|}
\hline $\begin{array}{c}\text { Basic Fabric } \\
\text { Weight }\end{array}$ & $\begin{array}{c}59.3 \mathrm{~g} / \mathrm{m}^{2} \\
\left(1.8 \mathrm{oz} / \mathrm{yd}^{2}\right)\end{array}$ & $\begin{array}{c}\text { Elongation at } \\
\text { Break }\end{array}$ & $\begin{array}{c}38 \% \text { Warp } \\
54 \% \text { Weft }\end{array}$ \\
\hline Total Weight & $\begin{array}{c}142 \mathrm{~g} / \mathrm{m}^{2} \\
\left(4.2 \mathrm{oz} / \mathrm{yd}^{2}\right)\end{array}$ & Thickness & $0.15 \mathrm{~mm}$ \\
\hline Tongue Tear & $\begin{array}{c}8.9 \mathrm{~N} \text { Warp } \\
7.6 \mathrm{~N} \text { Weft }\end{array}$ & $\begin{array}{c}\text { Strip Adhesion } \\
\text { (Heat Sealed) Film } \\
\text { to Film }\end{array}$ & $48 \mathrm{~N} / 25 \mathrm{~mm}$ \\
\hline Breaking Strength & $679 \mathrm{~N}$ Warp & Permeability to & $1.5-2.0 \mathrm{~L} / \mathrm{m}^{2}$ \\
& $569 \mathrm{~N}$ Weft & Helium & $124 \mathrm{hrs}$ \\
\hline
\end{tabular}

Test Reference: Mil-C-83489, Fed-STD 191A, Mil-STD 810D, ASTM, Cal. Bulletin 117, CFR, NFPA 


\subsubsection{Envelope Size}

Selection of material and determination of the envelope size had to be considered simultaneously because the weight of the material was needed in order to determine the aerostat size that would be appropriate for the given application, as well as the forces that would be endured in a wind flow.

The size of the aerostat was calculated using equations ( 2.1 ) and ( 2.2 ) from section 2.2. $F_{L}$ was set to the minimum design value mentioned in section 2.1 of $44.1 \mathrm{~N}$, and because the experiments were expected to take place at sea level and in the $25^{\circ} \mathrm{C}$ temperature range, $\rho_{a i r}$ was taken to be $1.23 \mathrm{~kg} / \mathrm{m}^{3}$ and $\rho_{H e} 0.179 \mathrm{~kg} / \mathrm{m}^{3}$ [28]. The specific weight of the material, $\gamma$, was set to the $142 \mathrm{~g} / \mathrm{m}^{2}$ of the selected Lamcotec 70-denier urethane coated nylon. Substituting equation ( 2.1 ) for $F_{b}$ in equation ( 2.2 ) and solving for the radius $r$, the minimum radius of the balloon that meets the design requirements is calculated to be $1.19 \mathrm{~m}$. The radius chosen for the aerostat was $1.25 \mathrm{~m}$, which would generate a lift force of $53.2 \mathrm{~N}$ according to equations ( 2.1 ) and ( 2.2 ).

The worst-case load the fabric was expected to endure was that from a single tether at the maximum design speed distributed over a $25 \mathrm{~mm}$ width at the tetherenvelope interface, the width of an average tether attachment strap used by Aerostar [24]. Equations ( 2.3 ) and ( 2.4 ) were used to determine if the selected material would have the necessary strength for the forces experienced in the design wind speed of $10 \mathrm{~m} / \mathrm{s}$. The only experimental drag coefficient data available for tethered, buoyant spheres is that by Willamson and Govardhan for subcritical flow of up to $\operatorname{Re}=14000$ [14]. The Reynolds number for a $1.25 \mathrm{~m}$ radius sphere in a $10 \mathrm{~m} / \mathrm{s}$ wind is $1.74 \times 10^{6}$, which is supercritical [25]. Since subcritical drag coefficients tend to be larger than supercritical, the design was conservatively performed with the value of $C_{D}=0.7$ published by Williamson and Govardhan. Using equation ( 2.3 ) the drag force is found to be $211 \mathrm{~N}$. Using equation ( 2.4 ) the maximum, point-load tether force is $217 \mathrm{~N}$. This results in a stress of $57.9 \mathrm{MPa}$ when considering the application width of $25 \mathrm{~mm}$ and the Lamcotec 70 denier nylon material thickness of $0.15 \mathrm{~mm}$. Since the Lamcotec material has a breaking strength of $569 \mathrm{~N} / 25 \mathrm{~mm}$ in the weaker weft direction, or $152 \mathrm{MPa}$ when considering the material's thickness, there is a safety factor of 2.6 with the selected material. 


\subsubsection{Gore Configuration}

In designing an aerostat, a choice can be made regarding the number of gores and their shape. For smaller aerostats, cylindrical single-piece gores tend to be used, rather than conical or multi-piece gores, in order to reduce the number of seams, Figure 2.4.

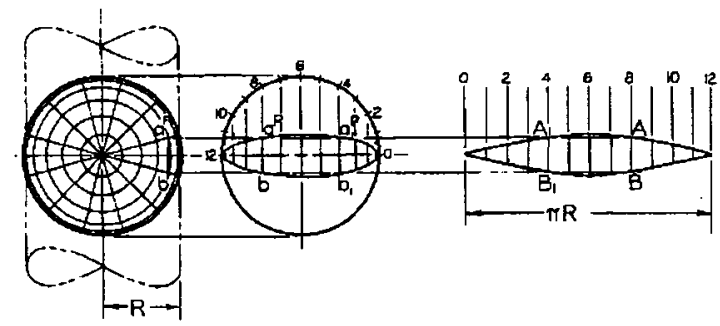

Cylindrical

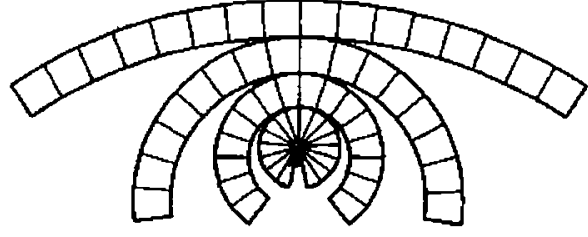

Conical

Figure 2.4 - Gore Types [29]

Increasing the number of cylindrical gores makes the balloon less polygonal and more spherical, and an even number of gores is used in order to have symmetry [10]. A 6gore configuration, as found on such spheres as the Southern Balloon Works bladders [30], is the minimum required to maintain a spherical shape and, in industry, preference is given to gore numbers that are multiples of 6 . The limiting gore arrangement of 6 was chosen in order to minimize the number of seams that needed to be sealed, thereby reducing both construction time and the chance for fabrication errors.

\subsubsection{Bonding}

There are several methods available to seal aerostat fabrics together. A more traditional method, used on the cotton-rubber envelopes in the early $20^{\text {th }}$ century, is to sew two gores together, glue the joint using rubber cement, and cover the seam with a strip of material, called a load tape, bonded over the seam. This method is still used in the hot air ballooning industry, where low permeability and stress resistance are not as critical requirements.

Modern Helium-impermeable materials tend to be either heat-sealed or glued in order to obtain a better load distribution throughout the seam and better resistance to shear, heat, and environmental degradation. Heat sealing is preferred over gluing as it 
improves joint reliability by allowing greater control over the joining process [1], and is more cleanly performed.

A series of $0.025 \mathrm{~m}$ wide by $2 \mathrm{~m}$ long test seams was constructed with the Lamcotec material to see if closing a seam using adhesives would yield any significant advantage over heat-sealing. HH-66 Vinyl Cement from the RH Company, the glue recommended by both Aerostar and Southern Balloon Works for bonding urethane coated nylon, was used to make the adhesively-sealed seam. The heat-sealed seams were made with a Teflon-coated Hobbico Custom Sealing Hobby Iron, typically used for building model airplanes. The adhesively-sealed seams were less smooth and less consistent with more penetrations than the heat-sealed ones. Further, though it took 50\% less time to create a seam by gluing rather than ironing, if curing time is taken into account, adhesivesealing took significantly longer. Thus, it was decided to heat-seal the aerostat's seams.

When heat-sealing Helium ballooning materials, larger airships go through a complex process of butt-joining the laminate material [1]. However, for smaller balloons that see lower stresses at the seams, a simpler edge-to-edge heat-sealing process is used, with the laminate welded coating-to-coating. The result is an aerostat in which the direction the coating faces changes from gore to gore, as illustrated in Figure 2.5. Alternating the gores in this way can be done because the fabric's single-sided coating is Helium impermeable whether it faces the inside or outside of the balloon. Noting that Aerostar uses 1" seams on their $3.5 \mathrm{~m}$ balloons [24], and based on our own tests with seams ranging from $1 / 4 "$ - 1 ", it was decided to use a 1 " seam on the $2.5 \mathrm{~m}$ balloon for additional robustness and Helium impermeability.

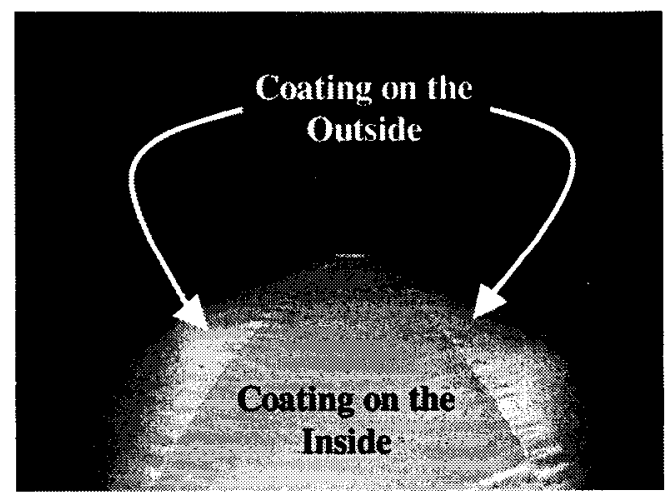

Figure 2.5 - Balloon Bonded Coating-to-Coating 


\subsection{Tether Attachment}

\subsubsection{Attachment Methods}

A critical design factor when building an aerostat is how to secure the tethers to the envelope. The tether attachment points must resist the resultant of the forces that are acting on the balloon system and, hence, are the areas most prone to envelope failure.

The method of fastening the main tether to the balloon used most commonly by aerostat manufacturers, such as TCOM [31], is to splice the tether into sub-ropes that are individually joined to the balloon via load patches, large patches of material on the side of the balloon that are designed to bear load, as shown in Figure 2.6. This method is lightweight and will support any aerostat configuration, but it generates large, undesirable point loads where the tethers meet the envelope. Furthermore, though the intention of splicing the main tether into sub-ropes is to somewhat distribute the forces over the aerostat, these forces are not always spread evenly among the ropes. An example of this is when an aerostat pitches or rolls in severe wind conditions and several of the tethers become slack while others are still taut.

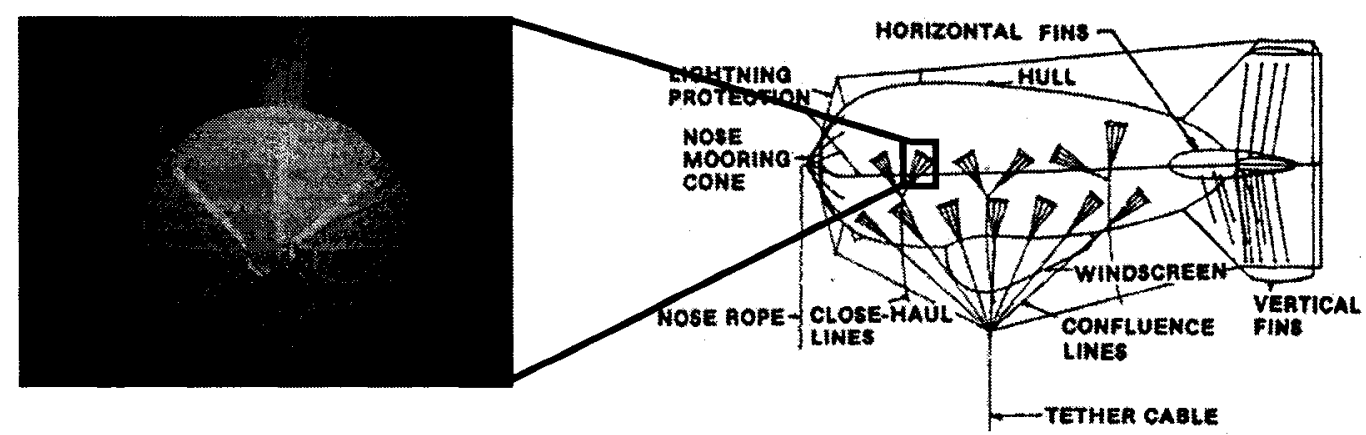

Figure 2.6 - Tether Attachment Using Load Patches [2]

A second attachment method is to fix the tethers to straps that start at the top of the balloon and run down its perimeter, as in Figure 2.7. This technique is lightweight and generally most useful on symmetric, round shapes. Though this method results in a slightly better load distribution on the envelope, there are still load concentrations at the point where the strap detaches from the aerostat surface. These load concentrations tend to be magnified in high winds and during uneven loading, as illustrated Figure 2.7. 


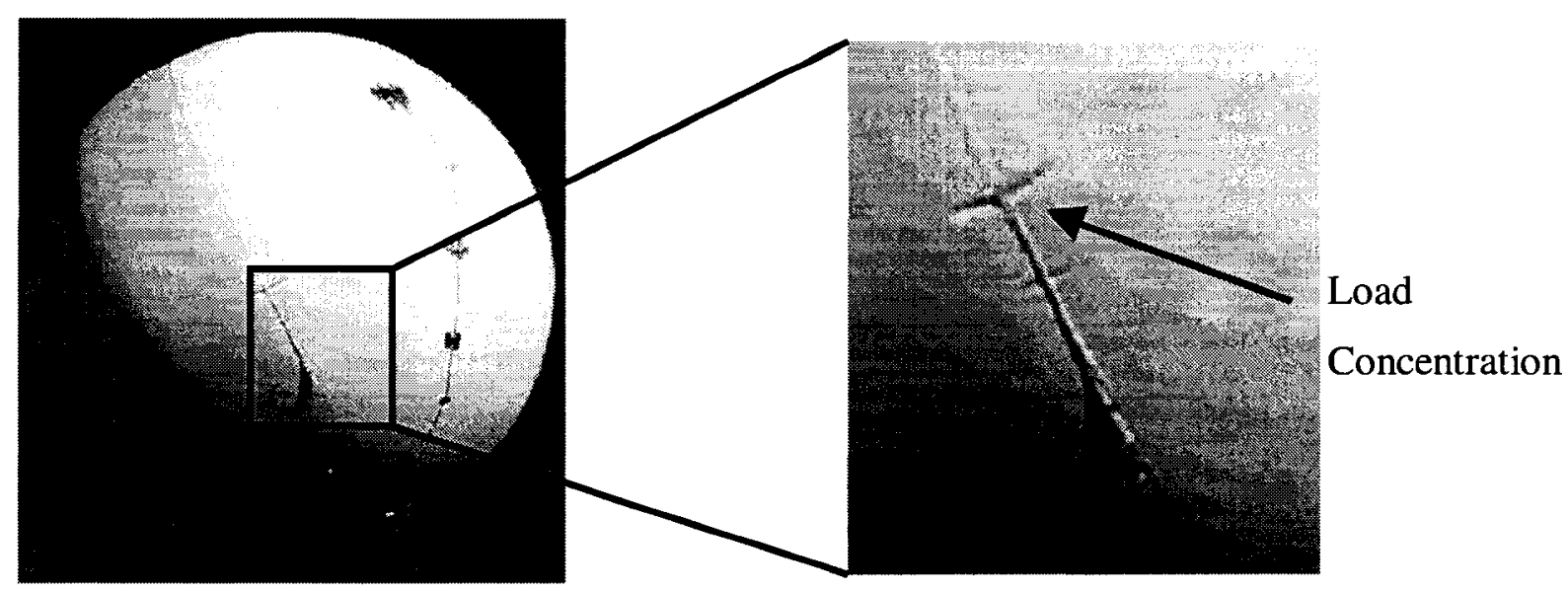

Figure 2.7 - Tether Attachment Using Straps

Yajima stated that the only way to properly distribute large loads generated in the tethers over a spherical envelope is to use a cover net or a short curtain with shrouds [32], a method that has been in use for well over a hundred years [10]. Since gas ballooning's start with Jaques Charles in 1783, passenger baskets were held on by tethers spliced into a net that hung over the balloon envelopes. This approach is the heaviest and, due to the high cost of manufacturing a specially shaped net, is most applicable to spherical balloons. But it is also the method that best distributes the loads over the envelope.

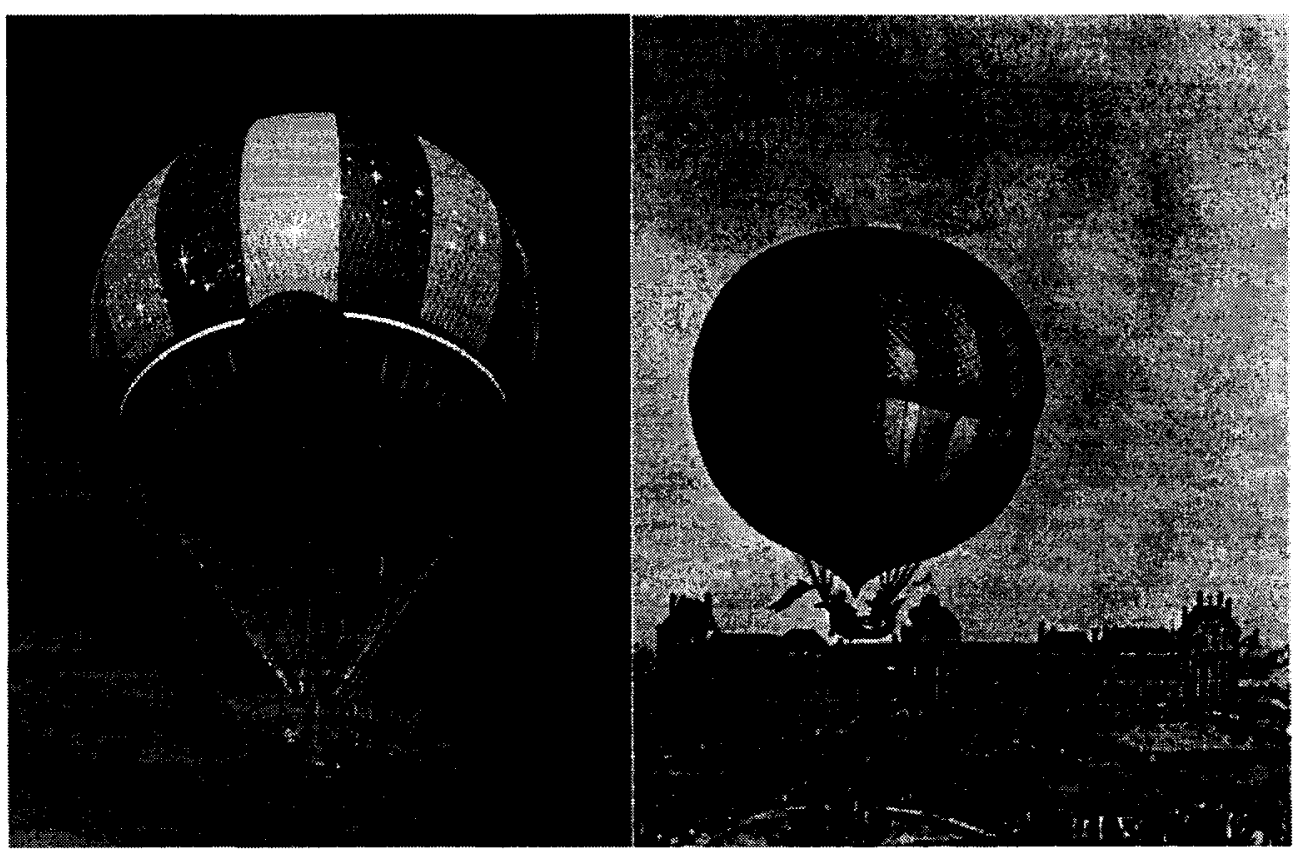

Figure 2.8 - A Modern, and Jacques Charles' Netted Balloon [23], [33] 
As our object was to study aerostats that can withstand high loads with a specific focus on the tether attachment points, the net attachment method was deemed to be most suitable due to its load distribution advantage.

\subsubsection{The Purchased Net}

Qued Seaway Plastics Ltd had an abundant supply of available product and was therefore chosen to source the balloon's net. Qued's 2-180B untreated, natural nylon netting was selected because it is their lightest and has a break strength of $890 \mathrm{~N}$, well above the needed $217 \mathrm{~N}$ minimum discussed in section 2.3.3. The net's properties are featured in Table 2.2 below. The untreated netting was chosen because the urethane coating, though it protects the net from degradation, was found to coarsen the strands, and scuffed the exposed urethane coating on the balloon when rubbed against it.

Table 2.2 - Properties of Qued's 2-180B Net [34]

\begin{tabular}{|c|c|c|c|}
\hline Net Mesh Size & $45 \mathrm{~mm}(13 / 4 ")$ & Break Strength & $890 \mathrm{~N}(200 \mathrm{lbf})$ \\
\hline $\begin{array}{c}\text { Material } \\
\text { Composition }\end{array}$ & $\begin{array}{c}\text { Untreated Natural } \\
\text { Nylon }\end{array}$ & Available Borders & Rope \\
\hline Strand Diameter & $2.5 \mathrm{~mm}$ & Specific Weight & $170 \mathrm{~g} / \mathrm{m}^{2}$ \\
& & & $\left(3.5 \mathrm{lbs} / 100 \mathrm{ft}^{2}\right)$ \\
\hline
\end{tabular}

\subsubsection{Net Design}

Upson described the optimal design of a load-bearing net [10]. He stated that the net should cover the balloon down to $35^{\circ}$ below the equator, with the subsequent tethers being long enough so they make a $35^{\circ}$ angle with the vertical. As well, the net should be form-fitted to the 3-D shape and should have a changing mesh size based on the loading requirements of each part of the sphere, in order to conserve weight. Upson also recommended that the net should taper off into a set of "crow's feet" that eventually become the tethers [10]. However, since changing the mesh size over the net significantly increases its price as well as manufacturing time, this was not done. For the same reasons, rather than having the net taper off into a set of "crow's feet" that eventually become the 
tethers, it was trimmed $35^{\circ}$ below the balloon's equator and a lash was placed around its bottom circumference to which the tethers were attached. A $6.43 \mathrm{~m}$ x $6.43 \mathrm{~m}$ square of the net, each side equivalent to half the $2.5 \mathrm{~m}$ balloon's circumference plus double its radius, was therefore purchased.

\subsubsection{Loss in Lift Due to the Net}

To determine the loss in lift from the chosen tether attachment method, the weight of the net was estimated by assuming a coverage of $3 / 4$ of the aerostat's entire surface area, corresponding to a net that came down to $35^{\circ}$ below the equator plus an extra allowance for the lash and the clips used to attach the tethers. The modified net static lift of the balloon, $F_{\text {Lnet }}$, is then

$$
F_{\text {Lnet }}=F_{L}-\frac{3}{4}\left(4 \pi r^{2} \gamma_{n e t}\right)
$$

where $\gamma_{n e t}$ is the specific weight of the net material, or $170 \mathrm{~g} / \mathrm{m}^{2}$. With $F_{L}$ being the previously calculated value of $53.2 \mathrm{~N}$, the net reduces the lift of the balloon to $28.6 \mathrm{~N}$.

In order to see how 'aloft' the final balloon design would be in the design wind speed of $10 \mathrm{~m} / \mathrm{s}$, the blowdown angle, the angle the tether makes with the vertical in the given stream flow ( $\theta$ in Figure 2.1), was evaluated. The blowdown angle is defined as

$$
\theta=\tan ^{-1}\left(\frac{F_{D}}{F_{\text {Lnet }}}\right)
$$

Using equation ( 2.6 ) for a $2.5 \mathrm{~m}$ diameter sphere in a $10 \mathrm{~m} / \mathrm{s}$ wind, taking $F_{D}$ to be the value of $211 \mathrm{~N}$ mentioned in section 2.3.3, the blowdown angle is $82.3^{\circ}$, which was considered marginal, but acceptable as a maximum.

\subsection{Envelope Construction}

To assemble the aerostat, the gores were first traced and cut from the sheets of urethanecoated nylon, and then fused together to make the spherical shape. One end of the aerostat was sealed off using a valve, and an end-patch of material was fixed to the other. Balloons of $1 \mathrm{~m}$ and $1.5 \mathrm{~m}$ diameters were built first in order to test ironing properties, seam size, and to identify any difficulties that might arise during construction. 


\subsubsection{Making the Gores}

When building naturally-shaped balloons, hot air balloon enthusiasts use a Smalley Chart [35], [36] to trace the gores on sheets of material. The chart, Figure 2.9, was created by Smalley in the 1960s during his research of naturally shaped axisymmetric balloons. Given the number of gores in the balloon, the diameter, and seam width or allowance, the chart gives a set of coordinates that, when plotted on a sheet of material, connect to produce the shape of a gore.

\begin{tabular}{|c|c|c|c|c|c|c|c|c|}
\hline \multicolumn{3}{|c|}{ Dianeter } & \multirow{2}{*}{$\begin{array}{l}2.50 \\
6.00\end{array}$} & \multirow[t]{2}{*}{ meters } & \multirow[t]{2}{*}{ Gore } & \multirow[t]{2}{*}{ Iength } & \multirow[t]{2}{*}{3.9270} & \multirow[t]{2}{*}{ meters } \\
\hline Hu=b & er & f Gores & & & & & & \\
\hline \multicolumn{3}{|c|}{ Sean Mllovance } & 0.025 & meters & & & & \\
\hline & & & & & & & & \\
\hline & & & & & & & & \\
\hline & & radius & station & station & & & sewn half & cut half \\
\hline $\mathrm{s}$ & & $r$ & height & radius & diameter & perimeter & gore & gore \\
\hline$\%$ & & $\%$ & meters & meters & meters & meters & meters & meters \\
\hline & .00 & 0.00 & 3.9270 & 0.00000 & 0.00 & 0.00 & 0.00000 & 0.01270 \\
\hline 0 & 98 & 0.06 & 3.8485 & 0.07849 & 0.16 & 0.49 & 0.04110 & 0.05380 \\
\hline 0 & 96 & 0.13 & 3.7699 & 0.15667 & 0.31 & 0.98 & 0.08203 & 0.09473 \\
\hline 0 & 94 & 0.19 & 3.6914 & 0.23423 & 0.47 & 1.47 & 0.12264 & 0.13534 \\
\hline 0 & .92 & 0.25 & 3.6128 & 0.31086 & 0.62 & 1.95 & 0.16277 & 0.17547 \\
\hline 0 & 90 & 0.31 & 3.5343 & 0.38627 & 0.77 & 2.43 & 0.20225 & 0.21495 \\
\hline 0 & 88 & 0.37 & 3.4558 & 0.46016 & 0.92 & 2.89 & 0.24094 & 0.25364 \\
\hline n & oc & $n \quad 1$ & ว วทวา & n巨วววว & 1 nc: & $=31$ & n $370<7$ & n 30137 \\
\hline
\end{tabular}

Figure 2.9 - Sample Smalley Chart

Referring to Figure 2.9 above and Figure 2.10 below, the third column of the Smalley Chart represents the station height, or the distance along the perimeter up the gore. The smaller the distance between two station heights, the smoother the gore profile. Typically, a gore is split into 30 stations for smaller balloons and airships, and up to 200 sections for larger ones [10], [11]. For the project at hand, 50 stations were arbitrarily selected.

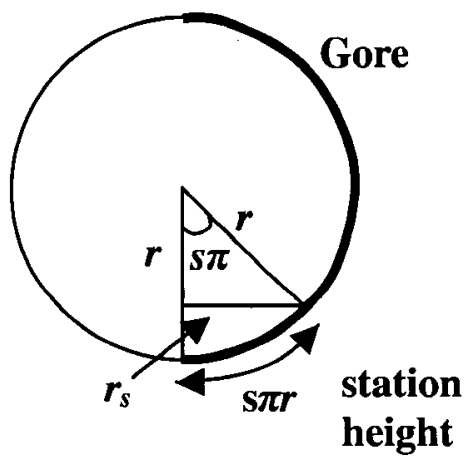

(a) A Gore on a Balloon

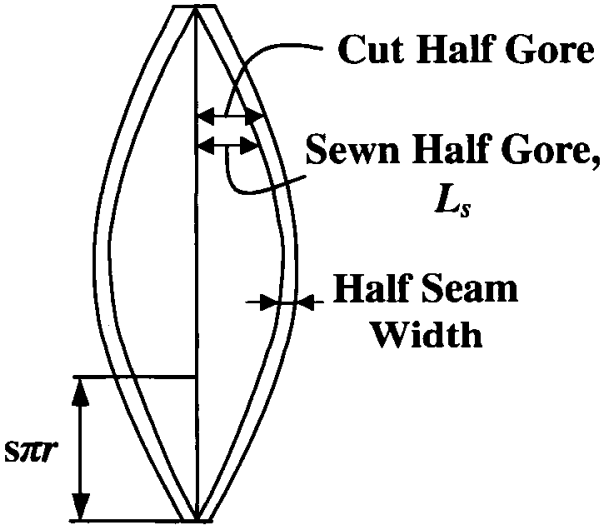

(b) The Gore from (a) Laid Flat

Figure 2.10 - A Single Gore 
The fourth column of the Smalley Chart is the radius of the balloon at the given station height, $r_{s}$. With $r_{s}$, the sphere's perimeter at each station height may be obtained. Based on that perimeter, we can calculate the width of the "sewn half gore," $L_{s}$, shown in Figure 2.10 and given in the seventh column of Figure 2.9, which is the distance from the middle of the gore to the outer edge, less the seam tolerance and defined as

$$
L_{S}=\frac{\pi r_{s}}{G}
$$

where $G$ is the number of gores. To get the "cut half gore" of column 8 , which defines the curve along which the gore is cut out of the material, half the seam width, or $1 / 2$ ", is added to $L_{s}$. As shown in Figure 2.11, the dashed lines on either gore are overlapped when the seam is sealed, thus creating a full 1 " seam out of the $1 / 2$ " contributions from each gore. The gore profiles were each traced onto the sheets of material using the Smalley Chart, and the gores cut out using ordinary scissors.
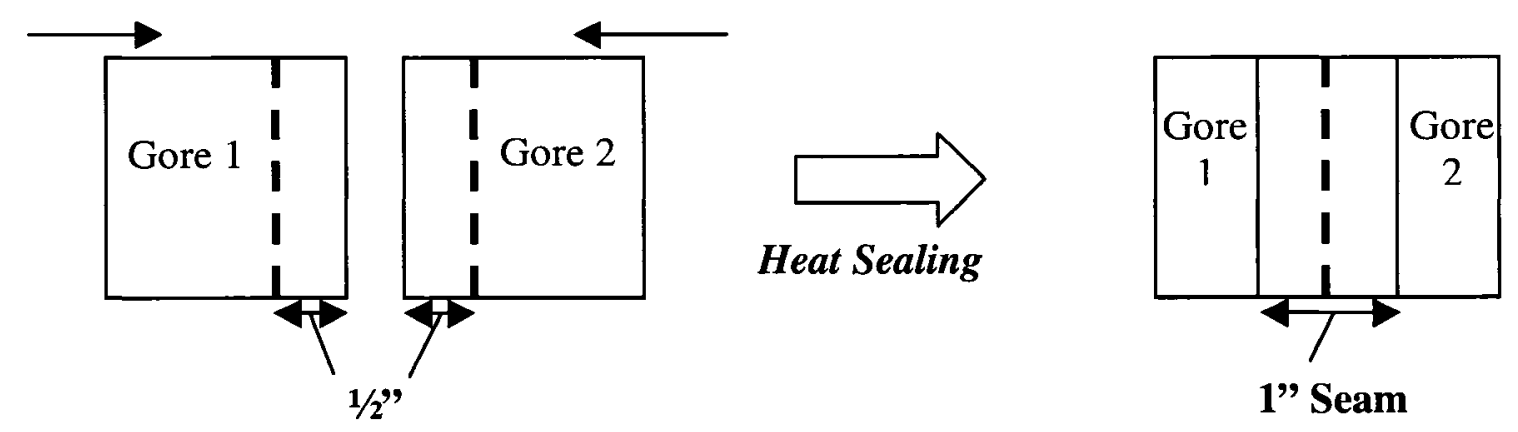

Figure 2.11 - Creating a Full Seam from Two Half-Seams

\subsubsection{Heat Sealing}

When constructing a test balloon from a flexible fabric, it was difficult to get the 2dimensional gores to conform to a 3-dimensional shape by hand. A template was therefore fabricated with the curvature of the final sphere, so that the seam between two gores would lay down as a perfectly straight and flat line on the template. This eliminated misalignment problems, reducing the need to manipulate the seams by hand as the heatsealing progressed, and improved the quality of the seal.

A flat $1 / 8$ " steel bar of the appropriate length, bent to the curvature of the balloon's surface, was used to guide the ironing process. Holes were drilled 1" from 
either end of the bar through which a rope was passed to help maintain the bar's curvature. The template was then clamped to a stool so that it would stand vertically during the heat-sealing process. The end result is shown in Figure 2.12.

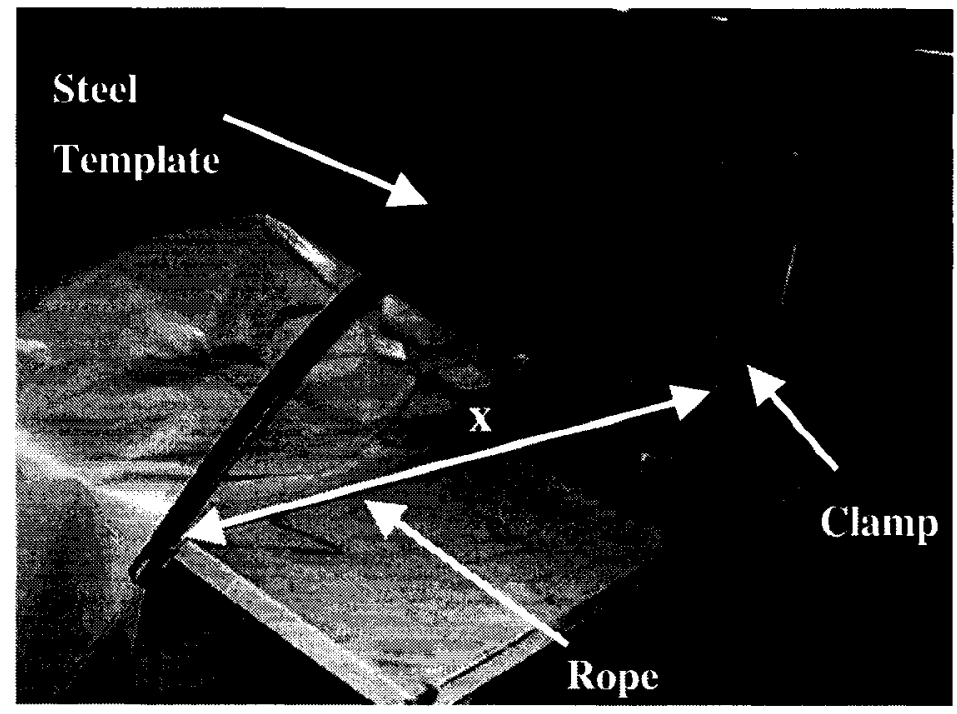

Figure 2.12 - The Ironing Template

The seams were sealed with a Teflon-coated Hobbico Custom Sealing Hobby Iron, Figure 2.13, typically used for making model airplanes. The temperature used in the ironing process is important to the quality of the seal in that too much heat can melt the material while too little may result in an incomplete seal. Following a process of trialand-error with small strips of material, it was found that optimal results were obtained when using a temperature of $175^{\circ} \mathrm{C}$ and oscillating the iron in place slightly for 60 seconds.

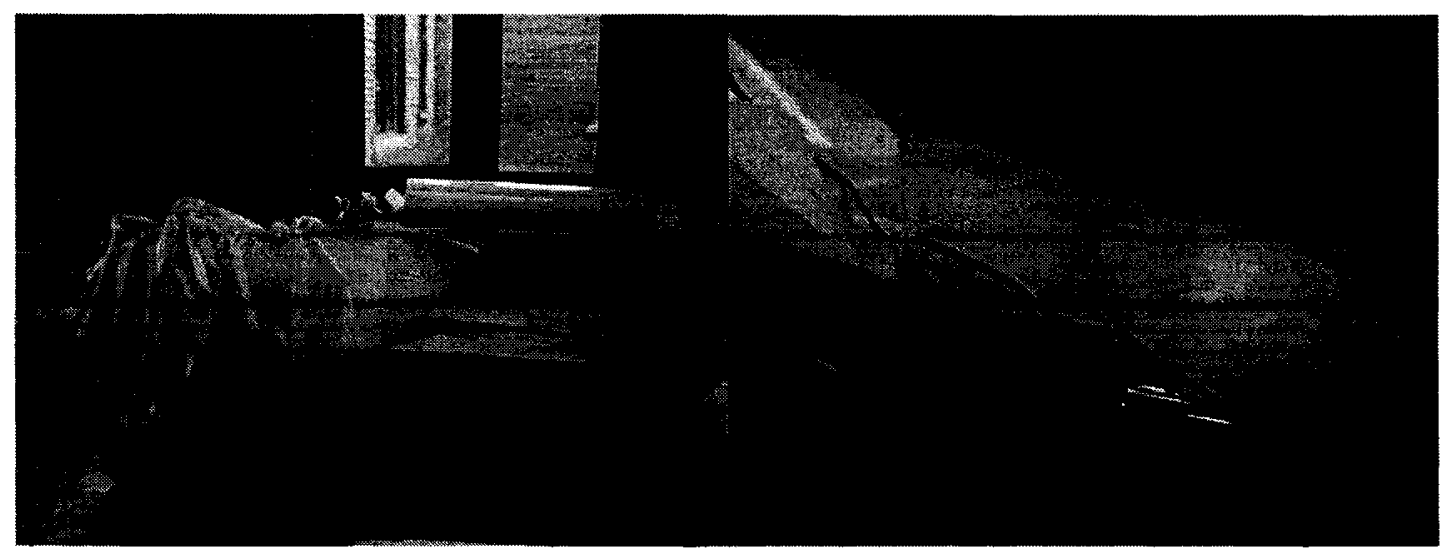

Figure 2.13 - Ironing 
The gores were ironed coating-to-coating, as described in section 2.3.5. Initially, two sphere halves were formed by fusing two sets of three gores together. The sphere halves were then joined, the final seam was sealed, and the balloon was closed once all five previous seams had cured and been inspected for potential leaks and imperfections. Since the ironing template was too large to use for the final seam, the seam was sealed by ironing small sections at a time with the aid of a wooden block.

\subsubsection{Sealing the Ends}

Once all six seams were made, there remained small holes at the top and bottom of the sphere where the gores met. These had to be closed using end patches; circular patches of material glued over the ends of the balloon. A filler valve was also needed. It is common for aerostat manufacturers to place the valve on the side of the balloon for easy access while it is aloft. To avoid putting new holes and seams in the envelope and also to maintain easy access, the valve was positioned on the bottom of the balloon in place of an end patch.

Aerostat manufacturers use a range of valve types, from a screw cap with an oring to a tire inflation valve. A Coleman Air-Tight System valve from a water mattress was selected for the $2.5 \mathrm{~m}$ balloon, the back- and front-side of which are illustrated in Figure 2.14. The end patches and the valve were adhered to the balloon using RH Company's HH-66 Vinyl Cement and a beach ball was placed under the aerostat envelope during gluing to induce a curvature, promoting a flatter contact surface between the end patch, valve, and the balloon.

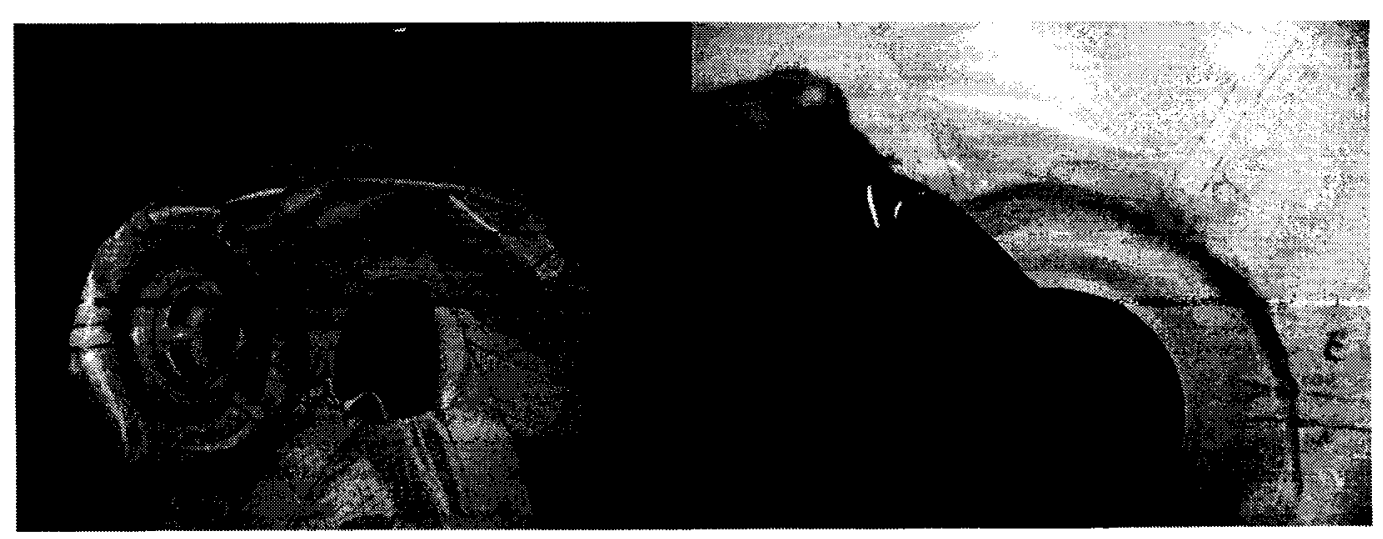

Figure 2.14 - Coleman Valve 
Once the glue was cured, the inflatable was filled with air and thoroughly inspected for leaks using soapy water. Any splits in the seam were sufficiently repaired using the aforementioned vinyl cement.

\subsection{Safety Considerations}

In case of an emergency, such as a critical tether or net failure, it may be necessary to bring about a controlled descent of the aerostat by releasing the contained Helium rapidly. As mentioned in section 2.1, it was desired that the balloon would touch the ground within a minute in a $10 \mathrm{~m} / \mathrm{s}$ wind. The fill valve at the bottom of the balloon cannot be used to do this, as the buoyant Helium tends not to flow downward. With the valve open, the balloon can stay afloat for hours, if not days.

A relatively new method of inducing a controlled descent in small blimps is to use a burn-out, a patch of material with a heat element on it that burns a hole in the envelope on command [11]. Burn-outs have also been made using chemically reactive patches that are catalyzed by electricity, but this method of causing a controlled descent requires the complexities of actuators and electrical power.

The most common way to induce a controlled descent is the rip panel. A rip panel consists of an opening in the aerostat, generally a slit that starts at the top of the balloon and runs $1 / 5^{\text {th }}$ the circumference down, covered by a reinforced piece of fabric [10], [33]. Activating the rip panel swiftly deflates the balloon without seriously damaging the envelope. It is important that the panel be on the top part of the envelope to avoid creating a sustainable zero-pressure balloon when it is open. The three types of rip-panels are those that are cemented in place, those that are sewn and then taped, and those in which the fabric itself is torn. The cemented option, though potentially more difficult to rip than the other two, was chosen as it is also less complicated to install and may be repeatedly used.

The rip panel for the $2.5 \mathrm{~m}$ aerostat consisted of 3 layers of 2" wide fabric glued together and placed over a narrow, 1" slit in the envelope. The slit was positioned along one of balloon's seams, starting at the top of the envelope and running $1 / 5^{\text {th }}$ of the circumference down. This resulted in a $1 / 2$ " seam on either side of the slit opening. A strap 
was sewn into the reinforced fabric to which a secondary tether was attached and fixed to the ground. The rip panel can be seen as part of the completed balloon in Figure 2.15.

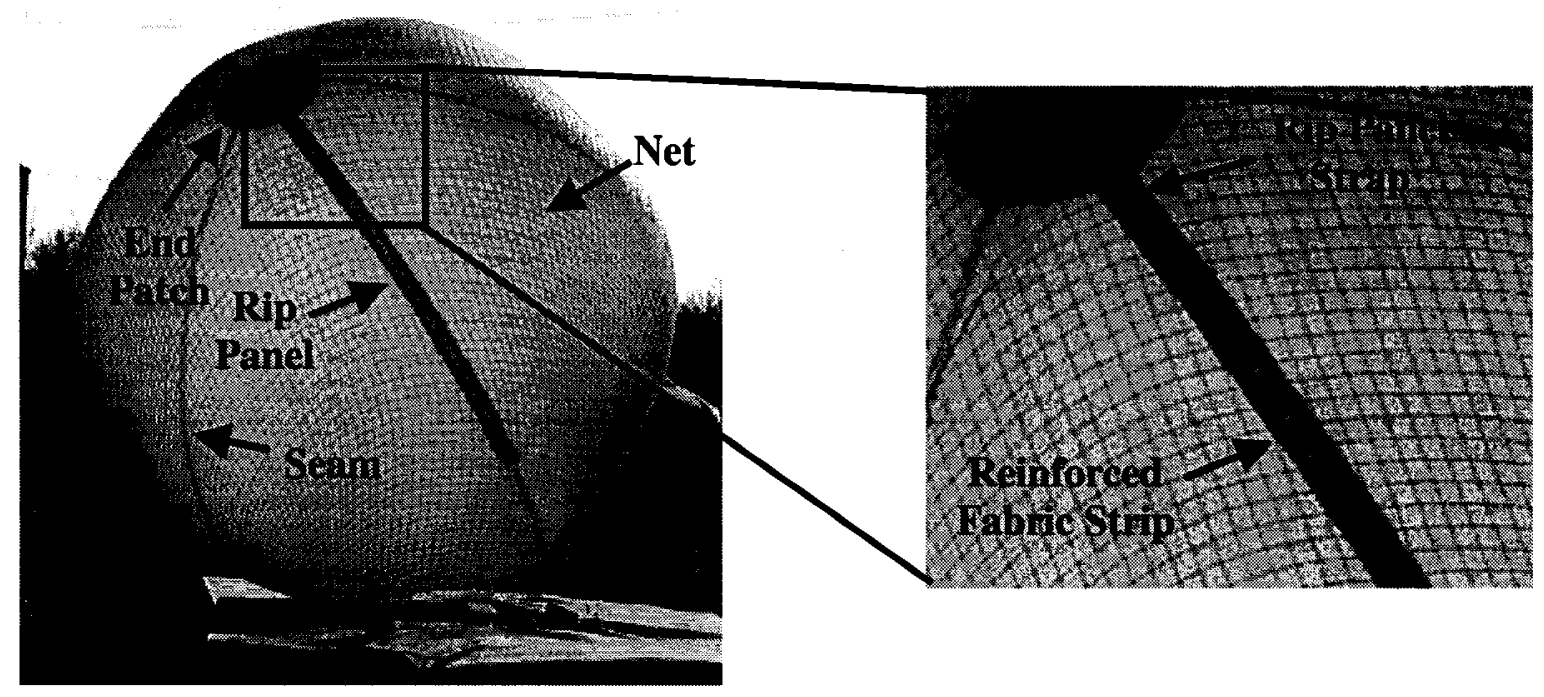

Figure 2.15 - Balloon, Net, and Rip Panel 


\section{Chapter 3 Dynamics of a Tethered Spherical Aerostat}

Williamson and Govardhan ran a series of experiments in which they studied singletethered spheres with varying tether length and sphere size exposed to controlled and steady fluid flows [13], [14], [15], [16]. They found that, rather than maintaining a steady tether angle in the flow, the spheres oscillated with a distinct figure-of-8 motion. Furthermore, the tethered spheres exhibited about twice the drag coefficient and the related blowdown angle when compared to fixed, smooth spheres.

It was desired to see if the aforementioned drag and motion characteristics would be reproduced by our tethered aerostat, discussed in Chapter 2, in a more turbulent, natural wind flow. The main goal of the experiment was to gain a better understanding of tethered aerostat dynamics before investigating and designing a robust version. The experiments were performed alongside those of a larger and more sophisticated, purchased $3.5 \mathrm{~m}$ diameter spherical aerostat system performed by Coulombe Pontbriand [37]. The relative merits of using a less sophisticated and far less costly experimental apparatus were also evaluated with respect to the quality of data returned.

The tests were performed outdoors, rather than in a wind tunnel, due to the size of the experimental apparatus. The balloon was flown at 15,30 , and $45 \mathrm{~m}$ tether lengths to study the effect of changing the tether length on the balloon's dynamics. The position of the balloon was recorded during the flights using a differential GPS system. The tether tension was also recorded, adding a level of redundancy to the data acquired. 


\subsection{Experimental Setup}

\subsubsection{Flight Environment}

The tests were carried out on an approximately $1 \mathrm{~km} \times 0.5 \mathrm{~km}$ flat plot of land with no large obstructions in close proximity. The air temperature during the experiments was between $5^{\circ} \mathrm{C}$ and $10^{\circ} \mathrm{C}$ and the winds blew steadily at speeds of 0 to $6 \mathrm{~m} / \mathrm{s}$. The aerostat was fixed to the ground by a single tether attached to an A.G.O. Environmental Electronics Ltd. CSW-1 Portable Instrumentation Winch [38], Figure 3.1. The main tether was a Cortland Plasma 12-strand Puget Sound Rope with a nominal diameter of $1.5 \mathrm{~mm}$ [39]. The tether ran from the winch to a confluence point below the aerostat where it spliced into 4 smaller, $1.79 \mathrm{~m}$ long and $1 \mathrm{~mm}$ diamter Cortland tethers. The 1 $\mathrm{mm}$ tethers attached to the net $35^{\circ}$ below the equator of the balloon.

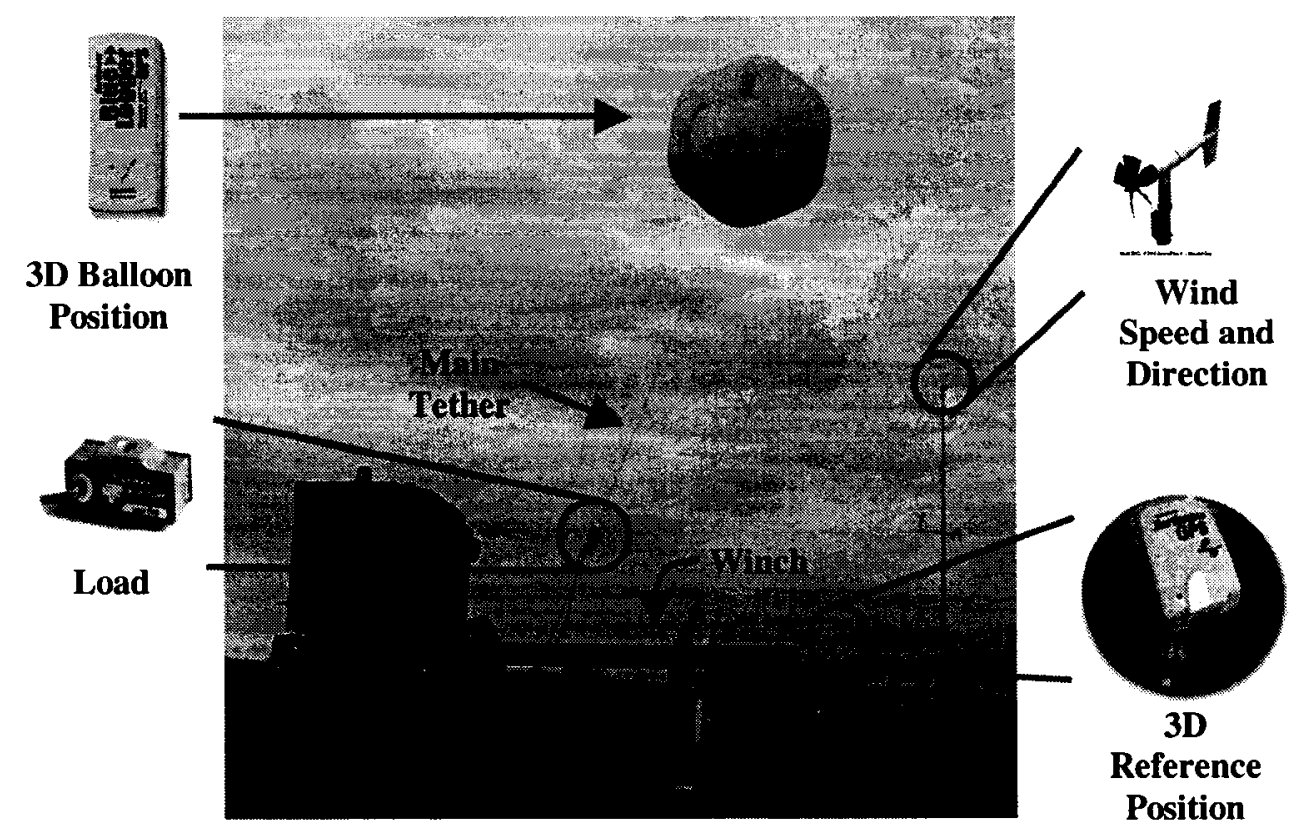

Figure 3.1 - Experimental Setup

\subsubsection{Data Acquisition System}

Wind speed was measured by two Campbell Scientific, Inc.'s 05103-10 R.M. Young Wind Monitors [40] located at $3 \mathrm{~m}$ and $10 \mathrm{~m}$ altitudes on a tower, Figure 3.1. The wind direction was measured only by the $10 \mathrm{~m}$ wind monitor. The load in the tether was measured by a Transducer Techniques MLP-75 load cell, rated for a capacity of $37 \mathrm{~kg}$ 
(75 lb) [41]. The output signal was routed through a Transducer Techniques TMO-1 Amplifier/Conditioner module, with a $0-5 \mathrm{~V}$ output capacity. A Measurement Computing PMD-1208FS USB-based Analog and 12-bit Digital I/O Module performed the analog to digital conversion of the wind and load signals [42]. The load and wind speed and direction were acquired using a sampling frequency of $300 \mathrm{~Hz}$, for reasons elaborated upon in section 3.3.1. The acquisition process was triggered using a modified version of DATAS, an in-house data acquisition program [37], which also recorded the data returned.

A low-cost differential GPS system, consisting of a roving remote station receiver attached to the top of the balloon along the axis of the tether, and a static base station receiver placed at a known, fixed location on the ground, was used to record the 3dimensional position of the aerostat. The concept behind the differential GPS technique is that measurement errors observed at the static base station will closely correlate to errors observed at the roving remote station and can be removed from the signal logged by the roving receiver during post-processing [43].

A Delorme Earthmate USB GPS Receiver, intended for hiking applications, was employed as the base station receiver, and the remote station receiver was a Delorme Blue Logger Bluetooth Wireless GPS Receiver [43]. Both sensors have a $1-5 \mathrm{~m}$ accuracy in the differential configuration. Activation of the Blue Logger and Earthmate and adjustment of their settings were performed separately from the wind monitors and load cell using Delorme's Blue Logger Manager and GPS PostPro 2.0 software. The GPS receivers were set to $\log$ at $0.5 \mathrm{~Hz}$, their fastest sampling frequency. NMEATime from Visual GPS, LLC [44] was used to reset the CPU clock to GPS time in order to synchronize the wind and load signals to the GPS signal with an accuracy of 1 second.

\subsection{Experimental Procedure}

The net lift of the balloon was obtained indoors using the load cell at the beginning and end of each day of flights. Following the lift acquisition, the winch was placed in a known location next to a marked reference point on the ground. The static position of the winch was determined for later post-processing by placing the Earthmate receiver at its reference location and the BlueLogger on the winch. Once the static acquisition was 
completed, the PC clock was set to GPS time with NMEA Time. The Delorme Blue Logger and Earthmate were set to acquire data, and the Blue Logger was then fixed to the aerostat envelope. Next, the PMD module was activated using the DATAS program, and the balloon was released by hand. Three flights were performed at the three different altitudes of evaluation during every day of experimentation. Each time, the balloon was left undisturbed in the air for 20 minutes at one altitude.

\subsection{Post Processing}

The PMD module's sampling frequency of $300 \mathrm{~Hz}$ was much faster than the $0.5 \mathrm{~Hz}$ frequency of the GPS system. A general frequency of $5 \mathrm{~Hz}$ was selected for post processing to attain a compromise between a number of data points that was cumbersome to manipulate and to facilitate clarity of the data curves. The GPS signal was interpolated and the wind and load signals averaged to the selected $5 \mathrm{~Hz}$.

\subsubsection{Wind Speed and Direction}

To measure wind speed, a $20 \mathrm{~V}$ input voltage was sent to the Young Wind Monitors, and they returned a sinusoidal signal with a varying frequency. From this frequency, the wind speed was measured as

$$
u=0.098 f_{\mathrm{WM}}
$$

where $u$ is the wind speed in $\mathrm{m} / \mathrm{s}$ and $f_{W M}$ is the frequency of the signal returned by the wind monitor in $\mathrm{Hz}$. Using equation ( 3.1 ), when measuring the design wind speed of $10 \mathrm{~m} / \mathrm{s}$, the frequency of the signal from the wind monitors is $102 \mathrm{~Hz}$. Thus, to measure a $10 \mathrm{~m} / \mathrm{s}$ wind the sampling frequency had to be at least $204 \mathrm{~Hz}$ to satisfy the Nyquist criterion. A $300 \mathrm{~Hz}$ sampling frequency was used for the experiments.

The frequency of the signal from the wind monitors was determined by measuring the zero crossings. However, due to noise the zero crossings were difficult to measure accurately, as seen in Figure 3.2 (a). To mitigate this problem, the signal was filtered to remove the noise. A break frequency of $30 \mathrm{~Hz}$ was selected by plotting the power spectral density of the measured voltage, Figure 3.2 (b), and identifying the frequency of the noise. MATLAB's filtfilt command was used to apply a $5^{\text {th }}$ order Butterworth filter with 
the given break frequency to remove the noise. The command applies the filter forward and then in reverse to avoid phase lag. The result is shown in Figure 3.2 (a). After filtering, the signal was linearly interpolated to determine the zero crossings.

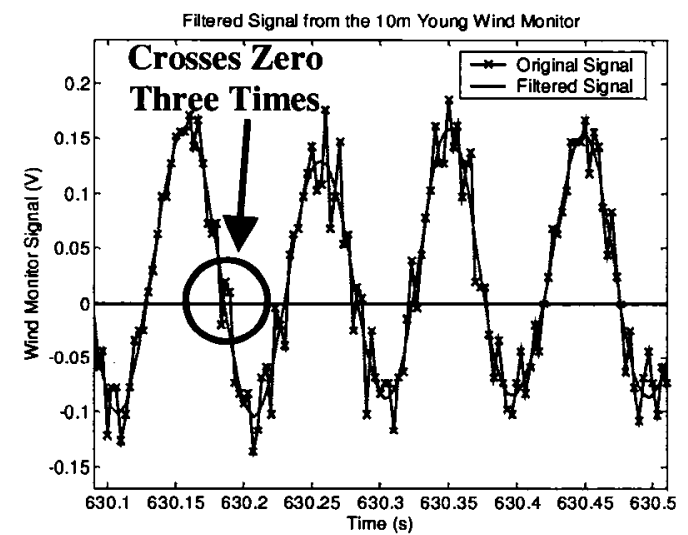

(a)

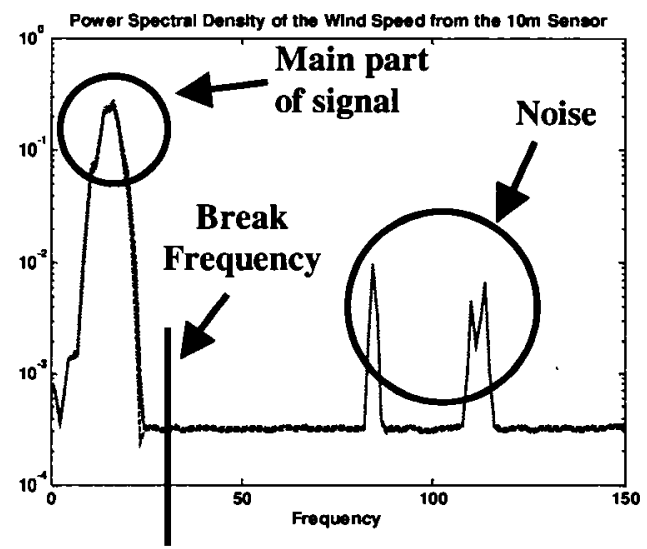

(b)

Figure 3.2 - Filtering the Wind Signal for the $30 \mathrm{~m}$ flight of Nov. 17

To measure wind direction, a $2.5 \mathrm{~V}$ excitation was sent to the Young Wind Monitor direction potentiometer every 2 - 3 seconds, eliciting a response "spike" in the 0 to $2.5 \mathrm{~V}$ range. From this spike the direction was measured as

$$
\varphi=142 V_{s}+180
$$

where $V_{S}$ is the magnitude of the returned spike in volts, and $\varphi$ is the direction to which the wind is heading in degrees clockwise from true north. A sample of a returned signal is shown in Figure 3.3 on the next page. The height of the spike was taken to be the average of the data points in the plateau, neglecting any points in the plateau more than $0.1 \mathrm{~V}$ different from the previous point as noise. The wind direction returned is uncertain from $175^{\circ}$ to $194^{\circ}$ due to the signal falling in the $0.12 \mathrm{~V}$ noise floor in that range.

\subsubsection{Load}

The TMO-1 amplifier was calibrated using static load tests and known weights. Since the load cell is a linear sensor, the resulting conversion formula is

$$
F_{T}=84.9 V_{L C}-43.9
$$

where $V_{L C}$ is the output voltage from the amplifier and $F_{T}$ is the tether load in Newtons. 


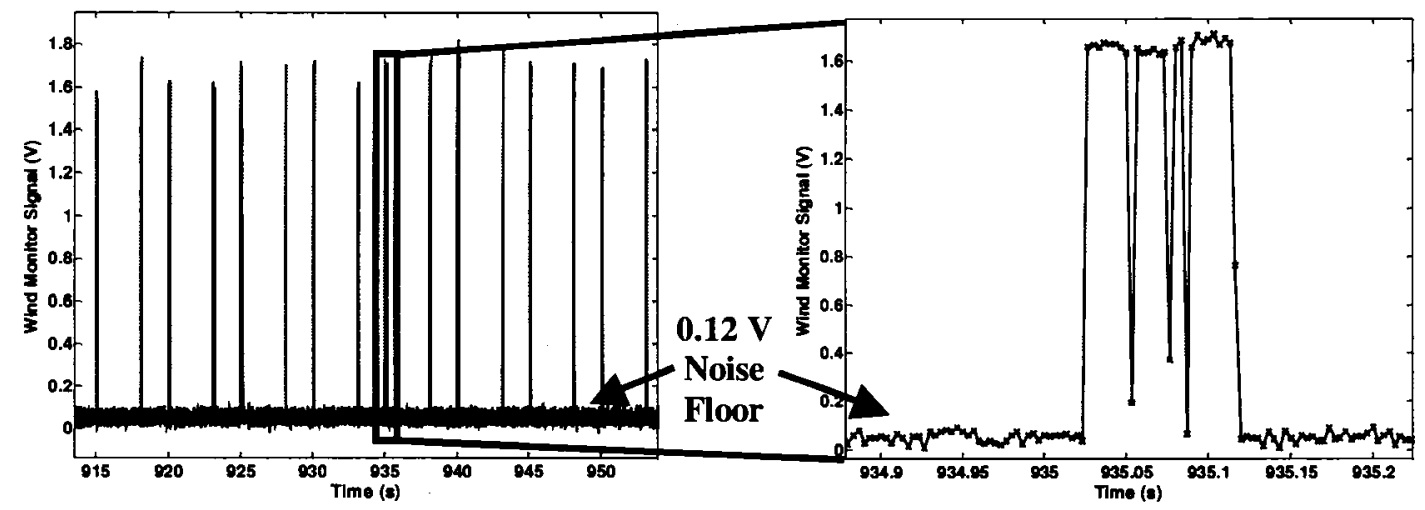

Figure 3.3 - Measured Wind Direction Signal for the 15 m Flight of Nov. 15

\subsubsection{3-Dimensional Position}

Delorme's GPS PostPro 2.0 program was used for the initial post-processing of the GPS signal to obtain the balloon's 3-dimensional position during the flights in standard latitude/longitude/altitude format. The program was also used to determine the 3dimensional position of the winch from the pre-flight static acquisition. The positions of the winch and the balloon were converted to the Cartesian Universal Transverse Mercantor (UTM) coordinate system using a C-program created by Dana [45].

The position of the winch as read during the pre-flight static acquisition was subtracted from the position of the balloon, measured by the roving remote receiver on the aerostat during the flights. The result was the aerostat's relative position in terms of its distance east, north, and up from the winch. The absolute horizontal distance of the aerostat from the winch in meters, $H$ in Figure 3.4, was found using the equation

$$
H=\sqrt{{x_{N E}^{2}+y_{N E}^{2}}^{2}}
$$

where $x_{N E}$ is the distance east and $y_{N E}$ the distance north, both in meters.

The distance from the static reference point on the winch to the roving receiver, hereon referred to as the "receiver length", was measured by hand and known for each flight. The receiver length, $L$, was also calculated from the horizontal and vertical positions of the balloon read by the GPS sensors, $H$ and $V$ in Figure 3.4 respectively, as

$$
L=\sqrt{H^{2}+V^{2}}
$$




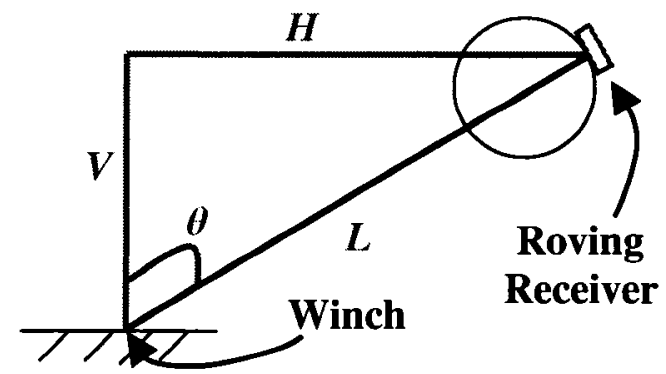

Figure 3.4 - Decomposing the Aerostat's Position

When comparing the hand-measured receiver length to that obtained from equation ( 3.5 ), for example Figure 3.5 (a) for the $30 \mathrm{~m}$ flight of Nov. 23, it is clear just how imprecise the GPS receivers are. Rather than reading a constant receiver length, the Blue Logger and Earthmate returned receiver lengths with large variations. This variability indicates that the instantaneous data cannot be trusted to be exact. As a result, we will only consider time averaged values to be trustworthy.

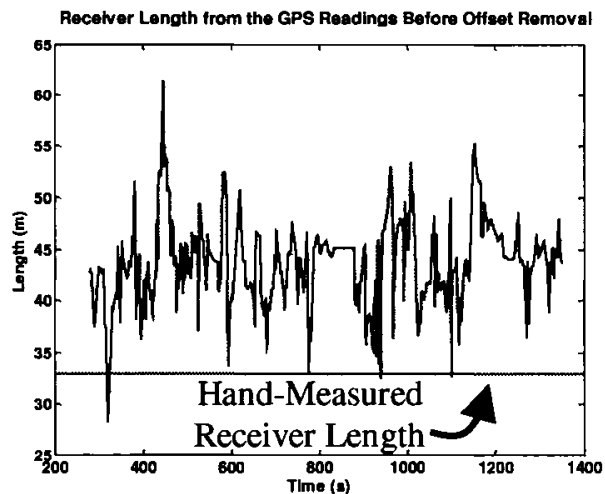

(a)

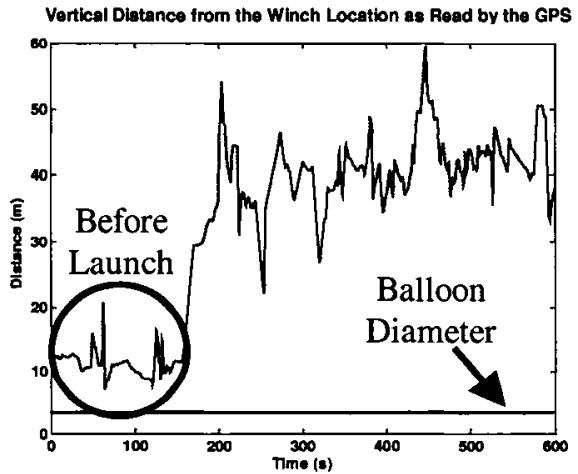

(c)

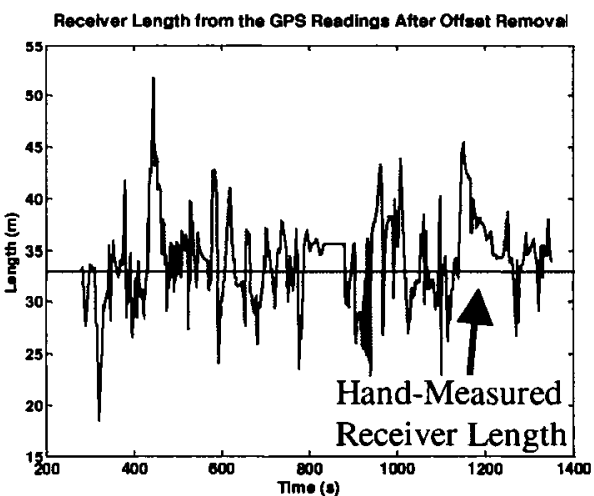

(b)

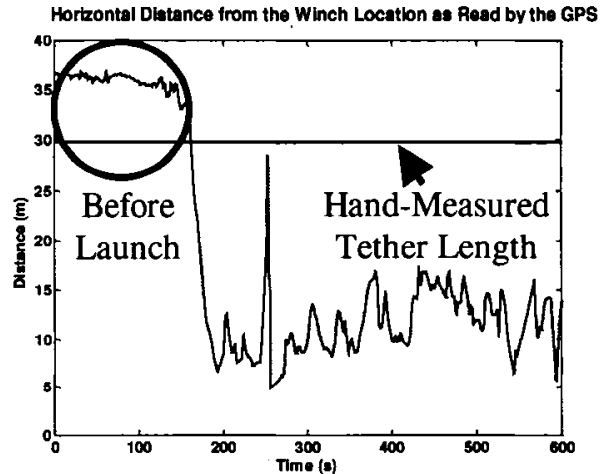

(d)

Figure 3.5 - Illustrating the Imprecision in the GPS Position Measurements for the $30 \mathrm{~m}$ Flight of Nov. 23 
Looking again at Figure 3.5 it is also clear that there exists an offset in the mean receiver length as read by the GPS. The offset errors are equally apparent when looking at the GPS reading of the balloon's position for the time when it was on the ground before launch, Figure 3.5 (c) and (d). On the ground the vertical position should have been roughly equal to the aerostat's diameter, and the horizontal position the length of the tether, which was also measured by hand and known for each flight. The offsets between the average GPS-returned vertical and horizontal positions of the aerostat while it was on the ground and the balloon diameter and tether length respectively were subtracted from the vertical and horizontal position signals over the entire flight. This resulted in a mean receiver length that was very close to the measured value, as seen in Figure 3.5 (b).

\subsection{The Drag Coefficient}

\subsubsection{Background Theory}

The drag coefficient of a sphere in a wind flow, $C_{D}$, defined in Chapter 2 and reiterated here for convenience, is

$$
C_{D}=\frac{F_{D}}{\frac{1}{2} \rho_{\text {air }} u^{2} \pi r^{2}}
$$

where $\rho_{\text {air }}$ is the density of the surrounding air, $u$ the wind speed that the sphere is subjected to, $r$ the radius, and $F_{D}$ the drag force on the sphere. Rather than maintaining a steady blowdown angle, a tethered sphere will oscillate about a mean position in a wind flow. If the motion of the balloon is averaged over several periods of oscillation, the inertial terms due to the balloon accelerations will average to be zero and a quasi-static state may be assumed. In this case, a free body diagram of the balloon, presented in Chapter 2, is as seen in Figure 3.6, where $\bar{\theta}$ denotes the blowdown angle, $\bar{F}_{L}$ the lift force, and the overbar indicates averaging over several periods.

The drag force, necessary for determination of the drag coefficient, can be obtained in multiple ways using trigonometry and different combinations of the lift, load in the tether, and the blowdown angle from the 3-dimensional position of the balloon. These will be discussed in section 3.4.3. 

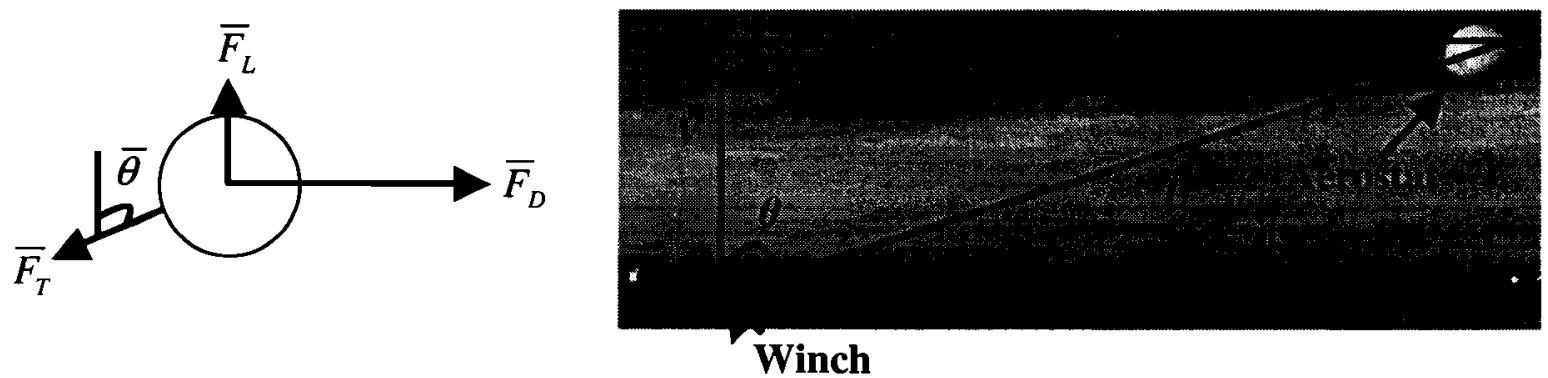

Figure 3.6 - Quasi-Static Free Body Diagram of the Balloon in Flight

\subsubsection{Blowdown Angle}

Referring to Figure 3.6 above, the blowdown angle can be determined from the GPS measurements using one of three equations

$$
\begin{aligned}
& \theta=\sin ^{-1} \frac{H}{L} \\
& \theta=\cos ^{-1} \frac{V}{L} \\
& \theta=\tan ^{-1} \frac{H}{V}
\end{aligned}
$$

The average blowdown angle, $\bar{\theta}$, can also be found from the tether load and lift as

$$
\bar{\theta}=\cos ^{-1} \frac{\overline{F_{L}}}{\overline{F_{T}}}
$$

Since equations ( 3.7$)-(3.9)$ are valid at all times while equation ( 3.10 ) is only valid on average, it was decided to use one of equations ( 3.7$)-(3.9)$ for the analysis. GPS measurements in the horizontal direction tend to be more accurate than vertical ones and the receiver length, $L$, was measured and known for each flight, and thus equation ( 3.7 ) was chosen for the analysis.

The blowdown angle of the aerostat was calculated for each instant with equation ( 3.7 ) and then averaged over at least 10 of the dominant oscillations under conditions of constant mean wind speed in order to minimize the influence of inertial effects. For comparison, the average blowdown angle, $\bar{\theta}$, was also calculated for each flight using equation ( 3.10 ); the results from both methods are shown in Table 3.1. In all cases 
where results could be obtained, the average $\bar{\theta}$ calculated from equations ( 3.7 ) and ( 3.10 ) differed by $15 \%$ or less. These differences may be a consequence of the non-zero inertial terms on the load signal or of the persistent offsets and errors in the GPS signal.

Table 3.1 - The Average Blowdown Angles and Drag Forces

\begin{tabular}{|c|c|c|c|c|c|}
\hline $\begin{array}{c}\text { Flight } \\
\text { (Day, Altitude) }\end{array}$ & $\begin{array}{c}\text { Interval } \\
\text { Duration } \\
\text { (s) }\end{array}$ & $\begin{array}{c}\text { Blowdown } \\
\text { Angle from } \\
\text { Eq. ( 3.7 ) } \\
\text { (Degrees) }\end{array}$ & $\begin{array}{c}\text { Blowdown } \\
\text { Angle from } \\
\text { Eq. ( 3.10 ) } \\
\text { (Degrees) }\end{array}$ & $\begin{array}{c}\text { \% } \\
\text { Difference }\end{array}$ & $\begin{array}{c}\bar{F}_{\text {D }} \text { from } \\
\text { Eq. ( 3.11) } \\
\text { ( N) }\end{array}$ \\
\hline Nov. 15, 15 m & 1600 & 63.6 & 62.1 & 2.1 & 49.4 \\
\hline Nov. 15, 30 m & 600 & 66.3 & 59.5 & 10.2 & 56.3 \\
\hline Nov. 16, 30 m & 600 & 40.2 & $\begin{array}{c}\text { Load Cell } \\
\text { Off }\end{array}$ & N/A & 18.1 \\
\hline Nov. 17, 30 m & 500 & 26.2 & 22.6 & 13.7 & 10.9 \\
\hline Nov. 18, 15 m & 600 & 24.0 & 24.1 & -0.2 & 6.62 \\
\hline Nov. 18, 30m & 800 & 28.1 & 26.9 & 4.6 & 9.90 \\
\hline Nov. 22, 15 m & 400 & 26.7 & 28.3 & -6.0 & 14.9 \\
\hline Nov. 22, 30 m & 325 & 22.8 & 19.2 & 15.9 & 9.81 \\
\hline Nov. 23, 15 m & 700 & 44.4 & 38.0 & 14.3 & 21.9 \\
\hline Nov. 23, 30 m & 450 & 16.1 & 17.0 & -5.6 & 6.66 \\
\hline
\end{tabular}

\subsubsection{Drag Coefficient}

Using the quasi-static assumption, and referring to Figure 3.6, the average drag force experienced by the aerostat can be calculated in one of three ways

$$
\begin{aligned}
& \bar{F}_{D}=\bar{F}_{L} \tan \bar{\theta} \\
& \bar{F}_{D}=\bar{F}_{T} \sin \bar{\theta} \\
& \bar{F}_{D}=\sqrt{\bar{F}_{T}^{2}-\bar{F}_{L}^{2}}
\end{aligned}
$$


where $\bar{\theta}$ is the average blowdown angle calculated with equation ( 3.7 ). Of these, equation ( 3.11 ) was deemed the most reliable since $\bar{F}_{L}$ was measured pre-flight and the use of $\bar{F}_{T}$ was avoided. The average drag force on the tethered aerostat, calculated using equation ( 3.11 ), is given in Table 3.1 above.

\subsubsection{Wind Speed at the Balloon}

Wind speed varies with height through the planetary boundary layer. Since the wind speed was only measured at heights of 3 and $10 \mathrm{~m}$, the wind speed at the altitude of the balloon had to be determined in order to calculate the drag coefficient of the aerostat. The altitudes of the flights were all within the earth's lower planetary boundary layer, in which the velocity profile with height can be described by a power law [46]. The wind speed at the center of the balloon is thus

$$
u_{z}=u_{z_{r f}}\left(\frac{(L-r) \cos \bar{\theta}}{z_{r e f}}\right)^{m}
$$

where $u$ is the wind speed, $z=(L-r) \cos \bar{\theta}$ is the height at the center of the balloon, $z_{\text {ref }}$ is some reference height, $m$ is an exponent that varies as a function of surface roughness, and $r$ is the radius of the aerostat, taken to be $1.25 \mathrm{~m}$.

The exponent $m$ was found by first calculating a value for each flight using the measured average blowdown angle and wind speeds at the $3 \mathrm{~m}$ and $10 \mathrm{~m}$ sensors for

Table 3.2 - Exponent $\boldsymbol{m}$ for Each Flight

\begin{tabular}{|c|c|}
\hline $\begin{array}{c}\text { Flight } \\
\text { (Day, Altitude) }\end{array}$ & $\boldsymbol{m}$ (unitless) \\
\hline Nov 15, 15 m & 0.133 \\
\hline Nov $15,30 \mathrm{~m}$ & 0.133 \\
\hline Nov $15,45 \mathrm{~m}$ & 0.166 \\
\hline Nov 22, 15 m & 0.123 \\
\hline Nov 22, 45 m & 0.145 \\
\hline Nov 23, 15 m & 0.145 \\
\hline AVERAGE & 0.14 \\
\hline
\end{tabular}
intervals of constant mean wind speed. The $3 \mathrm{~m}$ and $10 \mathrm{~m}$ Young Wind Monitors were incapable of reading speeds below $1.5 \mathrm{~m} / \mathrm{s}$ and $1.25 \mathrm{~m} / \mathrm{s}$ respectively due to noise in the signal. Thus, only flights with wind speeds higher than these thresholds could be used to find $m$. The exponent $m$ calculated for each flight is shown in Table 3.2. The value used in later calculations was the average over the 6 useful flights of the 12 undertaken, or 0.140 , which corresponds to the exponent one would expect over a grassy field [46]. 
The readings from the $10 \mathrm{~m}$ sensor were used as the reference values for extrapolation of the wind speed at the altitude of the aerostat. An example of the wind speed at the center of the balloon, determined using equation ( 3.14 ), is shown for the $30 \mathrm{~m}$ flight on Nov. 15 in Figure 3.7.

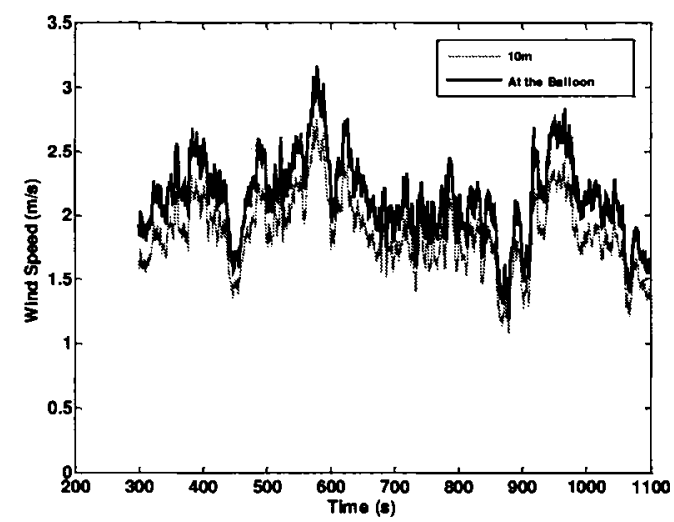

Figure 3.7 - The Wind Speed at the $10 \mathrm{~m}$ Sensor and the Altitude of the Balloon for the $30 \mathrm{~m}$ Flight of Nov. 18

\subsubsection{Drag Coefficient Results}

Knowing the wind speed at the altitude of the aerostat, the drag force, and the radius, and taking $\rho_{a i r}$ to be the density of air at $10^{\circ} \mathrm{C}$, or $1.25 \mathrm{~kg} / \mathrm{m}^{3}$ [28], the drag coefficient for each flight may be calculated with equation ( 3.6 ). The results, plotted against Reynolds number, are shown in Figure 3.8 (a). Those flights for which the wind speed was below $1.25 \mathrm{~m} / \mathrm{s}$, or $\mathrm{Re}=2.2 \times 10^{5}$, could not be used due to the limitations of the wind monitors. There is a general scatter in the drag coefficient data presented in Figure 3.8 (a). The scatter is most probably caused by the unknown offsets or drifts in the GPS sensors not being properly accounted for. Given this, and the sparsity of plotted data points, any inferred trends must be viewed as being tentative at best.

A fixed smooth sphere sees supercritical flow over its surface for Reynolds numbers higher than $3.5 \times 10^{5}$ [25]. However, surface roughness and upstream turbulence will induce an earlier onset of turbulent flow, shifting the critical Reynolds number to a lower value. An example of such a roughness is the net over the $2.5 \mathrm{~m}$ aerostat, and so the flow may be considered supercritical in the range of Reynolds numbers investigated: $2.8 \times 10^{5}-8.2 \times 10^{5}$, and in a domain where the drag coefficient changes little with Reynolds number. Thus, an average drag coefficient for the balloon may be calculated. 


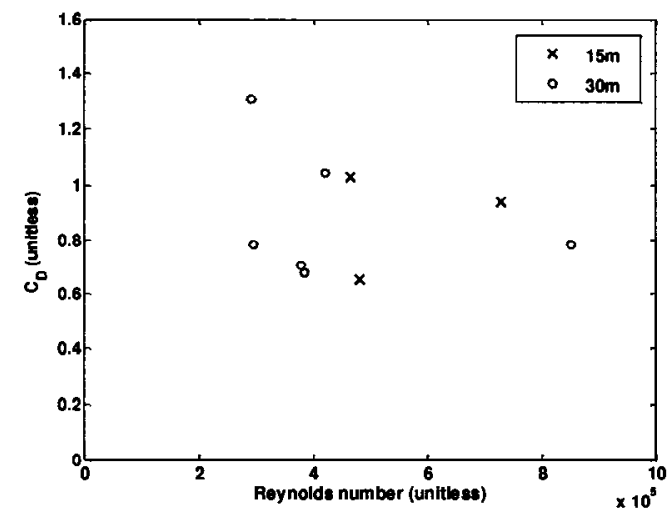

(a)

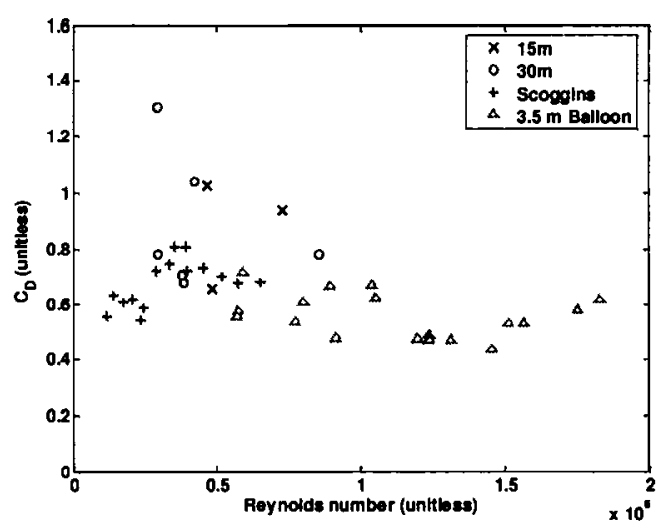

(b)

Figure 3.8 - Drag Coefficient of the Aerostat

The average drag coefficient over all flights was determined to be 0.88 , much higher than the value of 0.15 for a smooth fixed sphere in supercritical flow, and higher than the value of 0.7 found by Williamson and Govardhan for smooth, tethered spheres in subcritical flow [14]. Furthermore, the drag coefficient for the $2.5 \mathrm{~m}$ balloon was higher than that found by Coulombe Pontbriand for the $3.5 \mathrm{~m}$ balloon in the same flight environment [37], as illustrated in Figure 3.8 (b). The coefficient obtained was even higher than that of a rough free sphere, as presented by Scoggins [47] and also shown in Figure 3.8 (b).

The flow field around and behind a tethered sphere as it moves is more complex and turbulent than the flow field behind a fixed sphere, creating more drag on the former than on the latter in a manner not yet well understood. However, the $2.5 \mathrm{~m}$ aerostat exhibited a high drag coefficient even for tethered spheres. A possible source of the high drag coefficient is the surface roughness caused by the net. A second possibility is that the balloon was not perfectly spherical due to the use of only 6 gores, giving it a less streamlined, hexagonal shape.

\subsection{The Aerostat Oscillations}

\subsubsection{Oscillatory Motion}

A buoyant, tethered sphere in a steady stream flow will tend to oscillate in a direction inline with that flow and in a direction transverse to the flow, as illustrated in Figure 3.9. 
The combination of these two oscillations produces a figure-of- 8 motion for the tethered sphere [13].

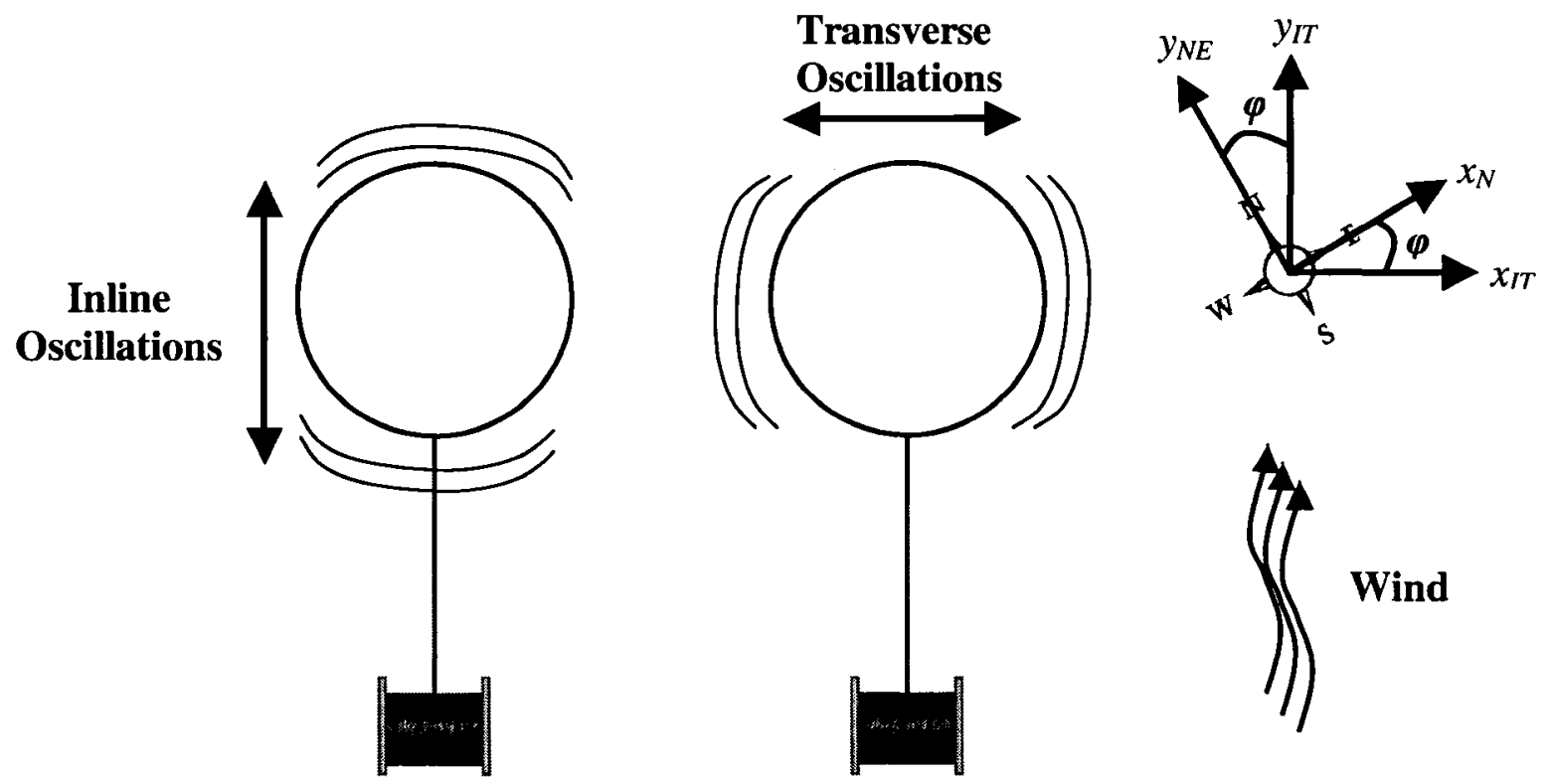

Figure 3.9 - Bird's-Eye View of the Aerostat's Oscillatory Motion

Time histories of the inline and transverse positions of the tethered aerostat can be obtained from the 3-dimensional position, as recorded by the GPS receivers, using the following coordinate transformation

$$
\left[\begin{array}{l}
x_{I T} \\
y_{I T}
\end{array}\right]=\left[\begin{array}{cc}
\cos \varphi & -\sin \varphi \\
\sin \varphi & \cos \varphi
\end{array}\right]\left[\begin{array}{l}
x_{N E} \\
y_{N E}
\end{array}\right]
$$

In equation ( 3.15$), x_{I T}$ and $y_{I T}$ are the distances from the winch in the transverse and inline directions respectively, $x_{N E}$ and $y_{N E}$ are the easting and northing of the top of the balloon along the axis of the tether, as read by the GPS receivers respectively, and $\varphi$ is the wind direction in degrees clockwise from true north.

Previous experiments performed by Schmidt showed that wind direction varies little with altitude [48], and it was therefore considered appropriate to use $\varphi$ as measured by the $10 \mathrm{~m}$ wind sensor for equation ( 3.15 ). The wind direction was averaged over a section of the flight that saw a constant mean wind direction and wind speed, an example of which is shown for the $30 \mathrm{~m}$ flight of Nov. 18 in Figure 3.10 (a). The resulting transverse motion for that same flight is illustrated in Figure 3.10 (b), showing a clear oscillatory behavior. 


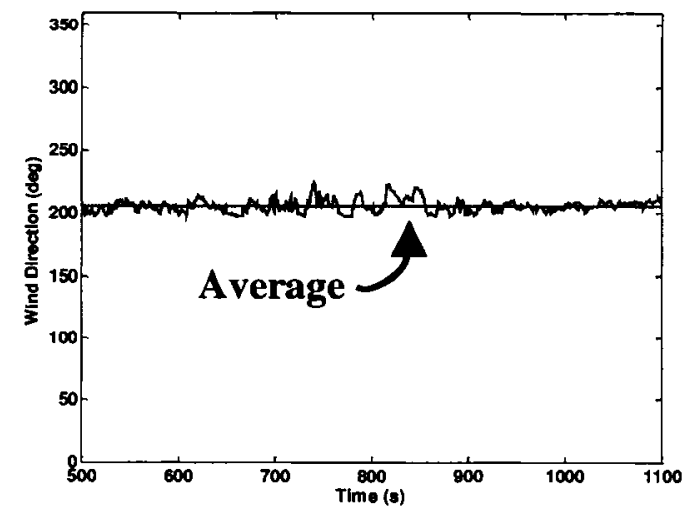

(a) Wind Direction from True North

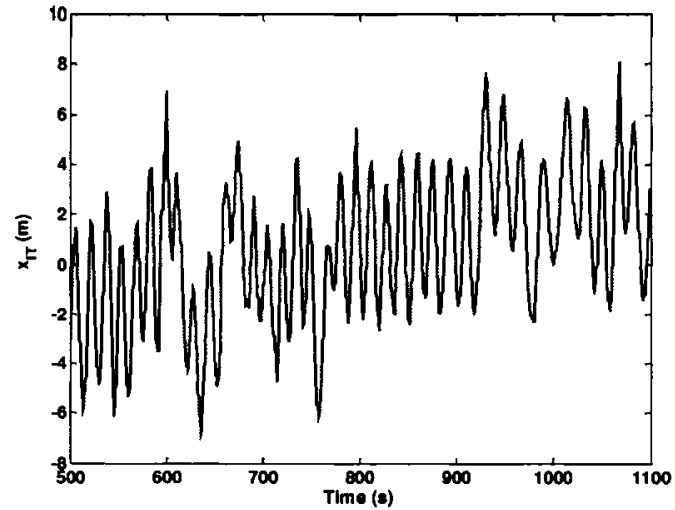

(b) Transverse Motion

Figure 3.10 - The Transverse Motion During a Section of Constant Mean Wind

\section{Direction for the $30 \mathrm{~m}$ Flight of Nov. 18}

The inline motions of the balloon tended to be erratic, without a regularly repeating pattern, as illustrated in Figure 3.11 (a). The same problem dominated the transverse oscillations for half of the flights investigated. The cause of this erratic motion is the varying wind conditions due to gusts: the wind speed and direction varied by several $\mathrm{m} / \mathrm{s}$ and tens of degrees and thus made the balloon's motion less regular. Figure 3.11 (b) shows that the overall movement in the horizontal plane has a dominant side-to-side motion with no discernable figure-of- 8 pattern.

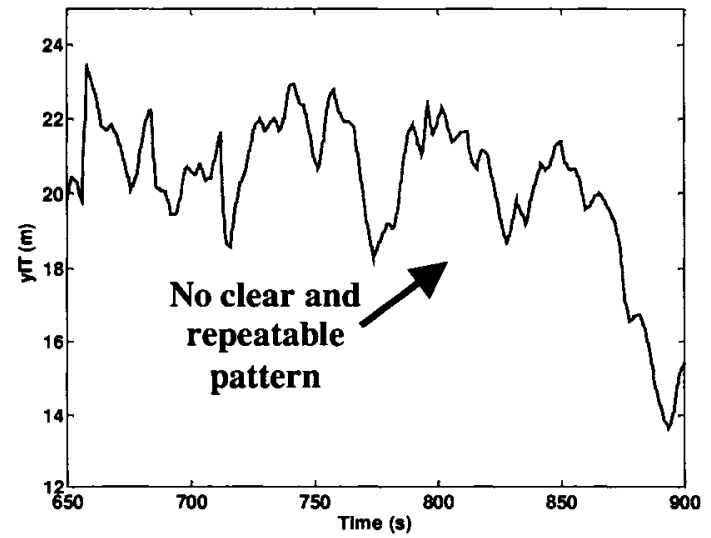

(a) $650 \mathrm{~s}-900 \mathrm{~s}$

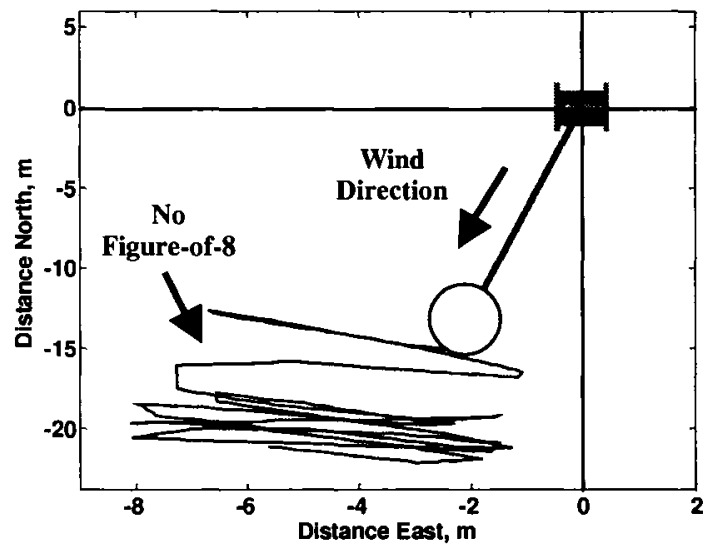

(b) $800 s-900 s$

Figure 3.11 - Motion of the Aerostat for the $30 \mathrm{~m}$ Flight of Nov. 18 


\subsubsection{Oscillation Frequencies}

Power spectral density plots of the inline and transverse motion of the balloon were used to determine the frequencies of oscillation, but there tended to be a drift in the recorded motion that appeared dominant in the plots, as shown in Figure 3.12. In order to better see the tethered balloon's oscillatory motion, a $5^{\text {th }}$ order Butterworth highpass filter, implemented with MATLAB's filtfilt command, was used to remove the drift. To obtain the break frequency of the filter, the main frequency of the signal was first estimated visually from the inline and transverse motion plots. The peak corresponding to the main frequency was then located on the power spectral density plot and the next lowest frequency valley was used as the break frequency for the filter. The results of this filtering are shown in Figure 3.13 (b), demonstrating that when the drift was removed, the main oscillatory signal remained. The oscillatory pattern that dominated the motion was the lowest, first-mode pendulum vibrations.

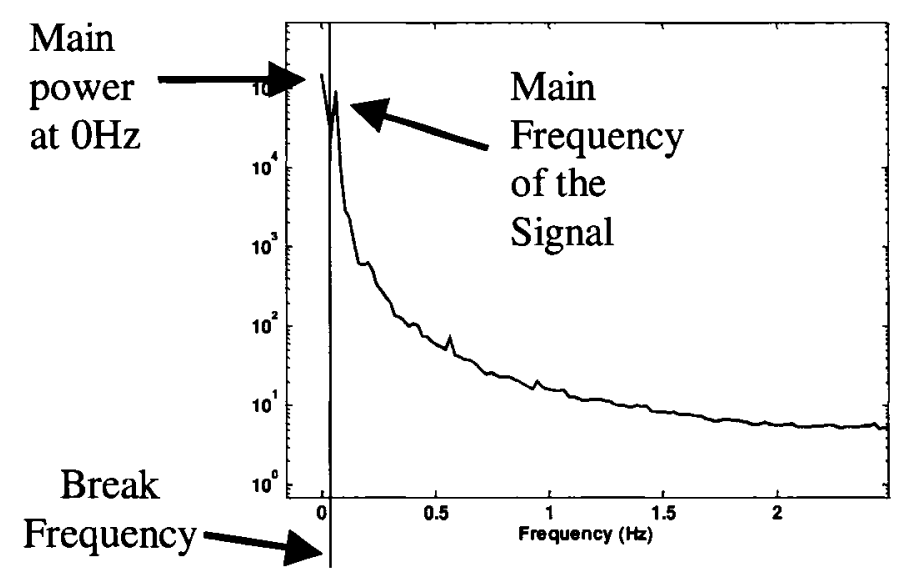

Figure 3.12 - Power Spectral Density of the Transverse Motions for the $30 \mathrm{~m}$ Flight of Nov. 18

The transverse frequencies that could be determined were first normalized by the lowest natural frequency of the system and then plotted against reduced velocity. For small oscillations about the mean blow down angle, the natural frequency of the transverse pendulum mode is

$$
f_{n_{t}}=\frac{1}{2 \pi} \sqrt{\frac{F_{L} \cos \theta_{E}}{\left(m_{e}+\frac{2}{3} \pi r^{3} \rho_{a i r}\right) l}}
$$


where $f_{n_{i}}$ is the natural frequency, $\theta_{E}$ the equilibrium blowdown angle, $l$ the distance from the winch to the center of the aerostat, and $m_{e}$ is the mass of the entire balloon and helium, measured to be $6.9 \mathrm{~kg}$. The second term in the brackets of the denominator is called the "added mass," and is included to account for the air that must be accelerated with the balloon as it moves [25]. It can be seen from equation ( 3.16 ) that shorter tether lengths and smaller blowdown angles increase the pendulum mode natural frequency.

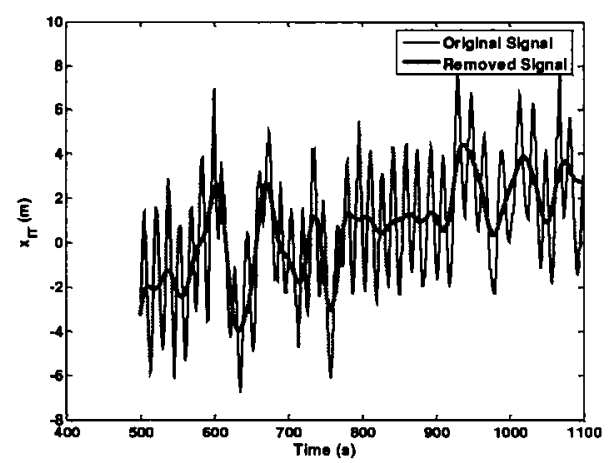

(a) Unfiltered

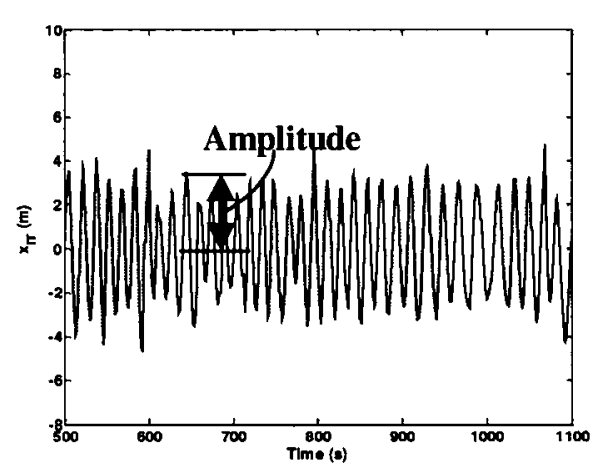

(b) Filtered

Figure 3.13 - Transverse Oscillations for the $30 \mathrm{~m}$ Flight of Nov. 18

The reduced velocity, $V_{R}$, is defined in the transverse direction as [14]

$$
V_{R}=\frac{u}{2 f_{n_{t}} r}
$$

The normalized transverse oscillation frequencies, plotted with respect to reduced velocity, are shown in Figure 3.14 (a). It can be seen that the tethered sphere is being excited at frequencies other than the natural frequency, and that the normalized oscillation frequencies tend to rise with reduced velocity. Williamson and Govardhan theorized that the motion of the sphere itself induced a flow field which yielded a selfsustaining net positive energy transfer every cycle [16]. They made no quantitative measurements in the supercritical Reynolds number range, however, and so a direct comparison with their data could not be performed.

The normalized frequencies for the $2.5 \mathrm{~m}$ balloon are plotted with those from the $3.5 \mathrm{~m}$ balloon investigated by Coulombe Pontbriand in Figure 3.14 (b) [37]. In normalizing the transverse oscillation frequencies, Coulombe Pontbriand assumed small 
equilibrium blowdown angles so the cosine term in equation ( 3.16 ) could be omitted. This is valid for the $3.5 \mathrm{~m}$ balloon as its average blowdown angle remained below $30^{\circ}$ for all of its flights, but not for the $2.5 \mathrm{~m}$ balloon, which saw a blowdown angle of up to $66^{\circ}$ (Table 3.1). Since there is a less than $10 \%$ difference between natural frequencies calculated with and without the cosine term for blowdown angles lower than $30^{\circ}$, however, the two sets of data can be compared.

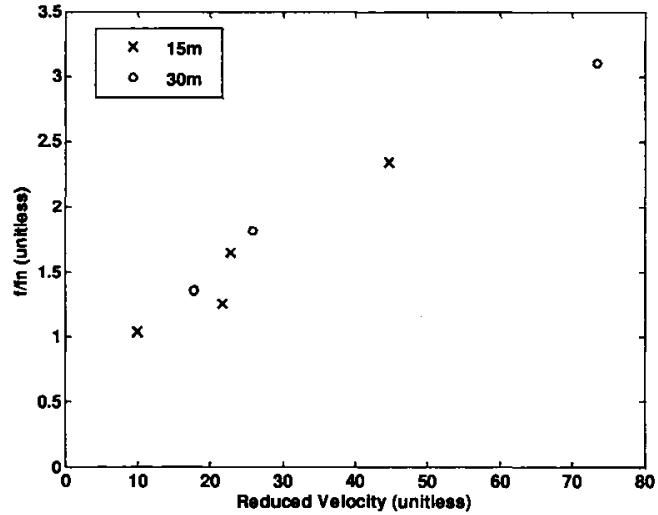

(a)

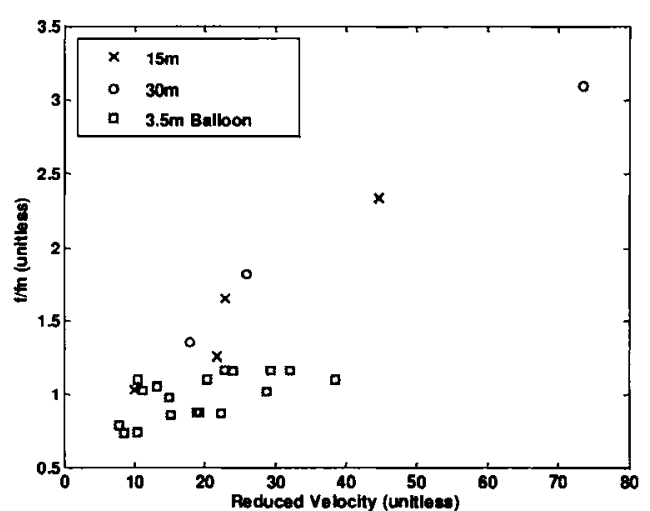

(b)

Figure 3.14 - Normalized Transverse Oscillation Frequencies

It can be seen from Figure 3.14 (b) that the results from the in-house balloon measured with the Delorme GPS conform well to those of the more sophisticated aerostat system for lower reduced velocities. For higher reduced velocities, the results of the $2.5 \mathrm{~m}$ balloon deviate from those of the $3.5 \mathrm{~m}$ balloon. At these wind speeds the blowdown angles of the $2.5 \mathrm{~m}$ aerostat were more than double those of the $3.5 \mathrm{~m}$. The higher blowdown angles may have affected how the forcing input is applied to the balloon, raising the frequency of excitation for the $2.5 \mathrm{~m}$ apparatus. Furthermore, the net on the $2.5 \mathrm{~m}$ balloon, which is absent on the $3.5 \mathrm{~m}$ balloon, as well as its less streamlined shape may have disturbed the flow over the tethered sphere, affecting its dynamics.

\subsubsection{Oscillation Amplitudes}

The amplitudes for each half-period of oscillation were determined by identifying and measuring the highest point in the summit of the half-period or the lowest point in the valley, as illustrated in Figure 3.13 (b). The results for the $30 \mathrm{~m}$ flight of Nov. 18 are 
shown in Figure 3.15 (a), and demonstrate substantial scatter. However, if the statistical distribution of the amplitudes is plotted, Figure 3.15 (b), a clear trend emerges.

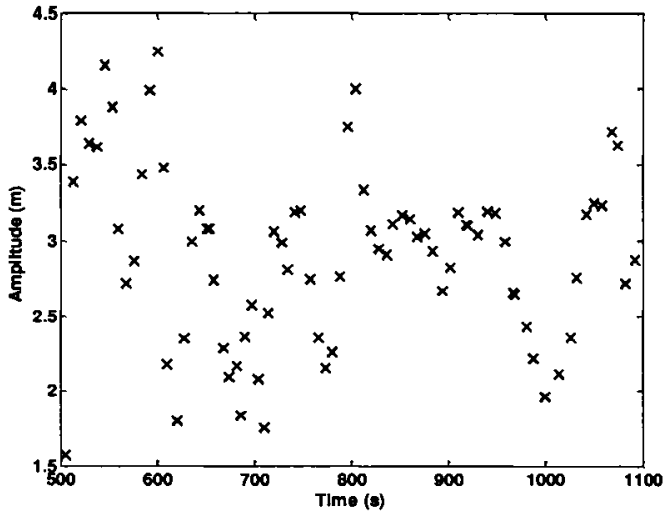

(a)

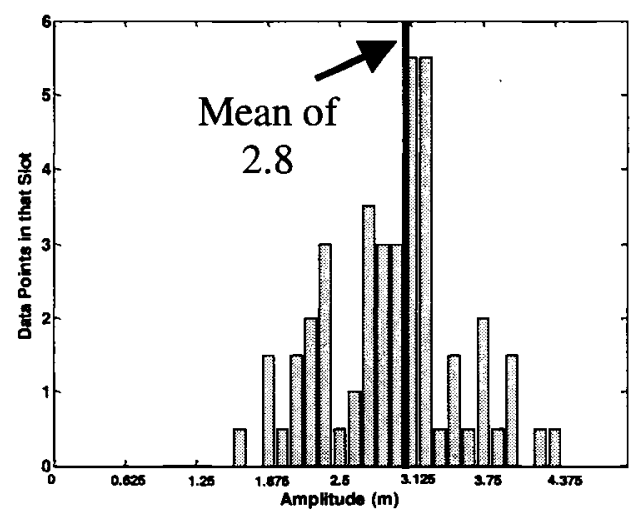

(b)

Figure 3.15 - Transverse Oscillation Amplitudes for the 30 m Flight of Nov. 18

As with the oscillation frequencies, the inline oscillatory motion for all flights and the transverse motion for some flights were too irregular to allow a reasonable determination of the amplitude. The transverse oscillation amplitudes for those flights from which a mean value could be determined, normalized by the balloon diameter of $2.5 \mathrm{~m}$, are plotted against reduced velocity in Figure 3.16 (a).

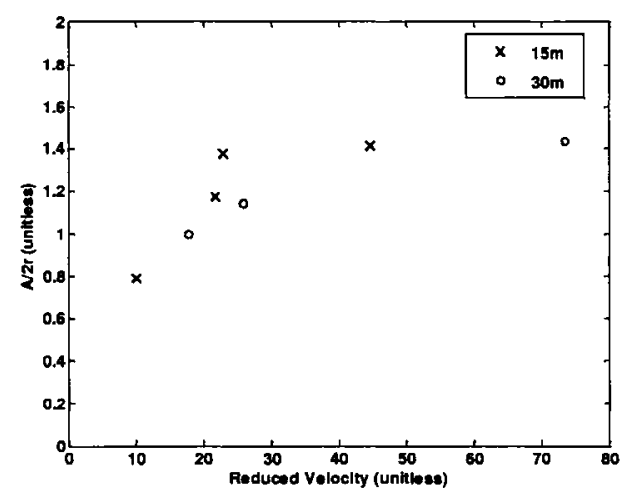

(a)

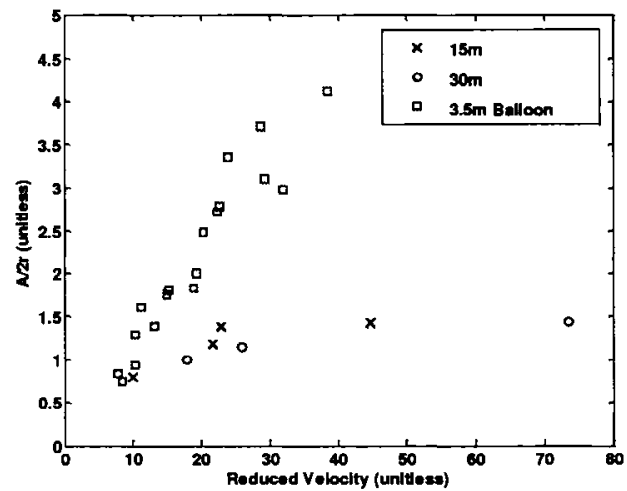

(b)

Figure 3.16 - Normalized Transverse Oscillation Amplitudes

As can be seen in Figure 3.16 (a), the transverse oscillation amplitudes appear to increase with reduced velocity and then saturate, but due to the lack of usable data, a clear and definite trend cannot be inferred. When the transverse amplitudes for the $2.5 \mathrm{~m}$ 
balloon are plotted against the findings from the more sophisticated system analyzed by Coulombe Pontbriand [37], Figure 3.16 (b), it is seen that the results between the two systems conform somewhat for reduced velocities below 20. However, for reduced velocities above 20 , the amplitudes of oscillation of the $2.5 \mathrm{~m}$ system are much lower than those of the $3.5 \mathrm{~m}$ system. The lower amplitudes presented here complement the higher frequencies presented in section 3.5.2, further supporting that the differences in blowdown angle or construction between the $2.5 \mathrm{~m}$ apparatus and the $3.5 \mathrm{~m}$ apparatus may have affected how the wind excites the tethered spheres.

\subsection{Comments About the Results}

A point of interest is that the Delorme GPS receivers were unreliable at higher altitudes, with all of the $45 \mathrm{~m}$ flights being unusable due to cycle slips. At these altitudes the balloon tends to see higher velocities in its oscillatory motion as well as large angles, inhibiting the Blue Logger's ability to retain a fix with the GPS satellites. The main fault with the inexpensive GPS receivers, however, is their inclination to produce offsets and drifts, as seen in Figure 3.5. Signal errors of this sort bring into question the evaluation of the drag coefficient of the sphere over a flight, a quantity that relies on using accurate average values of the balloon's 3-dimensional position. The issue of the accuracy of the Delorme receivers appears to be of lesser importance when considering the balloon's oscillatory motion, as illustrated by the clarity of the transverse oscillations in Figure 3.13 and the emergence of a trend in the amplitude data plotted in Figure 3.15. It follows that an unsophisticated experimental system is valuable for exploring balloon motions in an average sense, and may even be preferable to a more sophisticated apparatus when testing for catastrophic failure, or in conditions in which such a failure may occur.

In contrast with the findings of Williamson and Govardhan, a regular figure-of- 8 motion was not reproduced in the natural wind flow. On the other hand, a much higher drag coefficient was observed for the single-tethered $2.5 \mathrm{~m}$ aerostat than what would be expected for a fixed, smooth sphere. This will prove to be key knowledge for the analysis of the stresses seen in the balloon's envelope during flight in the next two chapters. 


\section{Chapter 4 Finite Element Analysis of a Fabric Aerostat}

The catastrophic failure of aerostats in high winds tends to occur due to a local failure of the envelope that then propagates into a massive tear [21]. To quantify exactly how and why aerostats fail, an analysis of the stresses in the envelope was performed. Specifically, it was desired to see if and where stress concentrations existed and what limits fabric aerostats from being operable in high wind speeds.

Since the loads acting on the balloon are a complicated combination of drag, buoyant, and tether forces, the study could not be done using simple analytic means. Rather, finite element analysis, more suited to complex loading situations such as this, was employed. Finite element analysis is the process of dividing a body into a set of grid points interconnected by structural elements, and then calculating the element stresses based on the displacements of those points [49]. It was expected that the deflection of the envelope would be more than half its thickness, causing a geometric nonlinearity [49]. Thus, a nonlinear static analysis of the envelope, for which the solution is obtained iteratively, was performed. The analysis, being static, assumes a quasi-static state for the balloon with the inertial terms being equal to zero. The software chosen to perform the analysis was MSC.PATRAN/NASTRAN. This analysis package has been used by aerostat developer TCOM for over 20 years [17] and is well suited to the problem due to its robust nonlinear solver. 


\subsection{Finite Element Model}

\subsubsection{Geometry}

The analysis could have been performed on the $2.5 \mathrm{~m}$ diameter balloon described in previous chapters, but a balloon of that size is not very suitable for carrying useful payloads. Instead, the investigation was performed on a more practical $10.15 \mathrm{~m}$ diameter aerostat, the size being considered for NRC's 1/3 scale Large Adaptive Reflector experiment [9]. The aerostat was modeled after an Aerostar $10.15 \mathrm{~m}$ balloon [24] with ballonets and seams omitted for simplicity due to their lack of influence on the major hull stresses.

The $10.15 \mathrm{~m}$ aerostat model, Figure 4.1, featured two $0.5 \mathrm{~m}$ diameter end patches on its geometric top and on bottom. The end patches were approximated as circular areas of the envelope where the thickness doubles, which assumes a perfect bond between the patch and envelope. In the model, 8 tethers were attached at equally spaced intervals around a ring $35^{\circ}$ below the equator of the sphere. The tethers were each $7.25 \mathrm{~m}$ long and converged to a confluence point $8.85 \mathrm{~m}$ below the center of the balloon. The tethers were modeled as cylinders of $11 \mathrm{~mm}$ in diameter, the appropriate tether thickness for a balloon of this size.

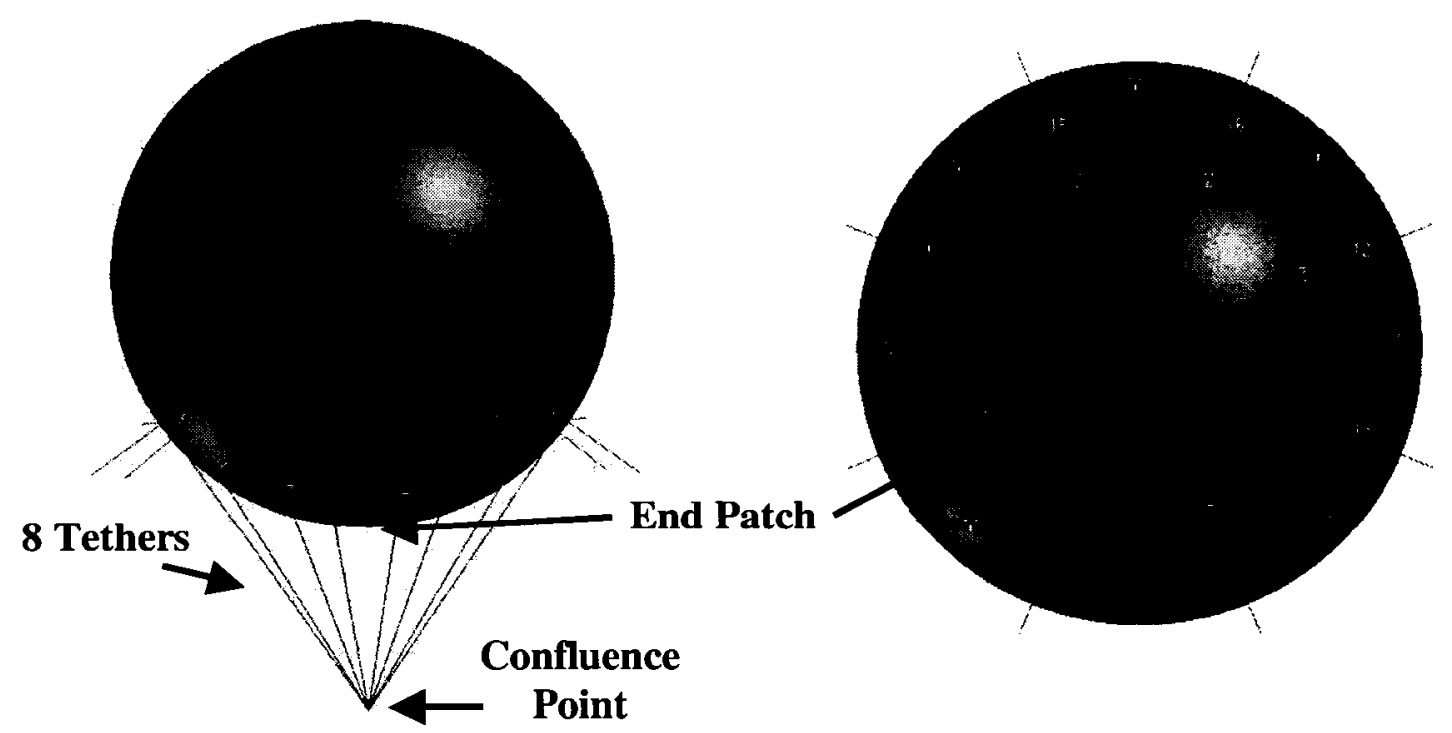

Figure 4.1 - Side and Bottom Views of the $10.15 \mathrm{~m}$ Diameter Aerostat Model 
The 8 tethers attached to the balloon's envelope using $0.5 \mathrm{~m}$ diameter load patches. As with the end patches, it was assumed there was a perfect bond between the load patches and the envelope so they could be modeled as circular areas where the thickness doubles. Referring to Figure 4.2, on a real aerostat the tethers coming from the confluence point split above the load patch into 8 "subtethers," or straps that attach to the patch at equally spaced points about a circle of $0.12 \mathrm{~m}$ diameter. In the model, each tether from the confluence point is split into 8 subtethers over the load patch, the end node of each of which is tied into nodes in the load patch at equally spaced points about a $0.12 \mathrm{~m}$ diameter circle, simulating a point attachment. Each subtether was modeled as a cylinder $15 \mathrm{~mm}$ in diameter, the width of the straps used on ordinary load patches.
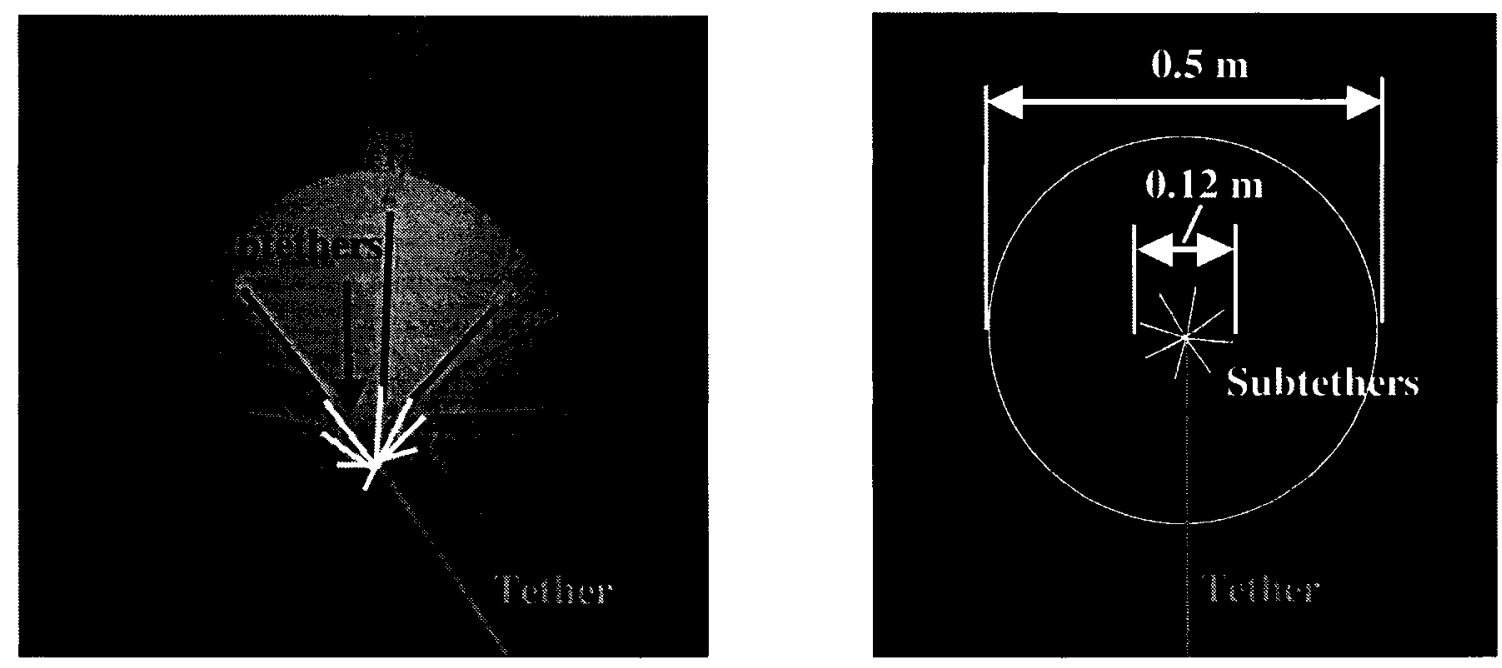

Figure 4.2 - A Real and Simulated Load Patch

\subsubsection{Material Properties}

Aerostar fabricates their $10.15 \mathrm{~m}$ diameter balloons out of $205 \mathrm{~g} / \mathrm{m}^{2}\left(6.05 \mathrm{oz} / \mathrm{yd}^{2}\right)$ Lamcotec urethane-coated nylon. The nylon is a woven material and has slightly different properties in the warp and weft directions. Unfortunately, Lamcotec has not determined the orthotropic mechanical properties of their material needed for a finite element analysis. Furthermore, these properties are not readily available for woven nylon material. As an approximation the envelope material was modeled as linear elastic isotropic Nylon 6, used as the load-bearing component of some airship envelope materials [1]. The mechanical properties of the nylon are given in Table 4.1 below. 
Table 4.1 - Mechanical Properties of Nylon 6 [27], [50]

\begin{tabular}{|c|c|c|c|}
\hline Young's Modulus & $2.5 \mathrm{GPa}$ & Thickness & $0.18 \mathrm{~mm}$ \\
\hline Poisson's Ratio & 0.39 & Area Density & $205 \mathrm{~g} / \mathrm{m}^{2}\left(6.05 \mathrm{oz} / \mathrm{yd}^{2}\right)$ \\
\hline Density & $1140 \mathrm{~kg} / \mathrm{m}^{3}$ & Break Strength & $142 \mathrm{MPa}$ \\
\hline
\end{tabular}

In the absence of more accurate data the tether material was also approximated as being linear elastic isotropic. The material used was Cortland's Plasma 12-strand rope. The mechanical properties, obtained from the company and experiments performed by Lambert, are featured in Table 4.2 below.

Table 4.2 - Mechanical Properties of Cortland Plasma Rope [39], [51]

\begin{tabular}{|c|c|c|c|}
\hline Young's Modulus & $37.4 \mathrm{GPa}$ & Subtether Diameter & $15 \mathrm{~mm}$ \\
\hline Density & $980 \mathrm{~kg} / \mathrm{m}^{3}$ & Tether Break Strength & $93.4 \mathrm{kN}$ \\
\hline Tether Diameter & $11 \mathrm{~mm}$ & Subtether Break Strength & $169 \mathrm{kN}$ \\
\hline
\end{tabular}

\subsubsection{Simulated Loads}

\subsubsection{Drag}

Consider a spherical aerostat in a steady wind stream. The air flowing over the sphere creates a static pressure profile that varies over the balloon's surface. Integrating this profile over the surface of the envelope yields the drag force on the balloon. The static pressure distribution over a tethered buoyant sphere as it moves through the air is not available in literature. The closest approximation is that for a smooth, fixed sphere in a steady flow.

The highest Reynolds number for which the static pressure distribution over a fixed, smooth sphere is available is $\operatorname{Re}=5 \times 10^{6}$, and was published by Achenbach [52], shown in Figure 4.3 (a). A Reynolds number of this magnitude corresponds to a relatively low $7.1 \mathrm{~m} / \mathrm{s}$ wind speed over a $10.15 \mathrm{~m}$ diameter spherical aerostat. It is of interest, however, to analyze stresses at higher wind speeds. Looking at Figure 4.3 (a) it is seen 
that for higher Reynolds numbers the static pressure distribution does not change dramatically. This is because the angle at which separation of the flow from the sphere occurs is relatively constant in the supercritical region. Thus, the static pressure distribution from the lower Reynolds number of $5 \times 10^{6}$ can reasonably be used for higher Reynolds number flow. A further issue with using the distribution depicted below is that it is for a fixed sphere and thus corresponds to a drag coefficient of only 0.23 . As discussed in Chapter 3, the drag coefficient of tethered, buoyant spheres tends to be much higher than that, an issue that will be addressed in section 4.3.

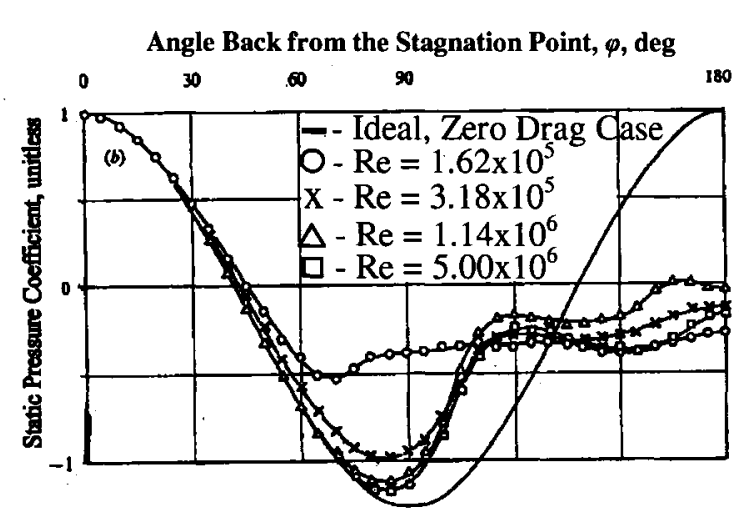

(a) Static Pressure Distribution

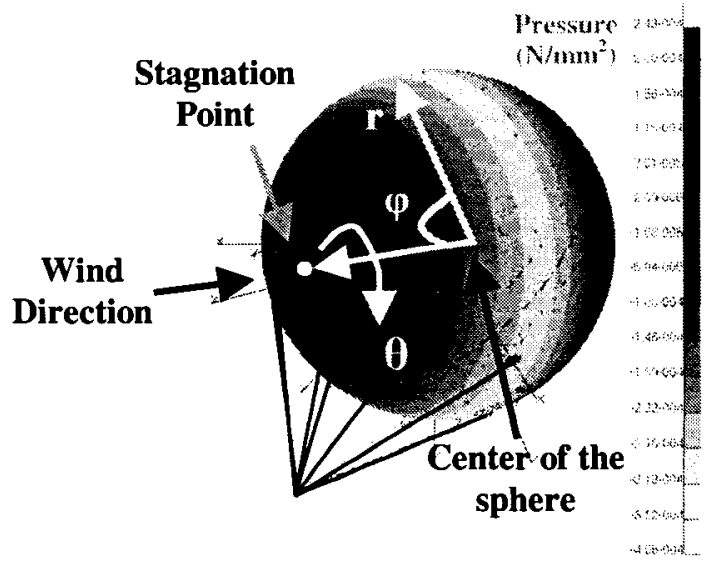

(b) Pressure Distribution for $\mathrm{Re}=5 \times 10^{6}$

\section{Figure 4.3 - Static Pressure Distribution Over a Smooth, Fixed Sphere [52]}

Figure 4.3 (b) shows a $10.15 \mathrm{~m}$ aerostat with an attached spherical coordinate system whose origin is at the center of the sphere. In the figure, the polar angle $\varphi$ runs in the direction of the wind from the front to the back of the sphere, the azimuthal angle $\theta$ runs perpendicular to the direction of the wind, $r$ denotes the sphere's radius, and the point $[r, \varphi, \theta]=[5.075 \mathrm{~m}, 0,0]$ corresponds to the stagnation point of the wind on the balloon. Since the pressure profile varies only with $\varphi$, and not with $\theta$, the wind pressure load is distributed over the sphere as rings of constant pressure from the stagnation point to the opposite end of the aerostat.

\subsubsection{Buoyancy}

It is commonly known that a body immersed in a gas or fluid experiences a vertical buoyant force equal to the weight of the fluid it displaces. This buoyancy occurs due to the pressure of the gas, which changes with height at a rate proportional to its density. 
Consider an arbitrary solid body immersed in a fluid, as in Figure 4.4 (a). Remembering that the pressure of a fluid or gas does not change with horizontal position, the buoyant force, $F_{b}$, is found by summing the vertical forces on vertical elements over the body [25]

$$
F_{b}=\int_{b o d y}\left(p_{2}-p_{1}\right) d A
$$

where $p_{1}$ and $p_{2}$ are the fluid pressures on the solid body at heights $z_{1}$ and $z_{2}$ respectively, as defined in Figure 4.4 (a), and $d A$ is the projection of the element's surface area onto a horizontal plane. If $\rho$ is taken to be the density of the fluid and $g$ the gravitational constant, we know that at each height, $z_{i}$,

$$
p_{i}=p_{o}-\rho g z_{i}
$$

where the subscript " $o$ " denotes some reference height. It follows that the buoyant force is

$$
F_{b}=-\rho g \int_{b o d y}\left(z_{2}-z_{1}\right) d A=\rho g V
$$

where $V$ is the volume of the body.

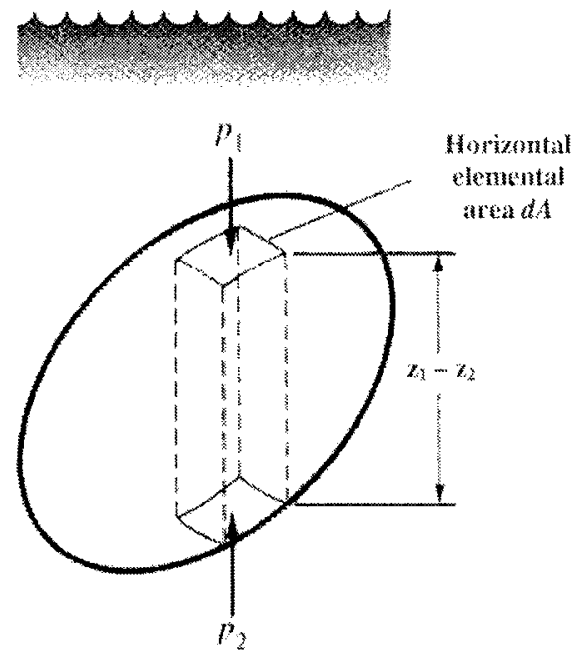

(a) Arbitrary Solid Body

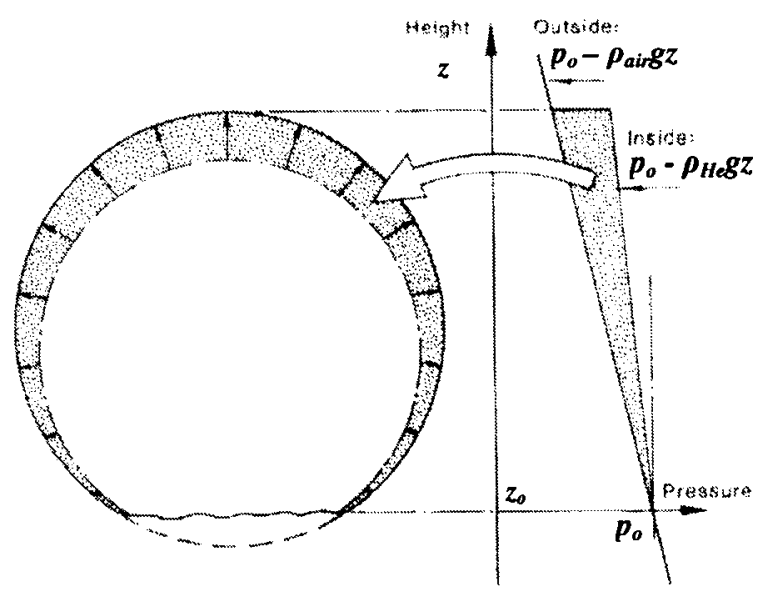

(b) Helium Balloon

Figure 4.4 - The Mechanism of Buoyant Lift [1], [25]

When considering an Helium aerostat, referring to the spherical balloon depicted in Figure 4.4 (b), because Helium has a lower density than air, its pressure decreases 
more slowly over a change in height, $\Delta z$. If the two pressures are equal at some reference height, $z_{0}$, a differential pressure will act outwards to the envelope above that height with the resultant being an upward, buoyant force.

In the simulation the $10.15 \mathrm{~m}$ spherical balloon was given the mean overpressure used by Aerostar of $249 \mathrm{~Pa}$ (1 inWG) [24]. The internal pressure, $p_{i}$, at each point on the sphere is given by

$$
p_{i}=\bar{p}+\left(\rho_{\text {air }}-\rho_{H e}\right) g z_{e}
$$

where $\rho_{\text {air }}$ is the density of air, taken to be $1.23 \mathrm{~kg} / \mathrm{m}^{3}, \rho_{H e}$ is the density of helium, taken to be $0.179 \mathrm{~kg} / \mathrm{m}^{3}$ [28], $g$ is the gravitational acceleration of $9.81 \mathrm{~m} / \mathrm{s}^{2}, \bar{p}$ the mean internal overpressure of $249 \mathrm{~Pa}$, and $z_{e}$ the vertical distance in meters from the balloon's equator. For a balloon diameter of $10.15 \mathrm{~m}$, we find that the internal pressure at the bottom of the balloon is $197 \mathrm{~Pa}$, while that at the top is $301 \mathrm{~Pa}$.

Integrating the pressure profile described by equation ( 4.1 ) over the surface of the $10.15 \mathrm{~m}$ aerostat yields a gross lift of $5621 \mathrm{~N}$. With gravity simulated as an inertial load calculated using the gravitational constant, $g$, and applied to the entire model, the weight of the envelope is determined by NASTRAN from the areal density of the envelope material to be $652 \mathrm{~N}$. The net lift on the aerostat is thus $4969 \mathrm{~N}$.

\subsubsection{Wind Speed}

It was desired to run the simulation for high wind speeds. However, the highest wind speed at which the model can be evaluated is constrained by "dimpling." When the dynamic pressure of the wind exceeds the internal pressure of the aerostat the balloon will "dimple," or lose its spherical shape, as seen in Figure 4.5. Dimpling will first occur at the stagnation point because, referring to Figure 4.3 (a), the pressure on the sphere's surface caused by the wind has its highest positive value there. Once dimpling occurs the balloon turns into more of a sail, causing the drag forces to rise as the entire dimpled area is exposed to the stagnation pressure. In such a situation the assumed static pressure distribution for the model is no longer valid, and so the dimple speed is the limiting wind speed for which the fabric aerostat can be simulated. 
The dynamic pressure of the wind, $p_{\text {wind }}$, is defined as

$$
p_{\text {wind }}=\frac{1}{2} \rho_{\text {air }} u^{2}
$$

where $u$ is the wind speed. Since the stagnation point will always be at the center of the balloon, where the internal pressure is equal to the mean internal pressure, dimpling will occur when $p_{\text {wind }}>249 \mathrm{~Pa}$, which takes place for $u>20 \mathrm{~m} / \mathrm{s}$. This corresponds to a flow of Reynolds number $14.1 \times 10^{6}$ over the $10.15 \mathrm{~m}$ aerostat.
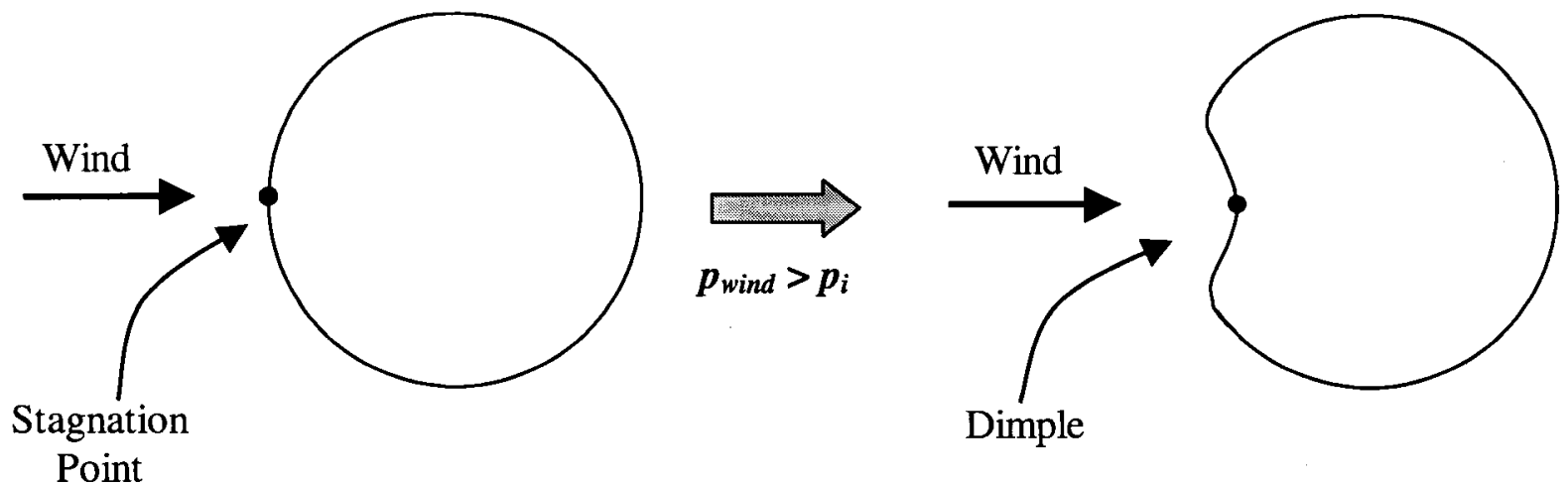

Figure 4.5 - An Aerostat Before and After Dimpling

It is interesting to calculate the blowdown angle of the $10.15 \mathrm{~m}$ aerostat subjected to a $20 \mathrm{~m} / \mathrm{s}$ wind. Using the quasi-static assumption, and equation ( 2.6 ) of Chapter 2 , the blowdown angle, $\theta$, is

$$
\theta=\tan ^{-1}\left(\frac{F_{D}}{F_{L}}\right)
$$

Setting the wind speed to $20 \mathrm{~m} / \mathrm{s}$, the drag force on the balloon, $F_{D}$, is calculated by integrating the pressure distribution depicted in Figure 4.3 (a) over the surface of the sphere, and is found to be $4556 \mathrm{~N}$. The net lift force, $F_{L}$, mentioned previously, is $4969 \mathrm{~N}$. From this, using equation ( 4.3 ), the blowdown angle of the $10.15 \mathrm{~m}$ balloon for a $20 \mathrm{~m} / \mathrm{s}$ wind is calculated to be $42.5^{\circ}$.

\subsubsection{Constraints}

Ideally, only the confluence point of the tethers in the model would be constrained from translating in any direction so the model would be free to pivot about that point. 
However, constraining the aerostat in this manner led to singularities in the stiffness matrix that caused the displacements generated by NASTRAN to diverge. The next most realistic solution that removed these singularities was to constrain each tether in its entirety, but not the subtethers, from translating in any direction relative to the model's global coordinate system. This is equivalent to having an aerostat moored by infinitely stiff tethers. Since the main interest of the analysis was the stress distribution in the balloon's envelope, this approximation was deemed acceptable.

\subsubsection{Finite Elements}

Beam elements were used to model the tethers and subtethers in the simulation, rather than rod elements, and the fabric envelope was modeled using shell elements rather than membrane elements. Rod and membrane elements would have been preferable for the tethers and envelope, respectively, due to their negligible bending stiffness. However, a tethered aerostat is a marginally constrained structure, and use of these more realistic, highly flexible elements in the model led to instabilities in the equations used by NASTRAN for the nonlinear analysis. As a result, beam and shell elements with a small bending stiffness, on the order of $1 \%$ of the tensile stiffness, had to be used.

Linear triangular elements (TRIA3 elements in NASTRAN) were used for the envelope mesh as they conform better to curved boundaries than linear rectangular ones and have reduced computational needs over those of quadratic triangular elements [49], [53]. The coarseness of the mesh was selected based on trial and error from plotting the maximum stress seen in the envelope. Mesh coarseness is described in NASTRAN by the "global edge length," or the approximate length of each element edge, defined as

$$
G E L=\frac{L_{E}}{n}
$$

where $G E L$ is the global edge length, $L_{E}$ the edge length of the longest geometry in the model, and $n$ the number of elements in the mesh. An example of the maximum stress seen in the envelope for a $20 \mathrm{~m} / \mathrm{s}$ wind plotted with the global edge length is shown in Figure 4.6. It was found that using a global edge length of 200 for the envelope and a finer global edge length of 50 for the load patch gave a good balance between the accuracy of the results and low computational time. 


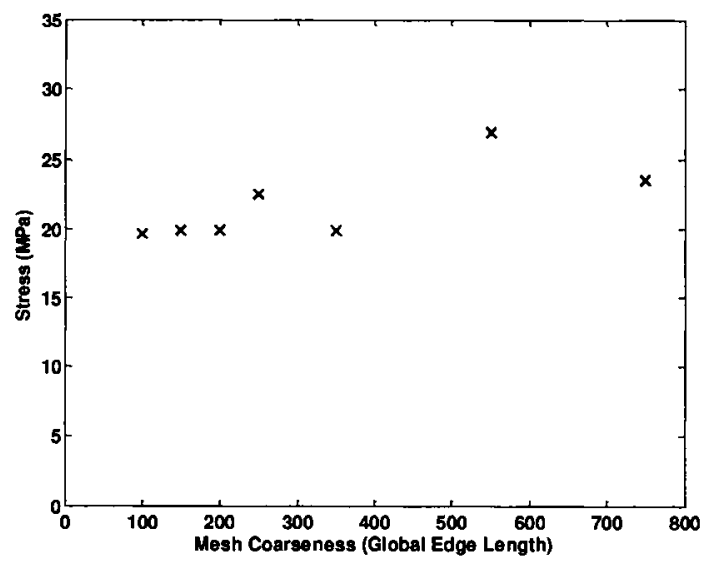

Figure 4.6 - Change in Maximum Envelope Stress with Mesh Size

\subsection{The Finite Element Analysis}

\subsubsection{Expected Results}

Both the constraint forces seen by the subtethers, and the stress in the envelope far from the tether attachment region could be predicted with simple analytic expressions. Using the quasi-static assumption for the model so that inertial terms may be neglected, the force in the main tether, $F_{T}$, shown in Figure 4.7, is calculated using equation ( 2.4 ) from Chapter 2 as

$$
F_{T}=\sqrt{F_{L}^{2}+F_{D}^{2}}
$$

Since the 8 tethers from the main confluence point are fixed in the model, $F_{T}$ will be distributed amongst the confluence points of each set of subtethers. The load is not necessarily evenly distributed among the eight tethers due to the asymmetry in the applied loads. The constraint forces at the 8 confluence points of the subtethers should nevertheless sum to the expected constraint force, $F_{c T}$, which is calculated as

$$
F_{c T}=\frac{\sqrt{F_{D}^{2}+F_{L}^{2}}}{\cos 35^{\circ}}
$$

where $\cos 35^{\circ}$ accounts for the $35^{\circ}$ angle between the tethers and the direction of application of $F_{T}$. Taking $F_{D}$ and $F_{L}$ to be the previously mentioned values of $4556 \mathrm{~N}$ and $4969 \mathrm{~N}$ respectively, the expected constraint force is calculated to be $8230 \mathrm{~N}$. 

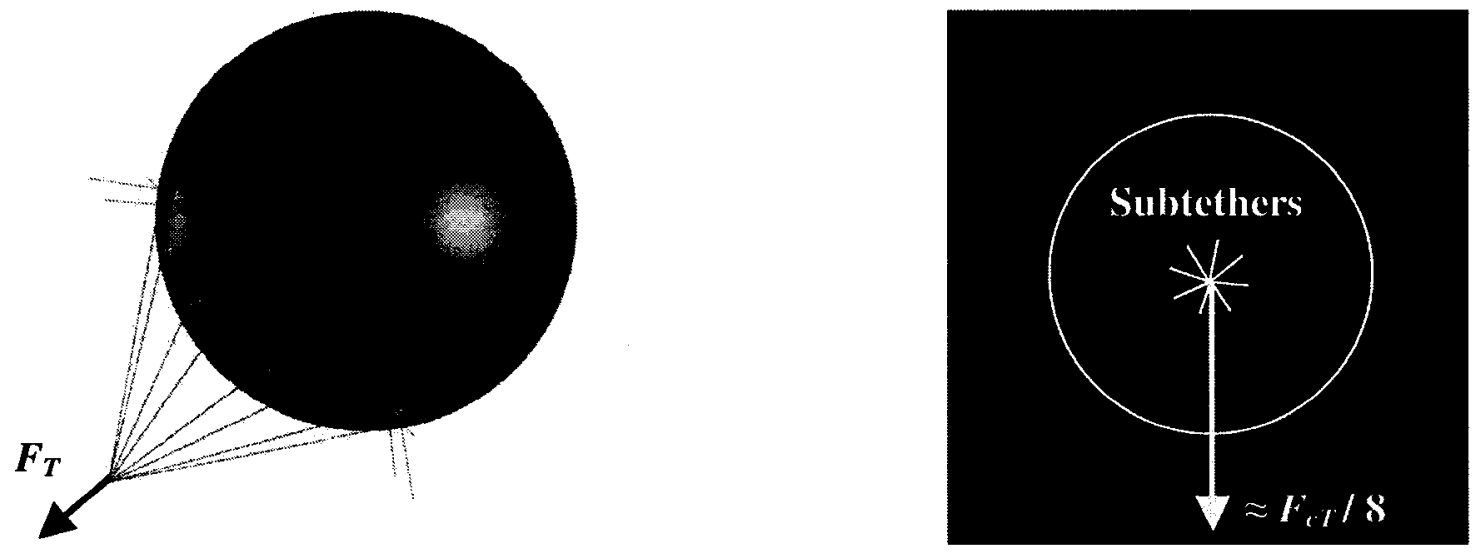

Figure 4.7 - Constraint Force on the Subtethers

The stress in the envelope in areas unaffected by the tether attachment points, $\sigma_{E}$, may be calculated using the formula for the hoop stress in a thin-walled spherical pressure vessel [54]

$$
\sigma_{E}=\frac{\left(p_{i}-p_{a}\right) r}{2 t}
$$

where $t$ is the thickness of the membrane material and $p_{i}$ and $p_{a}$ are the internal and aerodynamic pressures, respectively. If we consider the point on the aerostat that is diametrically opposite to the stagnation point, the internal pressure is equal to the mean value of $249 \mathrm{~Pa}$. Furthermore, looking at Figure 4.3 (a), the aerodynamic pressure in a $20 \mathrm{~m} / \mathrm{s}$ wind is equal to $-41.7 \mathrm{~Pa}$. Taking into account the $0.18 \mathrm{~mm}$ thickness of the nylon envelope, $\sigma_{E}$ is calculated with equation ( 4.7 ) to be $4.10 \mathrm{MPa}$.

\subsubsection{Results of the Analysis}

The constraint force calculated by NASTRAN for the case of a $20 \mathrm{~m} / \mathrm{s}$ wind was not evenly distributed amongst the tethers of the balloon, as illustrated by Figure 4.8. The summation of the constraint forces in each tether equaled $8167 \mathrm{~N}$, however, which is within $0.8 \%$ of the expected value of $8230 \mathrm{~N}$. The stress at the end of the balloon exactly opposite the stagnation point and far away from the influence of the tethers was 4.12 $\mathrm{MPa}$, within $0.5 \%$ of the expected value. With the accuracy of the model validated, an analysis can be made of the stresses and displacements in the envelope. 


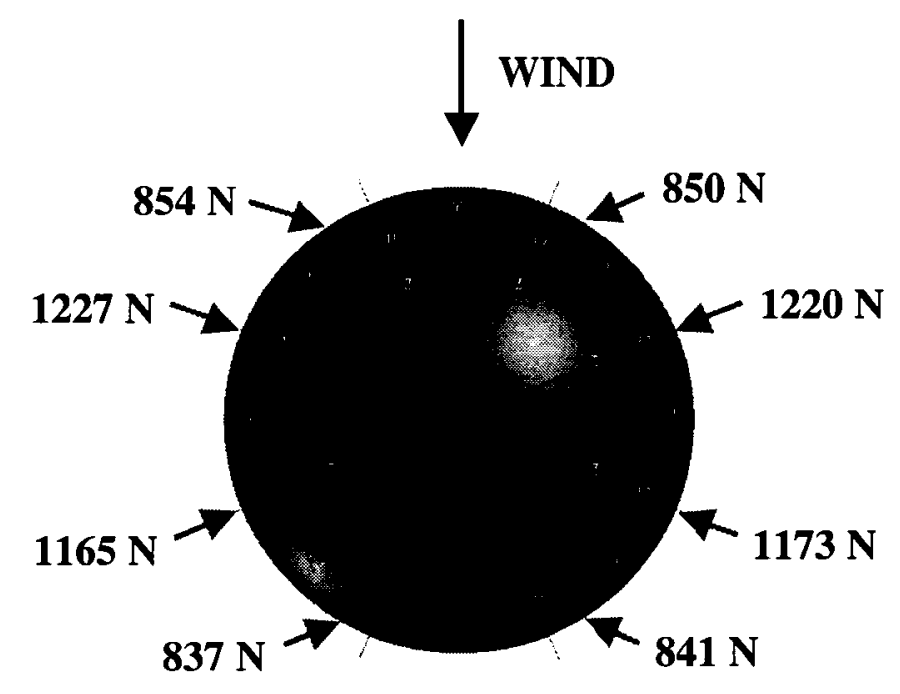

Figure 4.8 - Constraint Force in Each Tether (Bottom View of the Aerostat)

The distribution of the stresses over the envelope is shown in Figure 4.9 on the next page, and the distribution of the displacements in Figure 4.10. Those areas in which a mesh is seen represent regions where the deformed shape of the aerostat is internal to the original shape.

The first point of interest is the region where the highest stresses occur. Away from the influence of the tether attachment points the stress in the envelope changes with a profile similar to the static pressure distribution. From Figure 4.3 (a), the aerodynamic pressure of highest magnitude occurs approximately $80^{\circ}$ from the stagnation point, and is a suction from the surface. The high aerodynamic suction causes larger stresses in the envelope at $80^{\circ}$ past the stagnation point, with the largest stresses at the top of the balloon where the high internal and external pressures combine, as seen in Figure 4.9. The stress at the top of the balloon is approximately $9.7 \mathrm{MPa}$.

The highest stresses in the envelope were concentrated around the load patches. However, due to the variable membrane stresses caused by the aerodynamic pressures, these concentrations were not even amongst all 8 tethers. The maximum stress occurred at the lower load patch on the side of the balloon in Figure 4.9, located approximately $75-80^{\circ}$ back from the stagnation point in a region of high aerodynamic pressure, and was equal to $19.9 \mathrm{MPa}$. The stress concentrated just above the load patch, a consequence of the membrane thickness halving when moving from the load patch to the envelope. As 
seen in Figure 4.10, the largest displacements also occurred around the patches, with the tethers pulling the load patches out by $56 \mathrm{~mm}$, or $0.6 \%$ of the balloon's diameter.

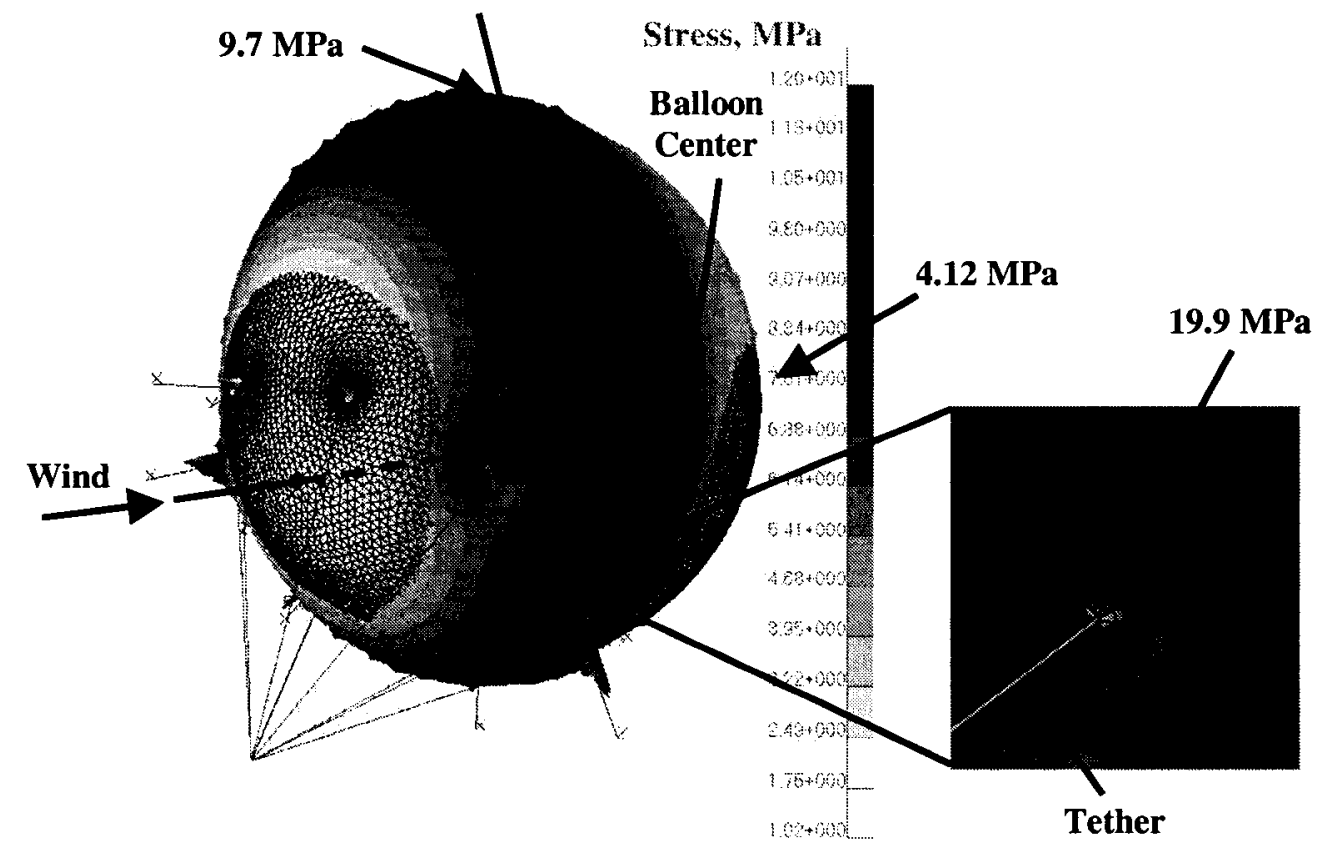

Figure 4.9 - Stress Profile Over the Envelope in a $20 \mathrm{~m} / \mathrm{s}$ Wind (Range Narrowed to 1.02 - 12 MPa)

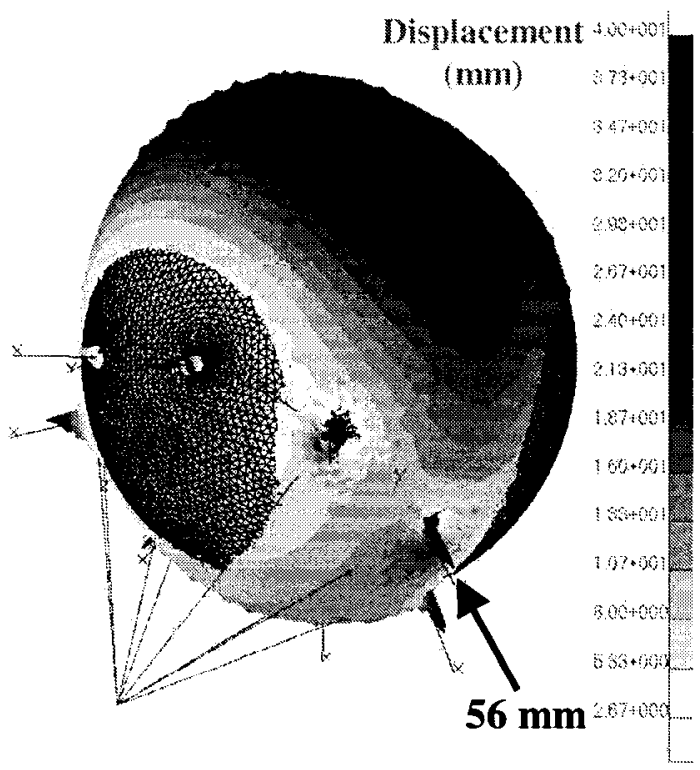

(a) Exaggerated View

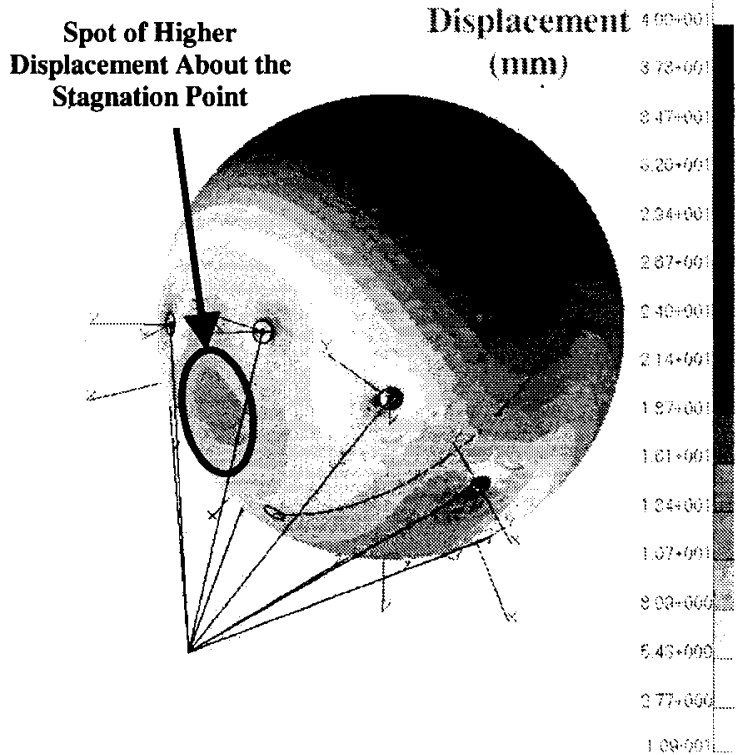

(b) Unexaggerated View

Figure 4.10 - Displacement Profile Over the Envelope in a $20 \mathrm{~m} / \mathrm{s}$ Wind (Range

Narrowed to $0.1-40 \mathrm{~mm}$ ) 
The second region of interest is at the stagnation point. The lowest stresses in the envelope, around 1.02 $\mathrm{MPa}$, are in this region. This is because in the near-dimpling wind speed of $20 \mathrm{~m} / \mathrm{s}$, the aerodynamic pressure is equal in magnitude and opposite in sense to the internal pressure and so they cancel each other out. As seen in Figure 4.10, the region of the stagnation point displaces back slightly farther than those areas around it, about $12 \mathrm{~mm}$ as compared to $7 \mathrm{~mm}$, indicating the onset of dimple.

\subsection{Practical Considerations}

There are a few serious simplifications made in the preceding analysis. The first is the drag coefficient of 0.23 for the aerostat. As noted in Chapter 3, the drag coefficient of a tethered, buoyant, free sphere in supercritical flow would likely be higher. The drag force on a sphere is related to the drag coefficient as

$$
F_{D}=\frac{1}{2} C_{D} \rho_{a i r} u^{2} \pi r^{2}
$$

Equation ( 4.8 ) indicates the higher drag coefficient will create a proportionally higher drag force on the tethered, buoyant sphere as compared to a smooth, fixed sphere.

To determine the relationship between the drag force on the tethered sphere and the stress in the envelope, the simulation was run for 7 different wind speeds from $0 \mathrm{~m} / \mathrm{s}$ to $20 \mathrm{~m} / \mathrm{s}$ and the maximum stress in the envelope as well as the drag force were evaluated. Figure 4.11 shows the correspondence between the drag force and the

maximum stress for each test case, and we can see that there is a linear relationship between the two. Since the drag force on the tethered sphere depends proportionately on the drag coefficient, it follows that the maximum stress in the envelope should as well depend proportionately on the drag coefficient.

Williamson and Govardhan published the only experimental drag coefficient data for tethered, free spheres. They found that for the subcritical Reynolds number of 14000 the drag coefficient on a tethered, buoyant sphere would be around 0.7 [14]. Following the logic presented in Chapter 2, since supercritical drag coefficients tend to be lower than subcritical, the drag coefficient of 0.7 was conservatively used for analysis purposes as well as for design purposes, as described in Chapter 5. If we assume the envelope 
stress will rise at a rate proportional to the drag coefficient, the highest stress in the envelope of the aerostat in a $20 \mathrm{~m} / \mathrm{s}$ wind will rise to $19.9 \mathrm{MPa}\left(\frac{0.7}{0.23}\right)=60.6 \mathrm{MPa}$.

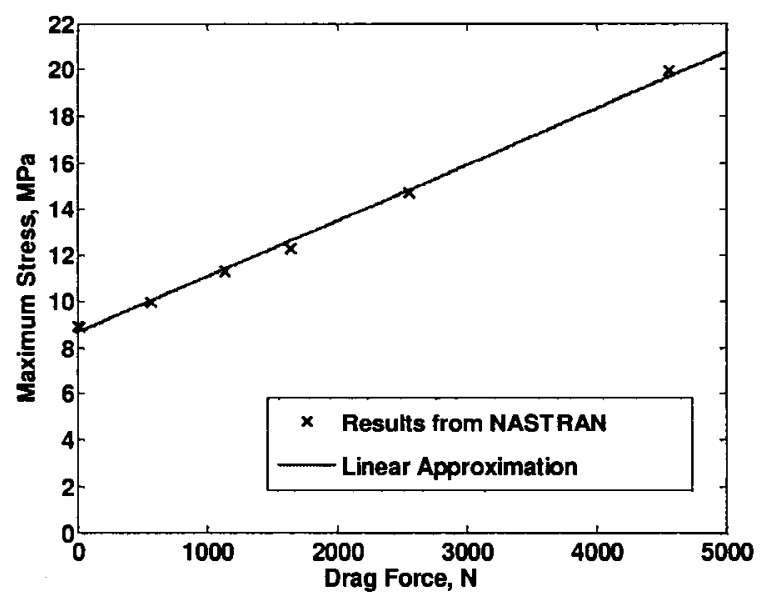

\section{Figure 4.11 - Rise in Maximum Envelope Stress with Drag Force}

Another simplification assumed for the above analysis is that the loads are distributed somewhat evenly amongst the tethers. However, it is very common for the tethers to be very unevenly loaded, especially in strong, turbulent wind conditions, causing a consequent rise in the stress experienced by the envelope. Consider a situation in which the aerostat pitches slightly about the confluence point and the tether around which the maximum stresses occur experiences the entire load while still attached to the tangent of the balloon. In this case we may say the maximum stress experienced by the envelope will rise by 8 times, from 60.6 $\mathrm{MPa}$ to $484 \mathrm{MPa}$. Referring to Table 4.1 in section 4.1.2, the breaking strength of Lamcotec's $6.05 \mathrm{oz} / \mathrm{yd}^{2}$ urethane-coated nylon is just 141.7 MPa. It follows that the fabric balloon would be incapable of surviving wind speeds even below the dimple speed under these assumptions.

The factor of 8 used above is not completely accurate. In the proposed loading scenario the aerostat would orient itself so the one tether would be subjected to the lower force in the main tether, $F_{T}$, rather than the higher constraint force, $F_{c T}$. On the other hand, the simulation, being static, does not take into account that the tethers can experience dynamic, or "shock" loading, significantly raising the stress in the balloon envelope. A thorough dynamic analysis of the forces on the balloon would be complex, 
requiring a time varying aerodynamic pressure distribution over the tethered sphere as it moved, which is presently unavailable in literature, or a fluid-structure interaction model. This is beyond the scope of the present research, which is to provide a preliminary study of the loads on an aerostat, and so the factor of 8 was used as a compromise to describe both uneven loading and dynamic effects.

The fabric aerostat experiences manageable stresses in a $20 \mathrm{~m} / \mathrm{s}$ wind when its tethers are evenly and steadily loaded, and it is expected to fail when they are not. However, even if evenly loaded the drag force on the balloon will rise significantly due to dimpling at the stagnation point once a $20 \mathrm{~m} / \mathrm{s}$ wind is reached. Since $20 \mathrm{~m} / \mathrm{s}$ winds can occur regularly in some environments, such as the Canadian prairies, it becomes relevant to consider how an aerostat might be redesigned in order to survive wind speeds much higher than this. 


\section{Chapter 5 Partial-Hard Aerostat Design}

It was established in Chapter 4 that traditional single-tethered fabric aerostats experience large stresses in their envelopes, especially in the region of the tether-envelope interface, when subjected to high wind speeds. Furthermore, the balloons will have a tendency to dimple at the stagnation point when the dynamic pressure of the wind exceeds the internal pressure of the balloon, occurring in a $20 \mathrm{~m} / \mathrm{s}$ wind for the aerostat investigated. There are aerostats in existence that can survive winds higher than $20 \mathrm{~m} / \mathrm{s}$ : TCOM's largest, $16000 \mathrm{~m}^{3}$ aerostats can survive up to a $167 \mathrm{~km} / \mathrm{h}$ (90 knot) wind [31], equivalent to a grade 2 hurricane. TCOM achieves this capability by using heavier materials unsuitable for smaller balloons, and avoids dimpling by using very large internal pressures [17], which proportionally raises the envelope stresses.

An alternative solution for increasing aerostat survivability, which we will investigate here, is to reinforce the envelope using a partial-hard shell on the bottom 1/3 of the sphere, to resist the highest stresses and to prevent dimpling. It was decided to create a $10.15 \mathrm{~m}$ diameter $\left(547.5 \mathrm{~m}^{3}\right)$ spherical aerostat that would be operable in a $46.3 \mathrm{~m} / \mathrm{s}$ (90 knot) wind with a safety factor of 1.5 [17], [18]. The design process included selecting an appropriate material for and determining the dimensions of the partial-hard shell, performing a finite element analysis on the preliminary design, and then modifying as necessary to achieve the desired safety factor. 


\subsection{Material for the Hard Shell}

Maintaining a low weight, and consequently a high lift, is a critical factor when designing an aerostat. It follows that a hard material with a high strength-to-weight ratio must be used for the shell, such as carbon fiber. Carbon fiber reinforced composite sheets consist of a fiber phase within a resin matrix phase. Altering each of these components allows for a range of different mechanical properties.

\subsubsection{Reinforcing Fiber Phase}

Carbon fiber reinforcement fabrics are most often found in one of three forms: unidirectional, multiaxial, and woven, Figure 5.1. Unidirectional fabrics have the majority of their fibers pointing in one direction, yielding very high strength along the fiber direction, but much lower strength transverse to that direction. Multiaxial fabrics consist of one or more layers of typically unidirectional carbon fiber sheets held together by a non-structural stitching thread. Multiaxial fabrics have high strength and good mechanical properties in multiple directions, but the process of manufacturing these sheets can be slow and the cost high [55]. Alternatively, carbon fibers can also be woven together in different patterns. Woven fabrics are very stable and have semi-isotropic properties, but due to crimping in the weave their overall strength is not as high as the unidirectional or multiaxial fabrics.

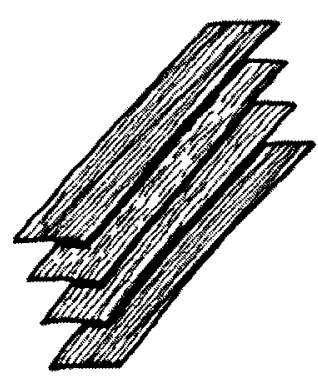

a) Unidirectional

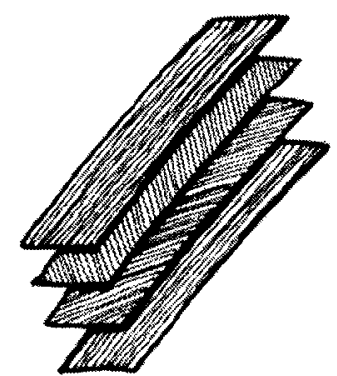

b) Multiaxial

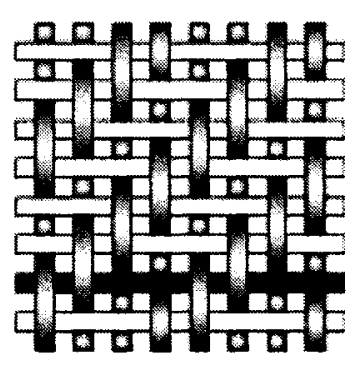

c) Woven ( $2 \times 2$ Twill Weave)

Figure 5.1 - Carbon Fiber Fabric Types [55], [56]

As the tethers in the balloon can transmit loads in varying directions to the envelope, a fabric with more isotropic properties is desired, warranting the use of either a woven or multiaxial fabric. Woven was chosen over multiaxial due to its lower cost and higher availability. Quasi-isotropic mechanical properties can be attained with a woven 
carbon fiber if at least two layers, with fiber directions oriented at $45^{\circ}$ from each other, are used [57].

\subsubsection{Resin Matrix Phase}

The two common types of matrix resins are polyester and epoxy. Epoxy resins tend to be preferred over polyester for several reasons: they adhere better to carbon fibers, have a lower initial cure time, less shrinkage during curing, can be cured in a vacuum without the need of an autoclave, and are more resistant to solvents and chemicals [56], [58], [59].

Carbon fiber parts are usually made by laying carbon fiber fabric on a mold and then curing the final shape. The resin can be painted on the carbon fiber as a liquid during the molding process, which is referred to as a "wet-layup," or it can be pre-impregnated (prepregged) in the fiber reinforcement and partially cured by the material manufacturer before putting the material in the mold by hand, a "hand-layup". Prepregging is preferred as it eases the molding process and ensures that the resin becomes evenly distributed amongst the fiber reinforcement, improving strength and reducing the variance in mechanical properties across the composite [56].

\subsubsection{Selected Material}

Advanced Composites Group recommended either their conventional LTM25 series woven prepreg carbon fiber sheets or their newer VTM260 series. Due to the availability of relevant information about the composite, LTM25/CF0511, with mechanical properties as shown in Table 5.1, was selected as the proposed material. LTM25/CF0511 employs an LTM25 epoxy resin that is common in industry and Toray T-300 standard modulus fibers, considered the aerospace industry standard, woven in a common $4 \times 4$ twill pattern as the reinforcement.

Table 5.1 - Advanced Composites Group's LTM25/CF0511 Prepreg Carbon Fiber

\begin{tabular}{|l|l|l|l|}
\hline Fiber Direction Modulus & $65.6 \mathrm{GPa}$ & Fiber Compression Strength & $405 \mathrm{MPa}$ \\
\hline Shear Modulus & $3.17 \mathrm{GPa}$ & Shear Strength & $78.2 \mathrm{MPa}$ \\
\hline Poisson's Ratio & 0.03 & Area Density & $0.435 \mathrm{~kg} / \mathrm{m}^{2}$ \\
\hline Fiber Tensile Strength & $562 \mathrm{MPa}$ & Per-Layer Thickness & $0.28 \mathrm{~mm}$ \\
\hline
\end{tabular}




\subsection{Designing the Partial-Hard Balloon}

Design of the partial-hard aerostat was performed for a $10.15 \mathrm{~m}$ balloon with 8 tethers in the flying harness, similar to the one discussed in Chapter 4. The epoxy resin used in carbon fiber composites is not Helium impermeable, thus requiring the use of a full $10.15 \mathrm{~m}$ fabric Helium-enclosing spherical envelope embedded in a carbon fiber shell. The fabric chosen for the envelope was Lamcotec's $142 \mathrm{~g} / \mathrm{m}^{2}\left(4.2 \mathrm{oz} / \mathrm{yd}^{2}\right)$ 70-denier urethane-coated nylon, presented in Chapter 2, as it is light and workable. To design the carbon fiber shell, a method of fastening the tethers to the shell was first determined. The dimensions of the shell required to encompass the tether attachment region were then calculated and checked to see if such a configuration would prevent dimpling. Finally, a method of affixing the fabric balloon to the carbon fiber shell was devised.

\subsubsection{Tether Attachment Plates}

The tethers were designed to connect to the tangent of the aerostat $35^{\circ}$ below its equator using mildly curved plates bonded to the side of the carbon fiber shell, Figure 5.2. The design of the tether attachment plates was kept simple, as the main interest of the analysis is the protective shell. The plates are rectangular, consisting of multiple layers of carbon fiber, a bonded region, and a protruding lip with a hole through which the tethers pass. The hole is lined with a metal grommet in order to reduce chafing between the tether and carbon fiber, and to better distribute the tether load. The recommended adhesive to attach the plates is Loctite's Hysol E-20HP, which has a tensile strength of $39.3 \mathrm{MPa}$ and a shear strength of 28.6 MPa when bonded to epoxy [60].
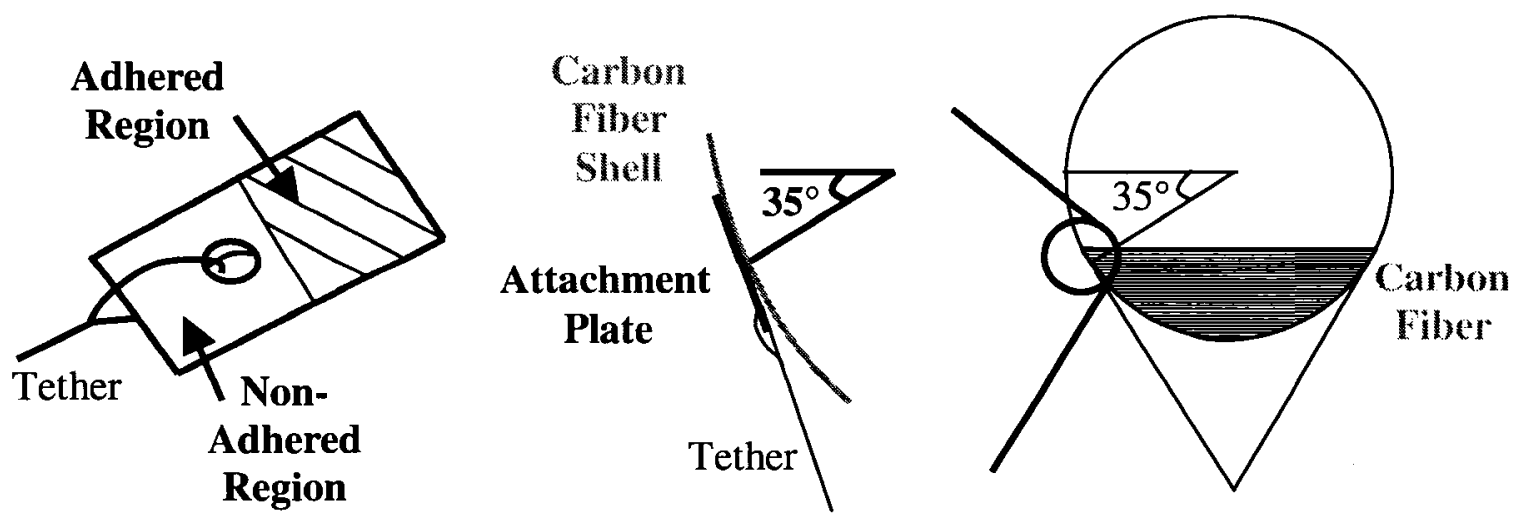

Figure 5.2 - Attaching the Tethers to the Aerostat 
To determine the size and thickness of the attachment plates, the loads to be resisted must first be calculated. Consider a $10.15 \mathrm{~m}$ fabric balloon made of Lamcotec's $142 \mathrm{~g} / \mathrm{m}^{2}\left(4.2 \mathrm{oz} / \mathrm{yd}^{2}\right)$ urethane-coated nylon embedded in a $1 / 3$ sphere of 3 layers of LTM25/CF0511 carbon fiber (the selection of three layers is discussed later in section 5.2.2). The lift of the aerostat will be approximately

$$
F_{L}=\frac{4}{3} g \pi r^{3}\left(\rho_{a i r}-\rho_{H e}\right)-4(1.15) g \pi r^{2} \gamma_{n y l o n}-4 g \pi r^{2} \gamma_{c a r b}
$$

where $\gamma_{n y l o n}$ and $\gamma_{c a r b}$ are the weight per unit area of the nylon and carbon fiber materials respectively, and the factor 1.15 is included to account for the extra weight of seams and any other extra components (Chapter 2). Taking $r$ to be $10.15 / 2=5.075 \mathrm{~m}$, and setting $\rho_{\text {air }}$ to $1.23 \mathrm{~kg} / \mathrm{m}^{3}, \rho_{H e}$ to $0.179 \mathrm{~kg} / \mathrm{m}^{3}, g$ to $9.81 \mathrm{~m} / \mathrm{s}^{2}, \gamma_{\text {nylon }}$ to $142 \mathrm{~g} / \mathrm{m}^{2}$, and $\gamma_{\text {carb }}$ to $435 \mathrm{~g} / \mathrm{m}^{2}$, the lift of the balloon is $3.72 \times 10^{3} \mathrm{~N}$.

The drag on the sphere will be

$$
F_{D}=\frac{1}{2} C_{D} \rho_{a i r} \nu^{2} \pi r^{2}
$$

Using the drag coefficient of a tethered, buoyant sphere published by Williamson and Govardhan of 0.7 [14], the argument for which is presented in Chapter 4, the drag force on the aerostat in a $46.3 \mathrm{~m} / \mathrm{s}$ wind is calculated to be $7.44 \times 10^{4} \mathrm{~N}$. Assuming quasi-static motion, the resultant force as seen by the main tether is

$$
F_{T}=\sqrt{\left(3.72 \times 10^{3}\right)^{2}+\left(7.44 \times 10^{4}\right)^{2}}=7.45 \times 10^{4} \mathrm{~N}
$$

By applying a safety factor of 1.5 , the loading requirement rises to $1.12 \times 10^{5} \mathrm{~N}$. At worst one tether would have to take this entire load, and the appropriate Cortland Plasma rope tether size for this loading is $12 \mathrm{~mm}$ [39]. This constrains the hole in the attachment plate to be at least $12 \mathrm{~mm}$ in diameter.

The dimensions of tether attachment plates were designed so they would withstand the loading scenario in which one tether takes the entire load in a $46.3 \mathrm{~m} / \mathrm{s}$ wind while still coming off the tangent of the balloon, depicted in Figure 5.3. The shear stress in the adhered region due to the loading, $\sigma_{\mathrm{a}}$, is given by 


$$
\sigma_{a}=\frac{1.5 F_{T}}{x y}
$$

where $x$ and $y$ are shown in Figure 5.3 (a), and 1.5 is the safety factor. Assuming a square adhered area, $x$ and $y$ would have to be $0.063 \mathrm{~m}$ or larger in order that the stresses do not rise above the $28.6 \mathrm{MPa}$ tensile strength of the Hysol adhesive when $F_{T}$ is $7.45 \times 10^{4} \mathrm{~N}$.

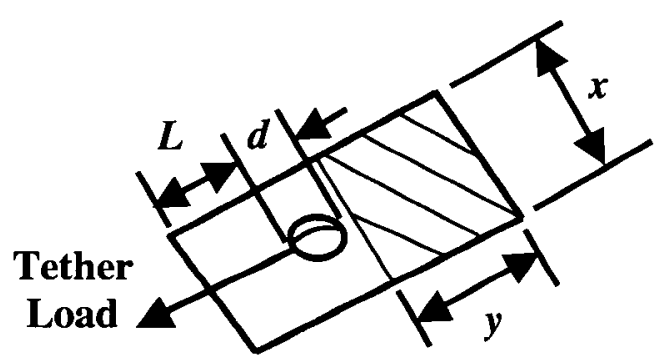

(a)

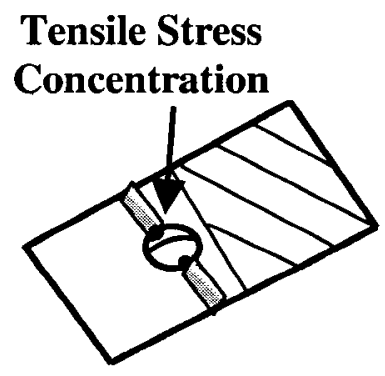

(b)

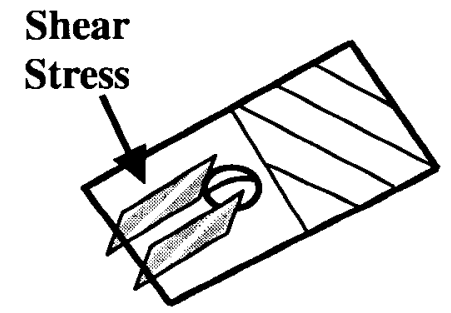

(c)

Figure 5.3 - Stresses in the Tether Attachment Plates

The tether loading will cause a tensile stress concentration at the hole, shown in Figure $5.3(\mathrm{~b})$, that is equal to

$$
\sigma_{h}=k_{t} \frac{1.5 F_{T}}{(x-d) t}
$$

where $\sigma_{h}$ is the tensile stress at the hole, $t$ is the thickness of the material, $k_{t}$ is the stress concentration factor, and $d$ the $0.012 \mathrm{~m}$ diameter of the hole. If $x$ were taken to be the $0.063 \mathrm{~m}$ stated above, and $k_{t}$ taken to be 2.8 [54], the part would have to be at least $11 \mathrm{~mm}$ thick in order that the stresses do not rise above the $562 \mathrm{MPa}$ tensile strength of the carbon fiber material. This equates to a numerous and unrealistic 40 layers of carbon fiber. If 10 layers were used, the number of layers found on conventional formula 1 vehicles [61], [62], $x$ would have to be at least $0.21 \mathrm{~m}$ for the part not to fail.

In the loading scenario of Figure 5.3, the shear stress in the lip of the plate, $\sigma_{l}$, will be equal to

$$
\sigma_{l}=\frac{1.5 F_{T}}{2 L t}
$$


where $L$ is the distance from the edge of the tether hole to the end of the lip. The factor 2 is used to account for the shear load being distributed amongst two square strips on either side of the hole, as in Figure 5.3 (c). If 10 layers of carbon fiber were used in the plate, $L$ would have to be $0.255 \mathrm{~m}$ in order for the stress in the lip to be lower than the $78.2 \mathrm{MPa}$ shear strength of the carbon fiber.

From the above analysis the selected dimensions of the tether attachment plate are as shown in Figure 5.4. A slight clearance of $3 \mathrm{~mm}$ was given between the tether hole and the edge of the adhered region so the tethers could pass between the plate and the hard shell. In reality the entire plate would also have to be raised $0.012 \mathrm{~m}$ to achieve this. However, this detail was neglected for further analysis as it was not expected to affect the stresses in the carbon fiber shell.

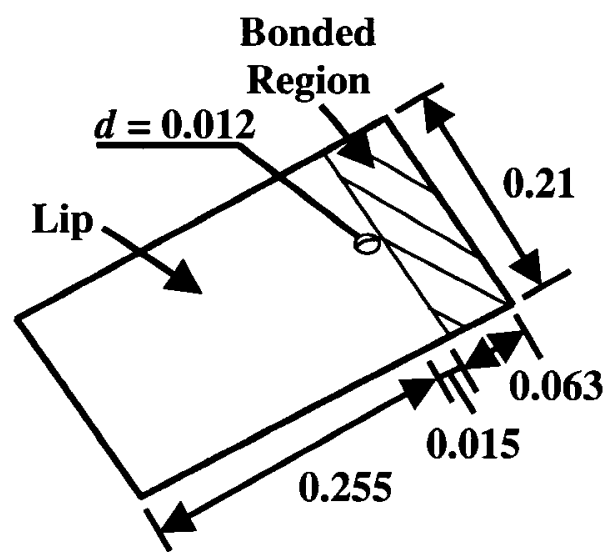

Figure 5.4 - Dimensions of the Tether Attachment Plates

\subsubsection{The Carbon Fiber Shell}

The edges of the adhered region of the plates are bonded to the shell $35^{\circ}$ below the equator of the spherical aerostat. The carbon fiber shell must clear the tether attachment plates. Thus, the carbon fiber shell must rise to least $35^{\circ}-\frac{0.063}{\pi(10.15)} 360^{\circ}=34.3^{\circ}$ below the equator of the balloon, and the shell was brought up $33^{\circ}$ below the equator to allow a slight clearance from the tether attachment plates.

We can consider whether a shell of this size will prevent dimple. Assuming the fabric envelope is filled with $249 \mathrm{~Pa}$ (1 inWG) internal pressure [24], a fully fabric balloon will experience a blowdown angle of $42.5^{\circ}$ when subjected to the dimpling wind 
speed of $20 \mathrm{~m} / \mathrm{s}$, calculated in Chapter 4 with a $C_{D}$ of 0.23 . The extra weight partial-hard balloon combined with a higher drag coefficient will result in a steeper blowdown angle, making this analysis conservative. It follows that at the dimple speed of $20 \mathrm{~m} / \mathrm{s}$ the stagnation point lies on the carbon fiber shell well below the fabric-carbon fiber interface, illustrated in Figure 5.5. Dimpling is thus prevented.

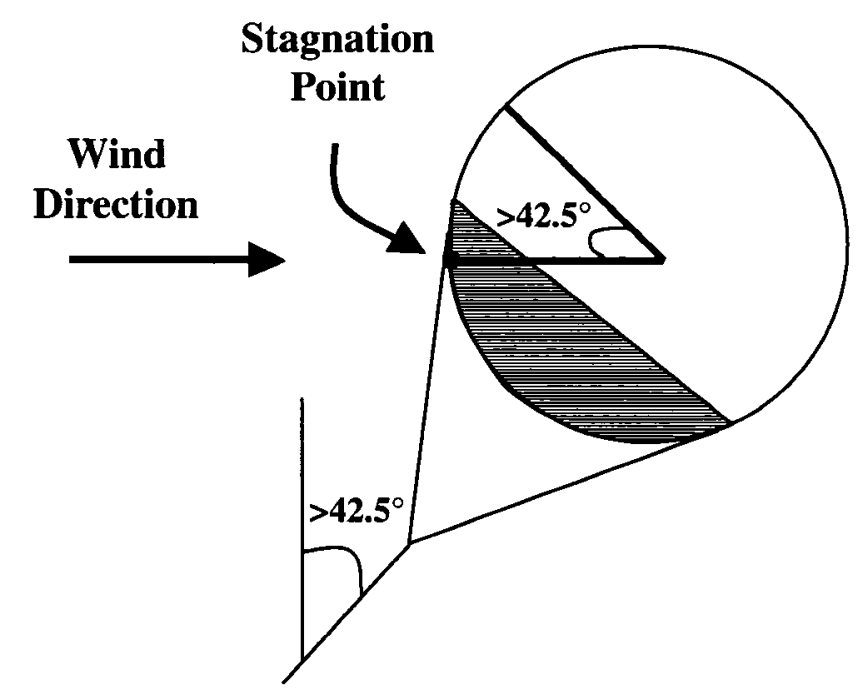

Figure 5.5 - Partial-Hard Balloon at the Dimpling Speed of $20 \mathrm{~m} / \mathrm{s}$

A clearance between the carbon fiber shell and fabric balloon was desired to account for the envelope expanding under internal pressure within the shell. It was found by running a finite element analysis of the $10.15 \mathrm{~m}$ fabric balloon made from Lamcotec's $6.05 \mathrm{oz} / \mathrm{yd}^{2}$ nylon and subjected to only internal pressure and gravity that its radius would expand by a maximum of $0.011 \mathrm{~m}$ in the region of maximum pressure: the top of the balloon. At large blowdown angles the region of maximum internal pressure will be close to the carbon fiber-fabric interface, and it was decided to make the radius of the carbon fiber shell $0.011 \mathrm{~m}$ larger than that of the fabric balloon, or $5.086 \mathrm{~m}$ total, to account for the bulging.

To select the number of layers of carbon fiber that were used for a preliminary evaluation of the shell, the stress in the envelope at the design speed of $46.3 \mathrm{~m} / \mathrm{s}$ was predicted. Since the drag force on the aerostat will dominate the buoyant force as wind speeds rise, the linear relationship between the drag force and maximum envelope stress described by Figure 4.11 in Chapter 4 was used for the estimation. The predicted stress 
was evaluated against the weaker $405 \mathrm{MPa}$ compressive stiffness of the LTM25/CF0511 carbon fiber, taking into account the difference in thickness between the Lamcotec nylon and Advanced Composites Group carbon fiber during the comparison. As a result, it was determined that 3 layers of carbon fiber should be used in the shell for an initial analysis of the partial-hard aerostat.

\subsubsection{The Fabric Envelope-Carbon Fiber Shell Interface}

Straps or load patches and tethers could have been used to tie the fabric envelope to the carbon fiber shell. Straps were preferred as they tend to better distribute loads while being lightweight. Eight 1" wide and $3.0 \mathrm{~mm}$ thick straps, modeled after those used by Aerostar [24], were employed to tie the Helium-enclosing fabric envelope to the carbon fiber shell. The straps ran over the top of the balloon and were sewn directly into the envelope. At the end of each strap was a metal ring through which one of the 8 tethers passes before going through the hole of a tether attachment plate, shown in Figure 5.6. This alleviates some of the load seen by the plates. The fabric envelope was also glued to the carbon fiber along the rim of the shell in order to minimize movement between the two. The glue used was Loctite's Fixmaster High Performance Epoxy, which has a 5 MPa bonding strength to the urethane coating [60].

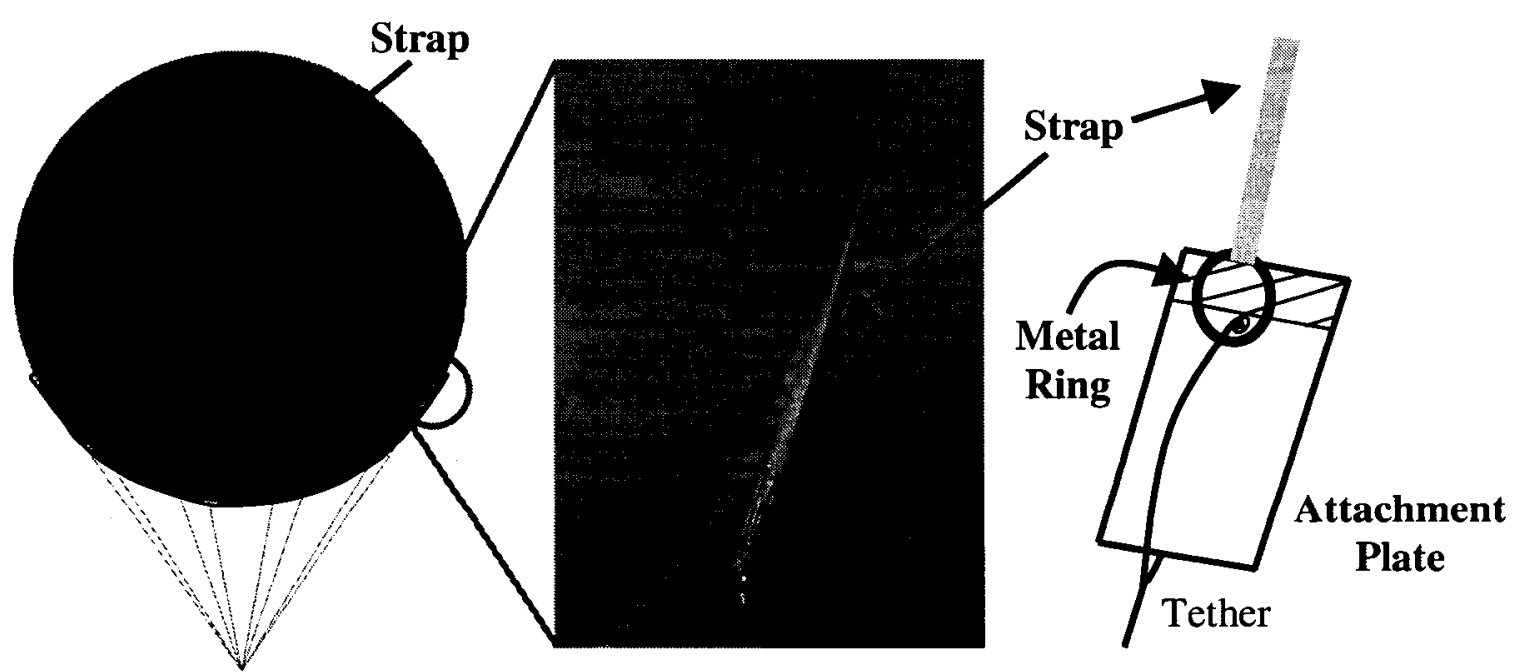

Figure 5.6 - Attaching the Fabric Balloon with Straps 


\subsection{Finite Element Model}

MSC.NASTRAN/PATRAN was used for the finite element analysis. Many aspects of the model were set up similarly to the one described in Chapter 4.

\subsubsection{The Carbon Fiber Shell}

Ideally, the LTM25/CF0511 carbon fiber would be simulated in NASTRAN using approximations from composites theory, but in the absence of detailed matrix and fiber information from Advanced Composites Group, this was not possible. As stated in Section 5.1.1, since more than one layer of the carbon fiber is being used, if the fibers are oriented at the largest angles possible from each other, the material is expected to be quasi-isotropic. In light of this, the carbon fiber sections were assumed to be linear elastic isotropic, with mechanical properties as listed in Table 5.1. The number of layers of the composite used was described in the model by the thickness of the carbon fiber, in multiples of the single-layer thickness, thus assuming a perfect bond between the sheets.

The carbon fiber shell was created as a single section encompassing the bottom of a theoretical sphere of $5.086 \mathrm{~m}$ in radius starting $33^{\circ}$ below its equator, Figure 5.7. The section was $0.84 \mathrm{~mm}$ thick, simulating the thickness of 3 layers of material. Eight tethers emanated from the tangent of the shell $35^{\circ}$ below the equator of the theoretical sphere, creating a $35^{\circ}$ angle with the vertical at the confluence point $3.78 \mathrm{~m}$ below the shell. The tethers themselves were modeled identically to those of Chapter 4, save that their diameter was increased to $12 \mathrm{~mm}$ to accommodate the higher loads in the present model. The adhered area of each tether attachment plate was approximated as a $0.21 \mathrm{~m} \mathrm{x}$ $0.063 \mathrm{~m}$ rectangle of $3.64 \mathrm{~mm}$ thickness in the carbon fiber shell, simulating the 10 layers of the plate plus the 3 layers of the hull and assuming a perfect bond between the two. At the end of each plate protruded a $0.21 \mathrm{~m} \times 0.27 \mathrm{~m}, 2.8 \mathrm{~mm}$ thick lip. The end node of each tether was tied to a node on the lip just below the edge of the adhered region of the plate to approximate the attachment interface. The carbon fiber shell and tether attachment plates were all modeled with triangular shell elements whose bending stiffness was calculated by NASTRAN from the associated material's modulus of elasticity. 


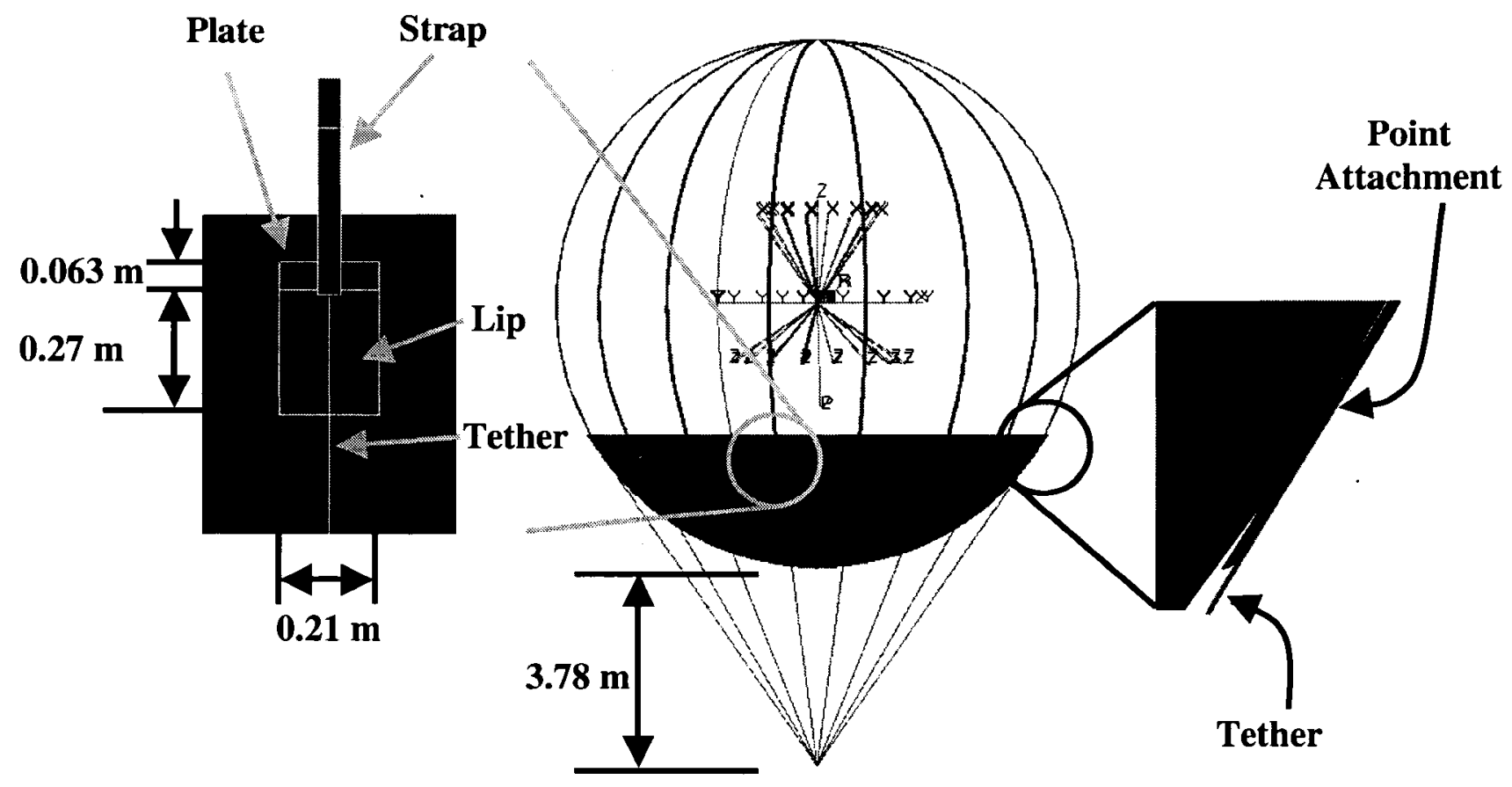

Figure 5.7 - The Simulated Carbon Fiber Shell and Tether Attachment Plates

\subsubsection{The Fabric Sphere}

The Helium-enclosing fabric envelope was modeled similarly to the $10.15 \mathrm{~m}$ aerostat of Chapter 4. The only differences were the absence of load patches, the inclusion of a glued region and straps, and the material used. The glued region was approximated by tying nodes around the rim of the carbon fiber shell to the fabric envelope. The straps were approximated to be 1 " wide sections in the fabric sphere that were $3.0 \mathrm{~mm}$ thick, equivalent to approximately 20 layers of nylon. The straps separated from the envelope $1^{\circ}$ above the fabric-carbon fiber interface. From there, a strip of 1 " wide, $3.0 \mathrm{~mm}$ thick nylon ran to the tether attachment point on the lip of the attachment plate. The nodes on one end of each strip were tied in with the nodes at the end of the straps in the fabric envelope, and one node on the other end of each strip was tied to the end of each tether and the lip of the attachment plate. 


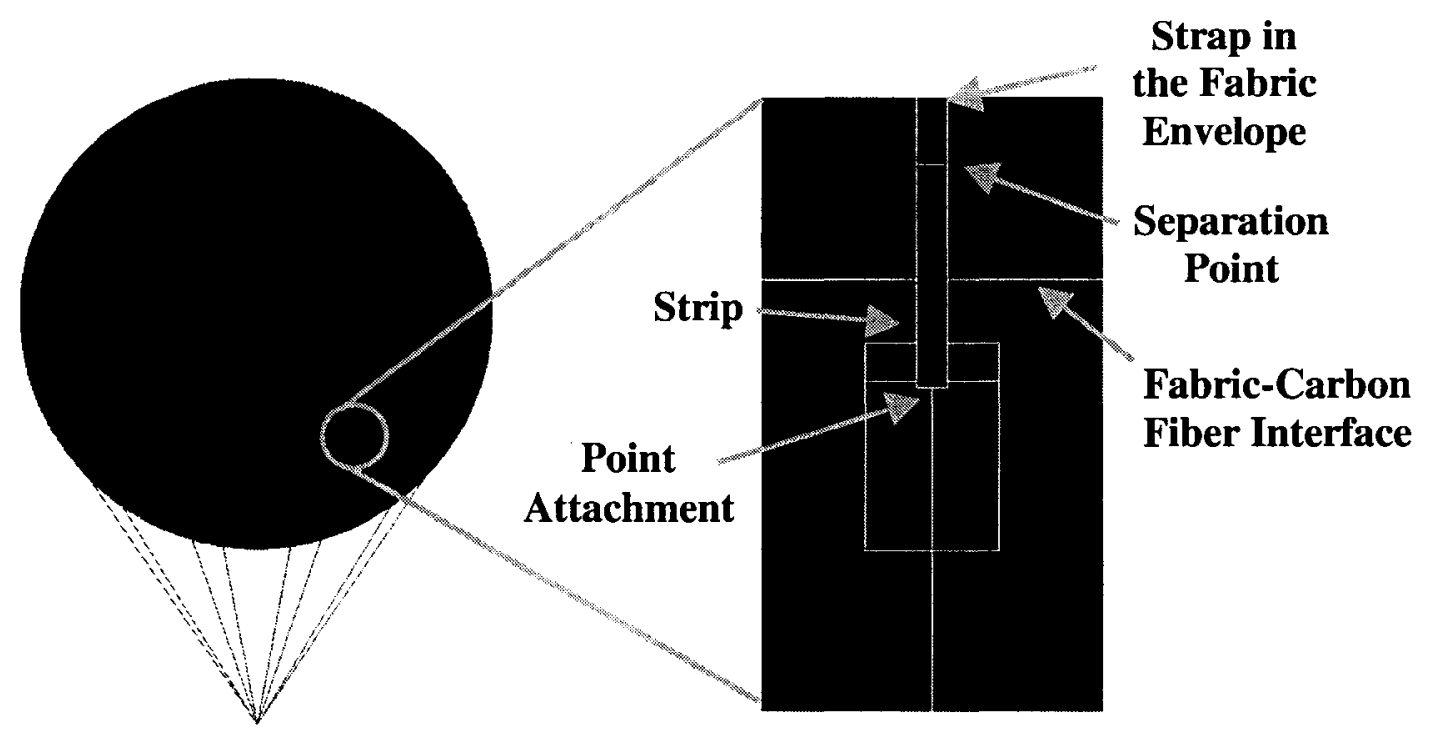

Figure 5.8 - The Simulated Straps

The material for the fabric balloon was assumed to be linear elastic isotropic nylon 6. As opposed to Chapter 4 the thickness was reduced to $0.15 \mathrm{~mm}$, that of $4.2 \mathrm{oz} / \mathrm{yd}^{2}$ urethane-coated nylon, and the density to $950 \mathrm{~kg} / \mathrm{m}^{3}$.

\subsubsection{Loads, Constraints, and Other Approximations}

The simulated loads and constraints for the partial-hard model were similar to that of the fabric model in Chapter 4. The dynamic pressure of the wind was higher due to the increase in wind speed from $46.3 \mathrm{~m} / \mathrm{s}$ to $20 \mathrm{~m} / \mathrm{s}$. The aerodynamic pressure was applied only to exposed surfaces, and not to protected areas such as the fabric enclosed within the carbon fiber shell. The internal pressure was applied only to the fabric sphere and straps. The tethers were constrained from translating in any direction identically to the model of Chapter 4.

\subsection{Initial Results of the Finite Element Analysis}

\subsubsection{Model Validation}

Taking into account the weight of the tether attachment plates, straps, end patches, and carbon fiber and fabric shells the expected lift of the partial hard balloon was calculated to be $3774 \mathrm{~N}$. Using the pressure profile depicted in Chapter 4, the drag on a sphere that 
has a diameter of $10.15 \mathrm{~m}$ is $2.44 \times 10^{4} \mathrm{~N}$. Assuming a quasi-static state, the resultant constraint force that is divided amongst the 8 tethers is calculated with equation ( 4.6 ) to be $3.02 \times 10^{4} \mathrm{~N}$. The constraint force returned by the simulation was $3.11 \times 10^{4} \mathrm{~N}$, which is within $3.0 \%$ of the predicted value. The expected stress in the fabric sphere at the end of the aerostat exactly opposite the stagnation point is calculated to be $7.98 \mathrm{MPa}$, using equation ( 4.7 ) and knowing $p_{i}$ and $p_{a}$ are $249 \mathrm{~Pa}$ and $-223 \mathrm{~Pa}$ respectively. The stress returned by the simulation was $8.1 \mathrm{MPa}$, which is within $1.5 \%$ of the expected value.

\subsubsection{Stresses and Displacement in the Fabric Sphere}

When observing a plot of the aerostat's exaggerated displacements, Figure 5.9 (a), it is easily seen where the fabric sphere is contained within the carbon fiber and where it is not. Since the $0.015 \mathrm{~m}$ clearance between the hard shell and the Helium-enclosing fabric envelope only accounted for stretching under internal pressure, and not aerodynamic pressure, the fabric envelope bulges beyond the carbon fiber. An allowance could be made to account for this extra stretching, but the balloon only bulges $0.01-0.05 \mathrm{~m}$ beyond the hard shell, and the slight contact pressure would aid the glue in fixing the two together.

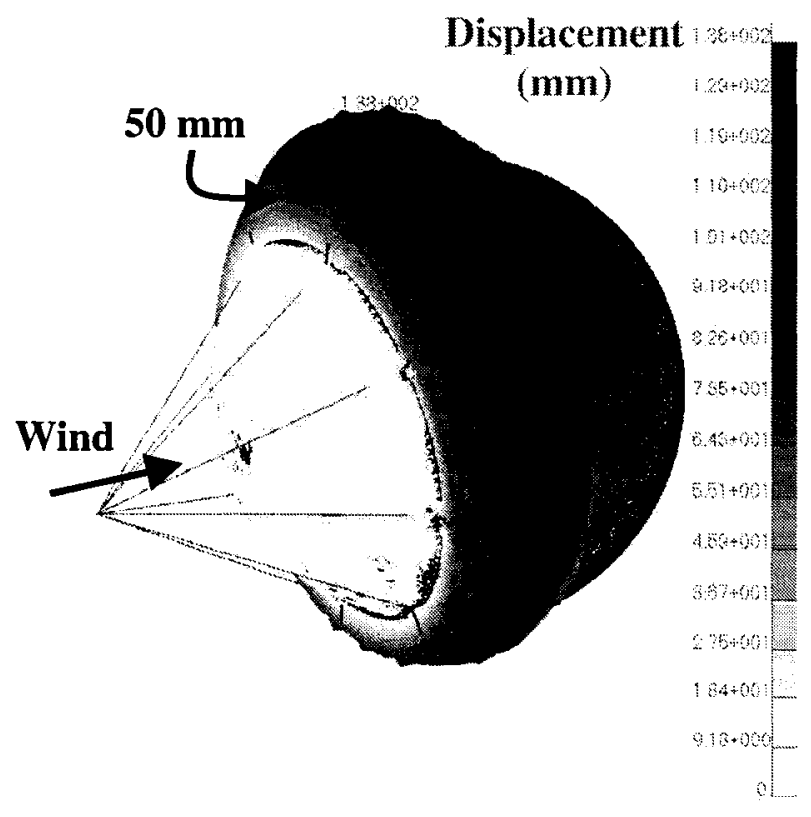

(a) Exaggerated View

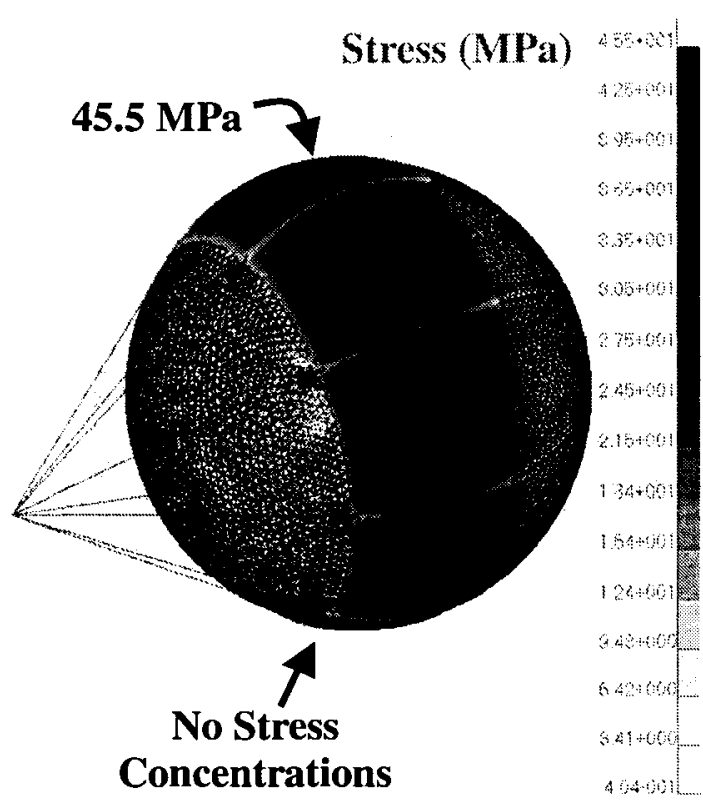

(b) Unexaggerated View

Figure 5.9 - Stresses and Displacements in the Fabric Section 
The highest stress in the fabric envelope is equal to $45.5 \mathrm{MPa}$. This stress is exclusively a membrane stress, described by equation ( 4.7 ) in Chapter 4, and is caused by the combination of internal and external pressures on the envelope at that point. Consequently, the high stress occurs at the top of the balloon approximately $80^{\circ}$ back from the stagnation point, where the highest negative aerodynamic pressure combines with the highest internal pressure.

The simulation was run assuming a low drag coefficient of 0.23 over the tethered sphere. Following the logic presented in section 4.3 , a more realistic drag coefficient of 0.7 , published by Williamson and Govardhan, should be considered. However, it is expected that the maximum stress of $45.5 \mathrm{MPa}$ will not rise significantly with a rise in drag coefficient from 0.23 to 0.7. If we consider Figure 4.3 (a) in Chapter 4, we find that the ideal, zero-drag (potential flow) case for a smooth, fixed sphere, denoted by the solid line, has a static pressure distribution that is symmetrical from the front half to the back half of the sphere. Any non-ideality, such as friction, will tend to reduce the flow velocity over the front half, thus tending to reduce the magnitude of the negative peak pressure reached when $\varphi=90^{\circ}$. This is exemplified by the experimental data points shown in that plot. The pressure coefficient over the rear half would then be bound to increase (become less negative) or stay constant as the flow decelerates, or separates, over the rear half. Based on this, it is reasonable to expect that a higher drag coefficient would not lead to a larger negative peak pressure coefficient. Rather, the mechanism for a larger drag coefficient is more likely to be exemplified by the one curve in the plot at a subcritical Reynolds number of $R e=1.62 \times 10^{5}$ for which we see a larger, negative low pressure region on the rear half of the sphere, but with a lower peak negative pressure coefficient.

The negative aerodynamic pressure over the rear of the fabric sphere will try to suck it out of the carbon fiber shell in high winds, loading the straps. Figure 5.9 (b) shows, however, that the stresses in the straps attached to the fabric sphere are counter intuitively much lower than the stresses in the surrounding envelope. This is because the straps are sewn directly to the fabric envelope and cannot move relative to it. The lack of relative movement causes the load and associated stresses to concentrate in the regions where the straps separate from the fabric sphere, as observed in Figure 2.7 of section 2.4.1. Hence, the stresses are lower in the thick straps than over the rest of the envelope. 
Figure 5.9 (b) also shows that the concentrated stresses around the regions where the straps separate from the fabric balloon, or the "separation points," depicted in Figure 5.8, are relatively low. The reason for this is that the glued area alleviates some of the strap tension, resulting in a maximum stress of $17 \mathrm{MPa}$ around the separation points. Gluing the fabric to the carbon fiber also ensures the straps are evenly loaded at all times, further relieving the stress concentrations.

The stresses around the separation points of the straps are different from the highest stress in the envelope membrane discussed previously. This is because the major contributing factor to the stresses at the separation points is not the aerodynamic and internal pressures at those points, but rather the aerodynamic suction on the envelope. The aerodynamic suction is associated with the distribution of negative pressures on the rearward part of the sphere, and so it is expected that this stress will rise linearly with a rise in drag coefficient, similar to the stresses around the load patches of the fabric balloon in Chapter 4. To test this hypothesis, the simulation was run for 5 different wind speeds and the maximum stress around the separation points of the straps from the fabric envelope were plotted with respect to drag force, as was done for the load patches in section 4.3. It was found that there was a linear relationship between the two quantities. Knowing that the drag force on the sphere depends linearly on the drag coefficient, there is consequently a linear relationship between the stress around the strap separation points and the drag coefficient as well. As a result, if one were to take into account the more practical drag coefficient for a tethered buoyant sphere of 0.7 , rather than the value of 0.23 assumed for the simulation, the maximum stress of $17 \mathrm{MPa}$ will rise to $17 \mathrm{MPa}\left(\frac{0.7}{0.23}\right)=51.7 \mathrm{MPa}$. Hence, there is a safety factor of 2.9 when considering the weaker 151.7 MPa breaking strength in the weft direction of the Lamcotec fabric mentioned in Chapter 2.

\subsubsection{Stresses in the Carbon Fiber Shell}

A plot of the stresses in the carbon fiber shell can be seen in Figure 5.10 below. The carbon fiber section saw high stresses, with the stresses on the bottom of the shell being 2 - $3 \mathrm{MPa}$ larger than at the top, a consequence of the buoyant fabric sphere pulling 
upwards on the carbon fiber shell. The highest stresses were from $6.5 \mathrm{MPa}$ up to 15.1 $\mathrm{MPa}$ and occurred in the regions around the tether attachment plates and behind the lips of the plates. Furthermore, there were large stresses, around $8 \mathrm{MPa}$, just at the rim of the hard shell where the fabric sphere came in contact with the carbon fiber section.

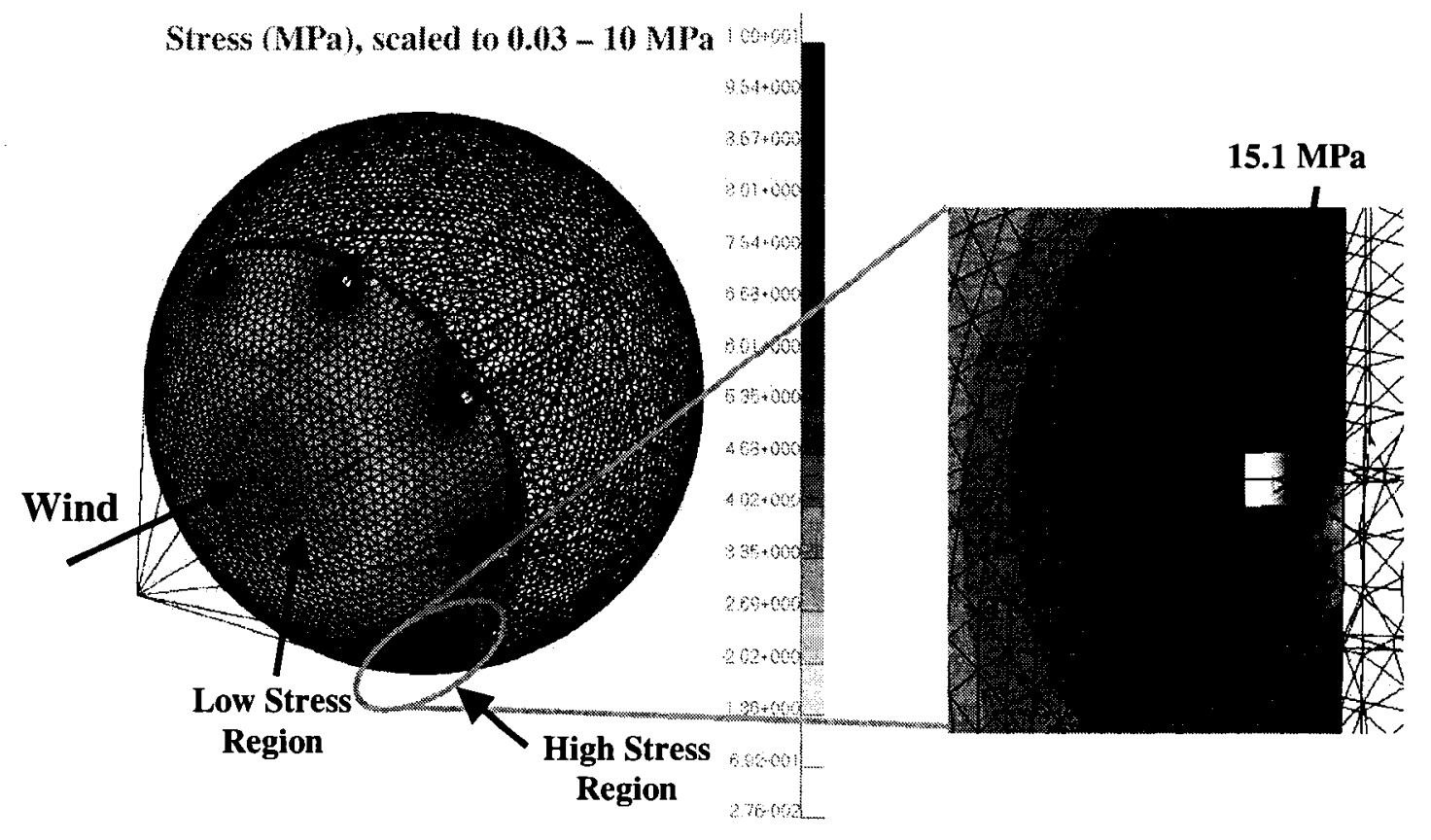

Figure 5.10 - Stress in the Carbon Fiber Shell (Undeformed Shape)

Following the logic and assumptions presented in Chapter 4, if the drag coefficient for a tethered buoyant sphere of 0.7 were taken into account, the maximum stress of $15.1 \mathrm{MPa}$ will rise to $15.1 \mathrm{MPa}\left(\frac{0.7}{0.23}\right)=46.0 \mathrm{MPa}$. Moreover, if the aerostat pitched slightly, and one tether coming off the tangent of the shell suddenly undertook the entire load, taking into account uneven loading and dynamical effects this stress rises by approximately 8 times to $368 \mathrm{MPa}$. The resulting safety factor is only 1.1 when considering the carbon fiber's $405 \mathrm{MPa}$ compressive strength. This would lead one to conclude that extra layers of carbon fiber should be used on the shell. However, for regions on the hard shell lower than $50^{\circ}$ below the equator of the balloon, the stresses are less than $6.5 \mathrm{MPa}$, producing a large safety factor of 2.6 when considering a drag coefficient of 0.7 and uneven loading, thus indicating that the number of layers used can be reduced in those regions. 


\subsection{Revised Design}

A ring of 5 layers of carbon fiber was placed around the tether attachment plates and the rest of the shell was made of 2 layers of carbon fiber, as illustrated in Figure 5.11. It was estimated visually from the stress plot shown in Figure 5.10 that the ring would have to start $45.2^{\circ}$ below the equator of the balloon and rise to $33^{\circ}$ below.

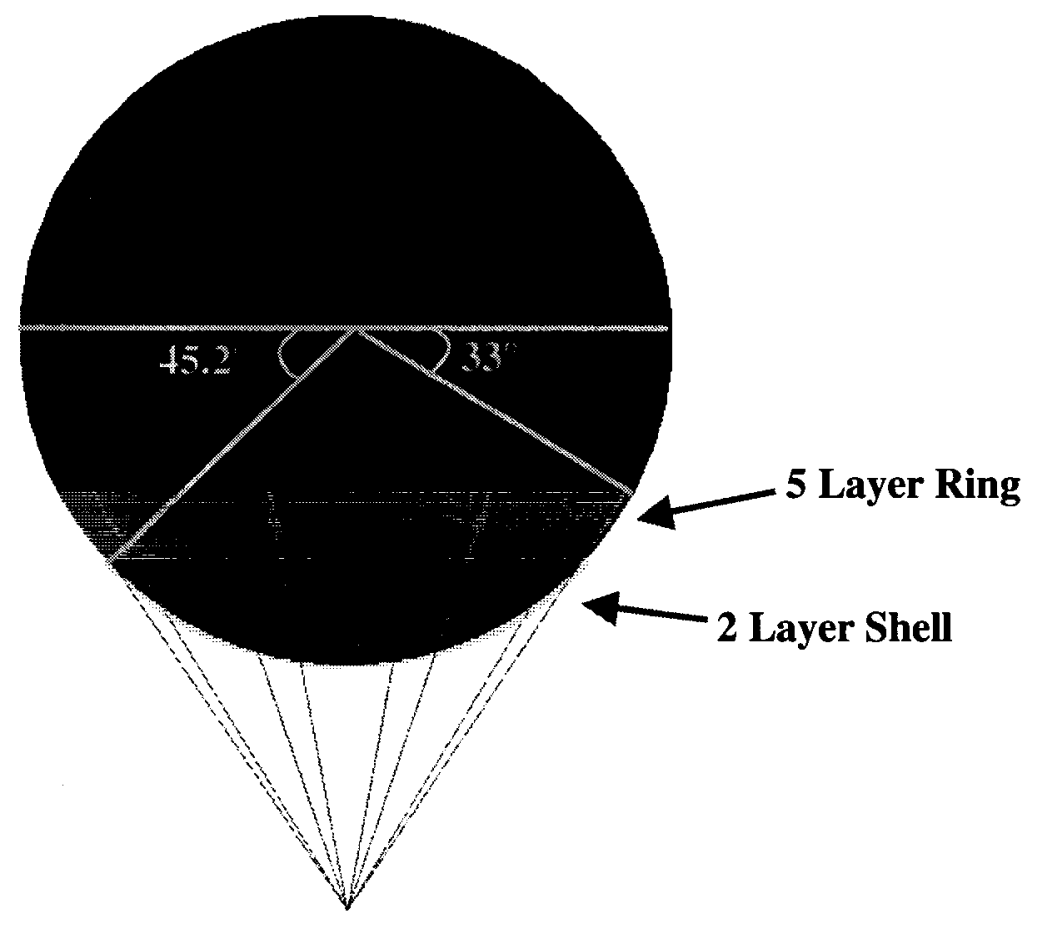

Figure 5.11 - Redesigned Carbon Fiber Shell

When a finite element stress analysis is performed on the revised partial-hard design, Figure 5.12 below, it is seen that the stresses concentrate somewhat around and below the tether attachment plates, similar to the 3 layer shell design, but are more distributed through the shell. The magnitude of the stresses are also reduced, specifically the largest stress is now 10.2 $\mathrm{MPa}$. If a $\mathrm{C}_{\mathrm{D}}$ of 0.7 is considered, as well as one of the tethers suddenly taking the entire load while still coming off the tangent of the balloon, the maximum stress rises to $10.2 \mathrm{MPa}\left(\frac{0.7}{0.23}\right)(8)=248 \mathrm{MPa}$. Considering the $405 \mathrm{MPa}$ compressive strength of the LTM25/CF0511 carbon fiber, a safety factor of 1.6 has been achieved, above the design value of 1.5 . 


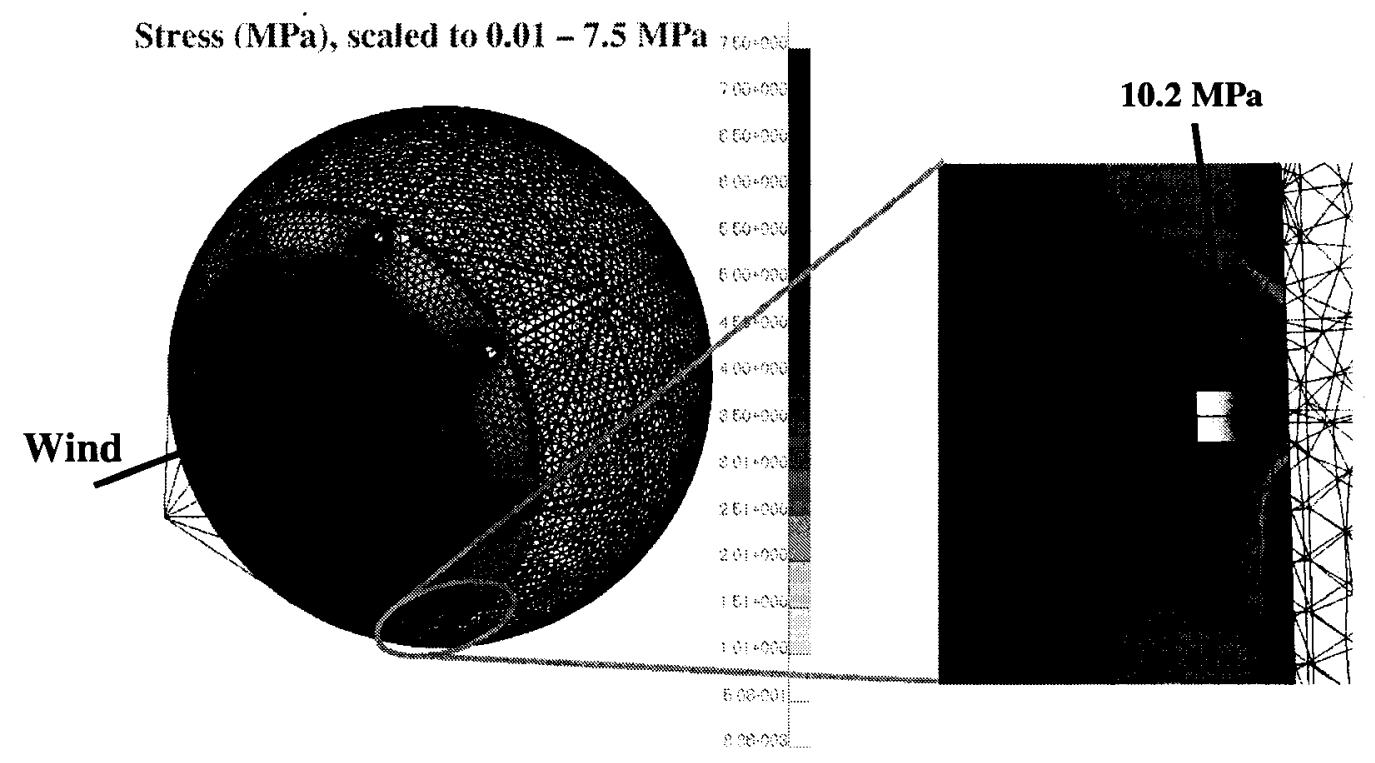

Figure 5.12 - Stresses in the Revised Carbon Fiber Shell

\subsection{Practical Considerations}

\subsubsection{Tradeoffs}

The partial-hard aerostat presented is capable of operating in a $46.3 \mathrm{~m} / \mathrm{s}$ wind with a safety factor of 1.6. However, the envelope and shell of the partial-hard aerostat weigh $165 \mathrm{~kg}$ together, while the envelope of a conventional $10.15 \mathrm{~m}$ spherical balloon made of $6.05 \mathrm{oz} / \mathrm{yd}^{2}$ urethane-coated nylon only weighs $79.5 \mathrm{~kg}$. This leads to an increase in the already steep blowdown angle for the $20 \mathrm{~m} / \mathrm{s}$ dimple speed from $70.5^{\circ}$ in the fully-fabric case to $73.9^{\circ}$ in the partial-hard case, calculated using a $C_{D}$ of 0.7 . Furthermore, the blowdown angle in the maximum $46.3 \mathrm{~m} / \mathrm{s}$ wind increases from $86.2^{\circ}$ to $86.9^{\circ}$ respectively. It should be noted that blowdown angles of this magnitude indicate the $10.15 \mathrm{~m}$ aerostat would hit the ground if moored by a tether less than 90 meters in length. However, the primary interest of the present analysis is increasing aerostat survivability in even the most extreme theoretical conditions.

To regain the original blowdown angle of the fabric version, the diameter of the partial-hard aerostat would have to be increased to approximately $11.75 \mathrm{~m}$, depending on the number of layers of carbon fiber needed to withstand the higher loads. If increasing the diameter by this magnitude is not acceptable, extra weight-saving strategies could be 
implemented. For example, the protected bottom $1 / 3$ of the fabric balloon could be made from a lightweight $2.5 \mathrm{oz} / \mathrm{yd}^{2}$ Southern Balloon Works urethane bladder [30], saving 18.7 $\mathrm{kg}$. As well, those sections of the carbon fiber shell that see the lowest stresses, less than 6.5 MPa, and do not risk being exposed to the stagnation pressure in wind speeds above the dimple speed could be removed, saving a further $13.1 \mathrm{~kg}$. Using these two strategies in conjunction would cut the weight difference and the difference in blowdown angle between the partial-hard and fully-fabric aerostats by more than a third.

\subsubsection{Fabrication}

The typical process for creating a carbon fiber part includes laying the composite in a mold, which can be done by hand with the LTM25/CF0511 carbon fiber, and then curing. The sections of the shell with multiple layers of carbon fiber should occasionally be vacuum debulked during layup, or put in a vacuum bag and pressurized, in order to remove excess resin and trapped air, vapor, and volatiles between the plies [56]. A typical debulking procedure, recommended by Advanced Composites Group [57], is to apply $850-950$ mbar of vacuum with the carbon fiber part in a vacuum bag for $15-30$ minutes.

The LTM25 material can be processed by vacuum, autoclave, or press molding, and the cure temperature can be carried out anywhere from ambient to $150^{\circ} \mathrm{C}$ [57]. Curing the carbon fiber in an autoclave gives little structural or mechanical advantage over vacuum bagging [63], and since ovens tend to be cheaper and more widely available vacuum curing would be preferred for fabrication. A typical oven cure cycle for the LTM25/CF0511 material, as recommended by the manufacturer [57], is

- Apply 860 mbar vacuum at room temperature

- Heat to $60^{\circ} \mathrm{C}+5^{\circ} \mathrm{C} /-0^{\circ} \mathrm{C}$ at a rate of $1^{\circ} \mathrm{C}$ per minute

- Maintain the part at $60^{\circ} \mathrm{C}$ under the applied vacuum for a minimum of 8 hours to an optimum of 15 hours

- Remove heating and cool to room temperature at $3^{\circ} \mathrm{C}$ per minute under vacuum

- Demould 
There are large ovens and autoclaves that can accommodate curing the fabric shell of the $10.15 \mathrm{~m}$ partial hard balloon in one piece [64]. However, ovens of this size tend to be expensive to run and, more importantly, making the shell in one piece begs the question of how that piece would be transported to the launch site. A more practical solution is to make the carbon fiber shell out of several pieces and then assemble it by adhesive bonding on site. If the shell were made out of 8 cylindrical gores it would fit into a standard 14.6 m (48') long x 2.6 m (102") wide x $2.8 \mathrm{~m}$ (110") tall Great Dane Trailer [65], as illustrated in Figure 5.13 below. Cylindrical gores are preferred as the highest stresses in the shell, which occur below the tether attachment plates, would be taken by a solid piece of carbon fiber. Further, if the part were constructed from 8 separate gores only two molds would be needed: one for the gores and one for the tether attachment plates.
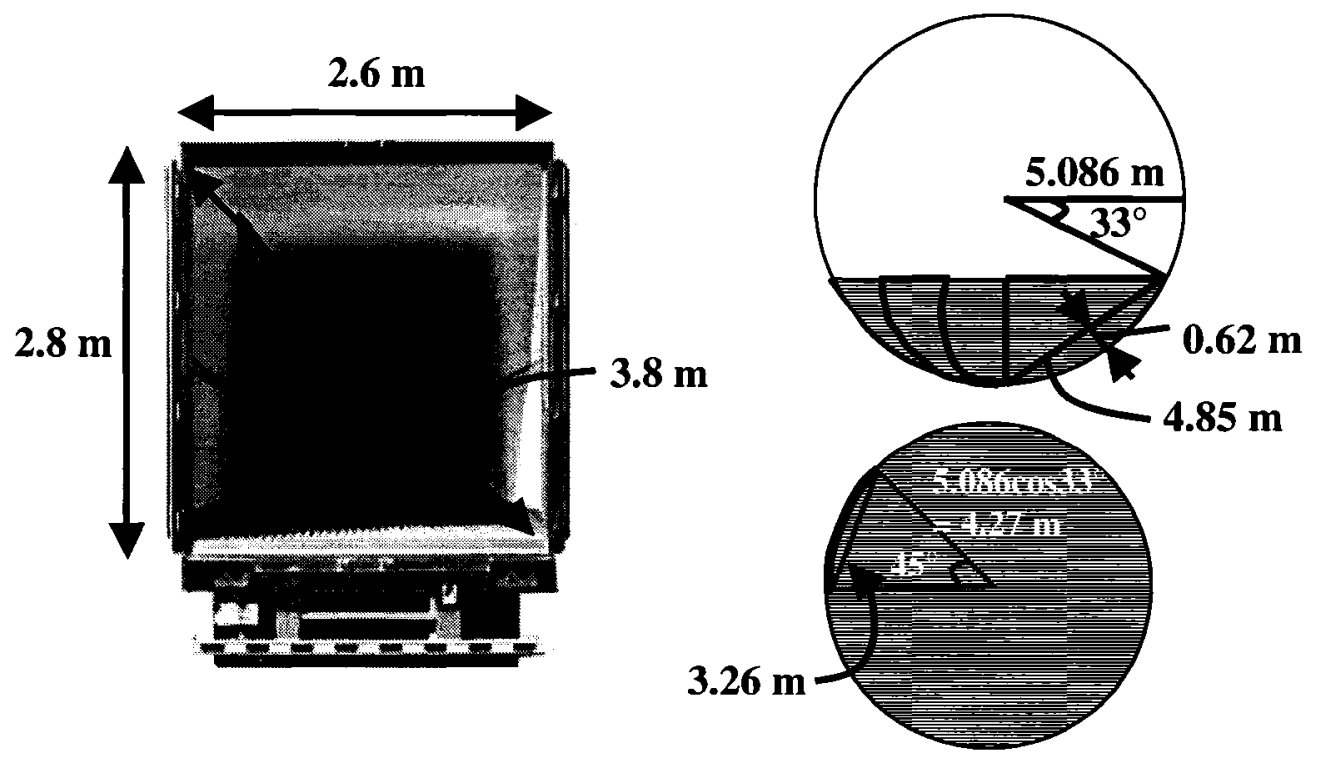

Figure 5.13 - Fitting the Shell Into a Standard Semi-Truck Trailer 


\section{Chapter 6 Conclusions and Recommendations}

\subsection{Aerostat Construction and Testing}

A $2.5 \mathrm{~m}$ diameter spherical aerostat was built to review conventional aerostat design and construction methods. It was found that many of the construction and design techniques were rudimentary and it was possible to complete the build process entirely in-house with just a hobby iron and vinyl cement. The material used was Lamcotec's light and workable $4.2 \mathrm{oz} / \mathrm{yd}^{2}$ urethane-coated nylon. Undesirable point loads were avoided by attaching the tethers to a nylon net draped over the balloon. Once the aerostat was built, an easy-toimplement rip-panel was installed to serve as the emergency controlled-decent mechanism. Though building an aerostat in-house is 3 to 5 -times cheaper than buying one off the shelf, construction time is lengthy, the potential for error is large, and the final result is of poorer quality. This led us to conclude that the purchase of experimental balloons from a professional supplier would be warranted for any future research.

The $2.5 \mathrm{~m}$ diameter spherical aerostat was flown outdoors at altitudes of 15,30 , and $45 \mathrm{~m}$ while moored to the ground by a single tether to see if the tethered, buoyant sphere would reproduce the characteristics described by Williamson and Govardhan. An 
inexpensive differential GPS system was used to track the balloon's position. The receivers exhibited cycle slips at higher altitudes, and offsets and drifts that impeded the calculation of quantities based on average values, such as the drag coefficient. The receivers were useful for tracking the balloon's oscillatory motion, and would mainly be attractive in applications where the aerostat system is being tested to failure.

An average drag coefficient of 0.88 was calculated for all the flights. This coefficient was expectedly larger than the supercritical drag coefficient of $0.15-0.25$ for a fixed, smooth sphere. However, it was also higher than the values of 0.56 found by Coulombe Pontbriand using a similar experimental apparatus, and 0.7 found by Williamson and Govardhan for subcritical tethered, buoyant spheres. The high drag coefficient was likely caused by the surface roughness of the net coupled with the use of only 6 gores in the balloon's construction, giving it a less streamlined shape.

The frequencies of the inline and transverse oscillations were determined using power spectral density plots of the motion, and the amplitudes were determined directly from the position measurements. Due to the erratic nature of the wind, a clear and repeatable pattern could not be discerned for the inline direction, and consequently the characteristic figure-of- 8 motion described by Williamson and Govardhan was absent. The frequency of transverse oscillation was generally higher than the natural pendulum frequency of the system indicating external forcing was present, probably from the wake vortices, but not enough data points were collected to infer a trend.

\subsection{Structural Analysis and Partial-Hard Balloon Design}

A structural analysis of the stresses in the envelope of a common $10.15 \mathrm{~m}$ diameter spherical aerostat in a wind flow was performed using MCS.PATRAN/NASTRAN's nonlinear static finite element solver. It was calculated that when the envelope is filled with the standard over pressure of 1 inWG, dimpling occurs at the stagnation point for wind speeds above $20 \mathrm{~m} / \mathrm{s}$, and so this was the speed simulated. The constraint force and hoop stress for the aerostat returned by the simulation were within $0.4 \%$ and $0.9 \%$ of their expected values respectively. The onset of dimpling could be detected by the low stresses and relatively high displacements at the stagnation point. The highest stresses in the model were up to $19.9 \mathrm{MPa}$, and concentrated around the load patches in the regions of 
maximum hoop stress. When uneven loading amongst the 8 tethers as well as the differences between the drag coefficients of fixed, smooth spheres and tethered, free spheres were considered, the maximum stress rose to $484 \mathrm{MPa}$. This maximum stress was much higher than the $142 \mathrm{MPa}$ breaking strength of the envelope fabric, showing that the balloon would need to be reinforced if it were to survive higher wind speeds.

A hard shell made of carbon fiber was designed for the bottom $1 / 3$ of the $10.15 \mathrm{~m}$ spherical aerostat so that it could operate in a $46.3 \mathrm{~m} / \mathrm{s}$ (90 knot) wind with a safety factor of 1.5. A full $10.15 \mathrm{~m}$ balloon had to be embedded in the porous hard shell to contain the Helium. A finite element model of the partial-hard aerostat, similar to the fully-fabric aerostat model, was created to evaluate its performance. The simulation was run for a $46.3 \mathrm{~m} / \mathrm{s}$ wind, and the constraint force and hoop stress in the envelope returned were within $3.0 \%$ and $1.5 \%$ of their calculated values respectively. In the high wind, the fabric envelope saw relatively low stresses, yielding a safety factor of 2.9. Using a 2 layer carbon fiber shell with a ring of 5 layers around the tether attachment points, a general safety factor of 1.6 was attained for the balloon. The weight of the aerostat was doubled for the ultra-robust aerostat design, increasing the blowdown angle. Considering there is not a comparably sized balloon that can survive $46.3 \mathrm{~m} / \mathrm{s}$ winds, the cost incurred may be deemed acceptable.

\subsection{Recommendations for Future Work}

The structural analyses performed on the fabric and partial-hard aerostats were limited by the approximations made. In future analyses, the following should be done:

- Determine the orthotropic mechanical properties of the ballooning nylon via biaxial stress cylinder tests and obtain specific matrix and fiber reinforcement mechanical properties for the carbon fiber material. These more detailed properties would increase the accuracy of the analysis

- Investigate using other finite element packages that have robust nonlinear solvers, such as ABAQUS, to see if the model can be more realistically constrained at the confluence point of the tethers, and if the envelope tethers can respectively be 
made from true membrane and rod materials with zero bending and compressive stiffness

- Determine a more realistic approximation of the drag-causing aerodynamic pressure profile to account for the differences in drag coefficient between smooth, fixed spheres and tethered, buoyant spheres

- Perform a coupled structural-CFD fluid-structure analysis to better predict the stresses in a fabric balloon beyond the point of dimpling

To further the design of an ultra-robust aerostat the following steps should be taken

- Investigate "shock" loading, whereby slackened tethers are suddenly loaded, to determine its influence on aerostat stresses

- Conduct a more thorough analysis of how to attach the tethers to the carbon fiber shell

- Construct a scale partial-hard aerostat to further evaluate the feasibility of the partial hard balloon presented here

- Research the possibility of designing a hard shell for the bottom and front of a lower-drag streamlined aerostat 


\section{References}

[1] G. A. Khoury, J. D. Gillett, Airship Technology, Cambridge Aerospace Series 10, Cambridge University Press, 1999

[2] E. M. Arnold, "Tethered Aerostats Used in TCOM Systems," Journal of Aircraft, vol. 14 , no. 12,1977 , pp. $1239-1243$

[3] J. Maresh, F. Fish, D. Nowacek, S. Nowacek, R. Wells, "High Performance Turning Capabilities During Foraging by Bottlenose Dolphins," Marine Mammal Science, vol. 20 , no. 3, 2004, pp. 498 - 509

[4] H. Nahum, S. Marom, "Defense and Procurement in Sweden - Aerostat-Borne Systems for Defense and Homeland Security," Military Technology, vol. 26, no. 8, 2002, pp. $102-107$

[5] N. Mayer, "Lighter-Than-Air Systems," Aerospace America, vol. 40, no. 12, 2003, pp.34

[6] M. Nahon, G. Gilardi, C. Lambert, "Dynamics/Control of a Radio Telescope Receiver Supported by a Tethered Aerostat," Journal of Guidance Control and Dynamics, vol. 25, no. 6, 2002, pp. 1107 - 1115

[7] Air Combat Command, United States Air Force, "Tethered Aerostat Radar System," 2003, http://www2.acc.af.mil/library/factsheets/tars.html

[8] Bosch Aerospace Division, "Bosch Aerospace Rapid Deploy Aerostat," 2002, http://www.boschaero.com/aerostat.htm

[9] Dominion Radio Astrophysical Observatory, "The Large Adaptive Reflector," 2004, http://www.drao-ofr.hia-iha.nrc-cnrc.gc.ca/science/ska/

[10] R. H. Upson, Free and Captive Balloons, The Ronald Press Company, NY, 1926 
[11] R. J. Recks, A Practical Guide to Building Small Gas Blimps, Recks Publications, Chula Vista, Ca, 1997

[12] R. J. Recks, An Introduction to Muscle Powered Ultra-Light Gas Blimps, Recks Publications, Chula Vista, Ca, 1998

[13] C. H. K. Williamson, R. Govardhan, "Dynamics and Forcing of a Tethered Sphere in a Fluid Flow," Journal of Fluids and Structures, vol. 11, 1997, pp. 293 305

[14] R. Govardhan, C. H. K. Williamson, "Vortex-Induced Motions of a Tethered Sphere," Journal of Wind Engineering and Industrial Aerodynamics, vol. 69, 1997, pp. $375-385$

[15] N. Jauvtis, R. Govardhan, C. H. K. Williamson, "Multiple Modes of VortexInduced Vibration of a Sphere," Journal of Fluids and Structures, vol. 15, 2001, pp. $555-563$

[16] R. Govardhan, C. H. K. Williamson, "Vortex-Induced Vibrations of a Sphere," Journal of Fluid Mechanics, vol. 531, 2005, pp. 11 - 47

[17] J. D. Hunt, "Structural Analysis of Aerostat Flexible Structure by the FiniteElement Method," Journal of Aircraft, vol. 19, no. 8, 1982, pp. 674 - 678

[18] J. D. Hunt, "Structural Analysis of the Light Weight Hard Nose on the 71M Aerostat," AIAA-93-4037, Proceedings of the 10 $0^{\text {th }}$ AIAA Lighter than Air Systems Technical Conference, Scottsdale, Az., Sept. 14-16, 1993

[19] G. A. Amiryants, V. D. Grigoriev, F. Z. Ishmuratov, A. Franz, E. d'Henin, B. Kaempf, "Investigations of Airship Aeroelasticity," ICAS Congress Paper, 2002

[20] M. Kraska, "Structural Analysis of the CL 160 Airship," Proceedings of the $10^{\text {th }}$ AIAA Lighter than Air Systems Technical Conference, Akron, Oh., July 15-19, 2001

[21] G. P. Durney, "Concepts for Prevention of Catastrophic Failure in Large Aerostats," Proccedings of the AIAA International Meeting and Technical Display on Global Technology 2000, Baltimore, Md., May 6-8, 1980 
[22] J. A. Winker, "Pumpkins and Onions and Balloon Design," Advnaces in Space Research, vol. 30, no. 5, 2002, pp. 1199 - 1204

[23] Aerophile S.A., "Aerophile.com, The Captive Balloon Website," 2003, http://www.aerophile.com

[24] Aerostar International Inc., “Aerostar International Home Page," 2001, http://www.aerostar.com

[25] F. M. White, Fluid Mechanics, $4^{\text {th }}$ Ed., WCB/McGraw-Hill, 1999

[26] The Balloon Federation of America, "BFA Gas Division," 2003, http://www.bfa.net/gasdivision.php

[27] Lamcotec Inc., "Laminating Coating Technologies Inc," 2004, http://www.lamcotec.com/index.html

[28] J.P. Holman, Heat Transfer, $8^{\text {th }}$ Ed., McGraw-Hill, 1997

[29] E. G. Pare, R. O. Loving, I. L. Hill, Descriptive Geometry, $4^{\text {th }}$ Ed., The Macmillan Company, NY, 1971

[30] Southern Balloon Works, Inc., "Southern Balloon Works Home Page," 2004, http://www.southernballoonworks.com/

[31] TCOM, "TCOM, Builder of World Class LTA Systems," 2005, http://www.tcomlp.com/

[32] N. Yajima, "Survey of Balloon Design Problems and Prospects for Larger SuperPressure Balloons in the Next Century," Advanced Space Research, vol. 30, no. 5, 2002, pp. 1183-1192

[33] B. Critelli, "Gas Ballooning," 2004, http://www.gasballooning.net

[34] Qued Seaway Plastics Ltd., "Qued Athletic Products," 2004, http://www.qued.com

[35] J. H. Smalley, "Development of the e-Balloon," Technical report AFCRL-700543, National Center for Atmospheric Research, Boulder, CO, 1970 

http://www.balloonbuilding.com

[37] P. Coulombe Pontbriand, "Simulation and Experimental Validation of Tethered Spherical Aerostat Model", M.S.c. thesis, McGill University, Montreal, QC, Canada, 2005

[38] A. G. O. Environmental Electronics Ltd., “A. G. O. Environmental Electronics Ltd. Home Page," 2004, http://www.agoenvironmental.com/

[39] The Cortland Companies, "Puget Sound Rope Corporation," 2004, http://www.psrope.com

[40] Campbell Scientific Canada Corp., "CSC Product Information - 05103-10," 2004, http://www.campbellsci.ca/CampbellScientific/Catalogue/05103-10.html

[41] Transducer Techniques, "MLP Series Load Cell," 2005, http://www.transducertechniques.com/MLP-Load-Cell.cfm

[42] Measurement Computing Corporation, "Measurement Computing Corp.: Product: 'PMD-1208FS'," 2003 , http://www.measurementcomputing.com/cbicatalog/cbiproduct_new.asp?dept_ID=36 7\&pf_id=1665

[43] Delorme, "Delorme I Mapping Software, GPS, and GIS Solutions," 2005, http://www.delorme.com/

[44] VisualGPS, LLC, "NMEATime," 2005, http://www.visualgps.net/NMEATime/

[45] Department of Geography, University of Texas at Austin, "Peter H. Dana Home Page," 2004, http://www.utexas.edu/depts/grg/gcraft/notes/datum/elist.html

[46] G. Guyor, Physics of the Environment and Climate, Wiley Series on Atmospheric Physics and Climatology, Wiley and Sons, 1998

[47] J. R. Scoggins, "Sphere Behavior and the Measurement of Wind Profiles," NASA Technical Note D-3994, June 1967 
[48] G. S. Schmidt, "Validation of Tethered Aerostat Performance Calculations," Proceedings of the $14^{\text {th }}$ AIAA Lighter-Than-Air Convention and Exhibition, Akron, Ohio, July 2001

[49] R. D. Cook, D. S. Malkus, M. E. Plesha, R. J. Witt, Concepts and Applications of Finite Element Analysis, $4^{\text {th }}$ Ed., John Wiley \& Sons, Inc., 2002

[50] C. A. Harper, Modern Plastics, Modern Plastics Handbook, McGraw-Hill Handbooks, McGraw-Hill, 2000

[51] C. Lambert, "Dynamics Modeling and Conceptual Design of a Multi-Tethered Aerostat System," Master's Thesis, Department of Mechanical Engineering, University of Victoria, 2002

[52] E. Achenbach, "Experiments on the Flow Past Spheres at Very High Reynolds Numbers," Journal of Fluid Mechanics, vol. 54, no. 3, 1972, pp. 565 - 575

[53] S. Moaveni, Finite Element Analysis, Theory and Application with Ansys, $2^{\text {nd }}$ Ed., Pearsons Education, Inc., 2003

[54] R. G. Budynas, Advanced Strength and Applied Stress Analysis, $2^{\text {nd }}$ Ed., McGraw-Hill, 1999

[55] Net Composites, "NETCOMPOSITES I Guide to Composites | Woven Fabrics," 2005, http://www.netcomposites.com/education. asp?sequence $=41$

[56] J. W. Weeton, D. M. Peters, K. L. Thomas, Engineer's Guide to Composite Materials, American Society for Metals, 1987

[57] Advanced Composites Group, “Advanced Composites Group UK," 2005, http://www.advanced-composites.com

[58] U.S. Department of Defense, "Plastic Matrix Composites with Continuous Fiber Reinforcement," Military Handbook, MIL-HDBK-754(AR), 1991

[59] W. D. Callister, Materials Science and Engineering, an Introduction, $5^{\text {th }}$ Ed., John Wiley \& Sons, Inc., 2000

[60] Loctite and Henkel Technologies, "Loctite US," 2005, http://www.loctite.com/int_henkel/loctite_us/index.cfm 
[61] N. Macknight, The Modern Formula One Race Car: From Drawing Board to Racetrack, Motorbooks International Publishers \& Wholesalers, 1993

[62] Formula 1 Administration Ltd., "The Official Formula 1 Website," 2005, http://www.formula1.com

[63] GMT Composites, "The Autoclave Myth," 2005, http://www.gmtcomposites.com/the_autoclave_myth.htm

[64] ACS Process Systems, "Composite Autoclaves," 2004, http://www.aschome.com/Composite-Autoclaves.htm

[65] Great Dane Limited Partnership, "Great Dane Trailers," 2005, http:// http://www.greatdanetrailers.com/ 